\title{
Chemical Analysis of Single Cells
}

Pieter E. Oomen, ${ }^{\dagger}$ Mohaddeseh A. Aref, ${ }^{\dagger, \perp}$ Ibrahim Kaya, ${ }^{\dagger, \downarrow, \S, \perp \odot}$ Nhu T. N. Phan, ${ }^{\dagger, \S, \|, \perp}$ and Andrew G. Ewing*, $\dagger, \S_{0}$

${ }^{\dagger}$ University of Gothenburg, Department of Chemistry and Molecular Biology, Gothenburg 41296, Sweden

${ }^{\ddagger}$ Department of Psychiatry and Neurochemistry, Sahlgrenska Academy at the University of Gothenburg, Mölndal Hospital, House V3, 43180 Mölndal, Sweden

${ }^{\S}$ The Gothenburg Imaging Mass Spectrometry (Go:IMS) Laboratory, University of Gothenburg and Chalmers University of Technology, Gothenburg 41296, Sweden

"University of Göttingen Medical Center, Institute of Neuro- and Sensory Physiology, Göttingen 37073, Germany

\section{CONTENTS}

Microfluidics

Trapping and Sorting

Geometrical and Gravitational Trapping and Sorting

Trapping and Sorting Using Hydrodynamic

Flow Patterns

Droplet-Based Trapping and Sorting

Other Techniques for Trapping and Sorting

Sample Analysis

Microfluidics-Assisted Sequencing and Gene

Expression Analysis

Other On-Chip Analyses

Super-Resolution Microscopy for Imaging of Individual Cells

STED Microscopy

Single Molecule Localization Microscopy (STORM, PALM)

Structured Illumination Microscopy

Challenges and Recent Developments in Super-

Resolution Microscopy for Single-Cell Imaging

Reduction of Photobleaching

Multicolor Imaging

Live Cell Imaging

Other Super Resolution Microscopic Techniques

for Single Cell Imaging

Super-Resolution Light Sheet Microscope

Super Resolution Optical Fluctuation Imaging

Super Resolution Imaging Using Expansion Microscopy

Super-Resolution Microscopy Implemented with DNA-PAIN and Exchange-PAIN

Fluorescence Labeling for Super-Resolution Microscopy

Mass Spectrometric Analysis of Individual Cells

Mass Spectrometric Analysis of Individual Cells

Based on Electrospray lonization

Mass Spectrometry Profiling and Imaging of Individual Cells Based on Laser Desorption Ionization

Mass Spectrometry Profiling and Imaging of Individual Cells Based on Secondary Ion Mass Spectrometry
Mass Spectrometric Analysis of Individual Cells Based on Inductively Coupled Plasma Electrochemical Analysis of Single Cells

Single-Cell Amperometry and Intracellular Electrochemical Analysis Enzymatic Biosensors Electrochemical Microscopy Electrochemical Impedance Spectroscopy Electrochemiluminescence Imaging

Author Information Corresponding Author ORCID

Author Contributions

Notes

Biographies

Acknowledgments 611

References

612

613

614

615

615

616

616

616

616

616

616

617

617

T eterogeneity in cell populations is a phenomenon 1 encountered in virtually all biological systems, in whole tissues and cell cultures and from bacterial to mammalian cells. Moreover, assessment and correct interpretation of these cellto-cell differences is increasingly being recognized as an important factor in biology. ${ }^{1}$ To study cell heterogeneity in phenotype, genotype, and their chemical products, new analytical methods that allow the examination of individual cells are constantly being developed. These methods are often characterized by their exquisite spatial and temporal resolution as well as extreme sensitivity. They often find application in biochemical research, clinical diagnostics, drug development, regenerative medicine, and tissue engineering.

This review aims to provide an overview of the technological advances made in this still rapidly expanding field during the last 2 years. We will focus on new developments or variations of existing techniques in three major areas of quantitative chemical analysis: electrochemical analysis, optical analysis and (super resolution) microscopy, and mass spectrometry and mass spectrometry imaging. Some relevant examples of qualitative analysis will be discussed as well. Techniques are

Special Issue: Fundamental and Applied Reviews in Analytical Chemistry 2019

Published: October 26, 2018 

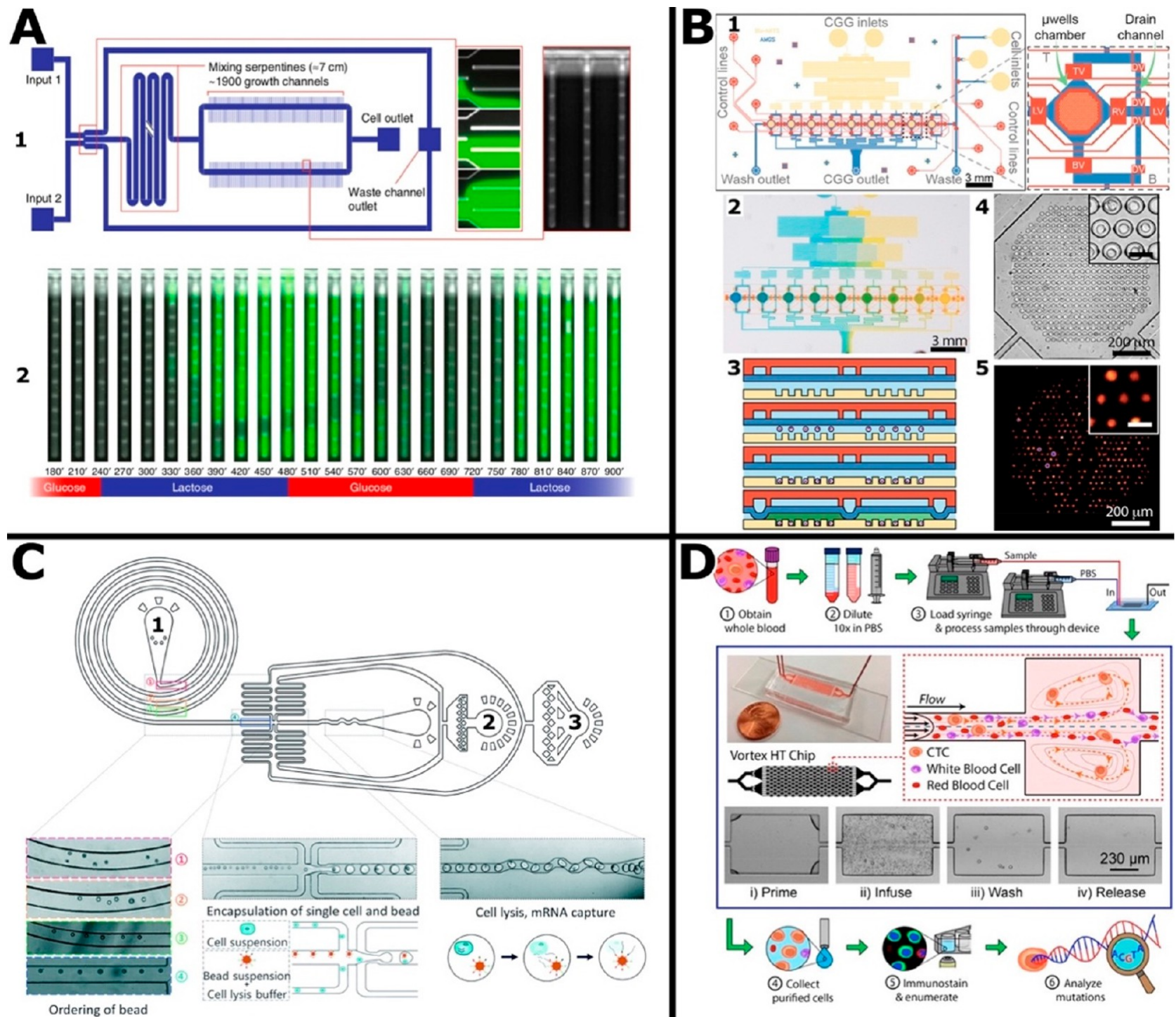

Figure 1. Examples of microfluidic devices for single-cell trapping and analysis. (A) Device for monitoring of gene expression in single E. coli bacteria: (1) design of the chip with two inlets, allowing mixing of two different compounds in different ratios, one micrograph shows $0: 1,1: 1$, and 1:0 inlet mixing ratios, while another shows E. coli growing in single file in the device; (2) using the inlet mixing, E. coli exposure is switched between glucose and lactose over time, after which expression of the lac operon in single cells can be monitored using quantitative fluorescence microscopy. Adapted from Kaiser, M.; Jug, F.; Julou, T.; Deshpande, S.; Pfohl, T.; Silander, O. K.; Myers, G.; van Nimwegen, E. Nat. Commun. 2018, 9 (1), 212 (ref 50) under a Creative Commons 4.0 International License (http://creativecommons.org/licenses/by/4.0/). (B) Design and working mechanism of single-cell trapping device: (1) design showing flow layer (blue), control/valving layer (red) and microwell/gradient generator layer (yellow), as well as a close-up of one of nine 492-microwell arrays with draining (DV), top (TV), bottom (BV), left (LV) and right (RV) valves; (2) photograph of the device, showing the generated gradient using colored fluids; (3) working mechanism showing inflow of cell suspension, single-cell trapping via sedimentation, closing of valves and inflow of (gradient of) stimulus; $(4,5)$ bright-field and fluorescence micrographs of a microwell array with trapped single-cells (insets are enlargements, scale bar $=30 \mu \mathrm{m}$ ). Adapted with permission from GonzalezSuarez, A. M.; Pena-Del Castillo, J. G.; Hernandez-Cruz, A.; Garcia-Cordero, J. L. Anal. Chem. 2018, 90 (14), 8331-8336 (ref 8). Copyright 2018 American Chemical Society. (C) Design and working mechanism of a microfluidic device for bead-ordering and single-cell drop-sequencing, with micrographs and close-up schematics: (1) bead inlet, (2) oil inlet, (3) cell suspension inlet. Adapted from Moon, H. S.; Je, K.; Min, J. W.; Park, D.; Han, K. Y.; Shin, S. H.; Park, W. Y.; Yoo, C. E.; Kim, S. H. Lab Chip 2018, 18 (5), 775-784 (ref 27), with permission from The Royal Society of Chemistry. (D) Design and working mechanism of the Vortex HT chip used to purify circulating tumor cells from patient blood samples. Reproduced from Renier, C.; Pao, E.; Che, J.; Liu, H. E.; Lemaire, C. A.; Matsumoto, M.; Triboulet, M.; Srivinas, S.; Jeffrey, S. S.; Rettig, M.; Kulkarni, R. P.; Di Carlo, D.; Sollier-Christen, E. NPJ Precis. Oncol. 2017, 1 (1), 15 (ref 18) under a Creative Commons 4.0 International License (http://creativecommons.org/licenses/by/4.0/).

increasingly applied in a hybrid fashion in an effort to answer evermore complex biological questions as the importance of differences between individual cells is better understood and recognized. Given the extent to which many developments rely on microfluidics, a dedicated section on this is included. Some of the many recent examples of single-cell "omics" performed in microfluidic devices are also discussed. In an effort to write a comprehensive yet not utterly exhaustive overview, we have decided to leave out other areas that have not seen as many new developments. We have also decided to omit techniques in the major areas that have become established and standard approaches, unless there have been significant new develop- 
ments. We sincerely hope we have paid attention to all the work done in this field and apologize to anyone whose work we omitted.

\section{MICROFLUIDICS}

Lab-on-a-chip technologies have become ubiquitous in the chemical analysis of individual cells, as was recently highlighted in several reviews. ${ }^{2-5}$ This surge in popularity is partly due to microfabrication becoming both more advanced and accessible over the years but also because of some distinct advantages that microfluidic devices offer when looking at single cells. Capturing, handling, and/or sorting of cells can be achieved using carefully engineered fluidic features. Some form of sample preparation is often performed on chip as well (e.g., cell lysis, reagent mixing), while analyses can be performed using external analytical instruments (e.g., microscopes) or via integrated elements (e.g., electrodes). Parallelization of analytical units leads to higher throughput, allowing the study of many individual cells, essential for the correct assessment of cell heterogeneity. This is further facilitated by the ease with which relatively complex structures can be replicated. This is generally achieved by employing the biocompatible, gas-permeable poly(dimethylsiloxane) (PDMS). This can be cast onto molds, lifted off after curing, and bonded to microscopy-compatible glass substrates.

In this section, examples of the use of lab-on-a-chip technologies for cell handling, sorting, lysis, and separation will be provided. Some important reports of microfluidicsassisted analyses that do not fit into other sections of this review will be discussed as well, primarily the fast-developing field of single-cell sequencing.

Trapping and Sorting. Efficient entrapment, handling, and sorting of single cells in microfabricated devices is critical for further analysis. In order to do so, a plethora of approaches has been developed and reported. These include the use of geometrical features, hydrodynamic flow patterns, magnetic and acoustic manipulation, and microdroplets; see some examples in Figure 1.

Geometrical and Gravitational Trapping and Sorting. Trapping of individual cells can be achieved by employing geometrical features such as obstructions, constrictions, or microwells, usually in the flow path through which a cell suspension is pumped or injected. These structures can provide a physical confinement for cells or force individual cells into a particular direction or place.

Microwells can be seeded with cells either via passive sedimentation ("stochastic seeding") or using some form of individualization of cells. Sedimentation was used in the work presented by Attayek et al., where passive seeding of cells on microraft arrays was combined with automated imaging to select wells containing a single cell with desired properties: either increased $\mathrm{T}$ cell activity rate ${ }^{6}$ or a successful gene edit. ${ }^{7}$ In an automated procedure, individual microrafts were then punched out (98\% efficiency) and transferred to 96-well plates (100\%) for proliferation and subsequent sequencing.

Gonzalez-Suarez et al. have developed a microfluidic platform comprising nine 492-microwell arrays (see Figure 1B). ${ }^{8}$ A concentration gradient generator was used to deliver a linear gradient of nine concentrations, each directed to one of the nine arrays. Cells were loaded into the $20-\mu \mathrm{m}$-diameter microwells by injecting cell suspension into loading channels and applying 15-s "cycles of sedimentations", during which the cells were able to settle. By combining the concentration gradient generator with an intricate system of pneumatic microvalves, both the frequency and amplitude (concentration) of chemical stimulation of the cells could be controlled. These valves were closed by pressurizing a second layer on top of the fluid channels. Incubated cells were monitored using fluorescence microscopy. The platform was used for assessing intracellular $\mathrm{Ca}^{2+}$ release in individual HEK293 cells that were stimulated with carbachol at different frequencies and concentrations.

Feng et al. presented a device that allows retrieval of single cells after they have been trapped. ${ }^{9}$ Using reactive ion etching, channels were created in a silicon substrate that was later covered by $500-\mu \mathrm{m}$-thick borosilicate glass. A main channel was used to flow in a suspension of fluorescently labeled human MG-63 cells. By applying negative pressure to trapping channels, individual cells were trapped at eight shallow sites in front of a geometrical feature ("island") at the end of these channels (>99\% capture efficiency). After all the sites were occupied with cells, the in- and outlets of the main channel were blocked and a positive pressure was applied to the trapping channel. This caused the trapped cells to move out of the trapping site into dedicated extraction channels that allowed retrieval of individual cells with minimal influence on viability.

Often seen drawbacks of microfluidic devices for single-cell trapping are the occurrence of channel blocking and/or trapping of more than one cell. Mi et al. developed a highly parallelized, PDMS-based trapping device based on the principle of least flow resistance. ${ }^{10}$ Each functional trapping unit contained two channels located around a central trapping channel, which contained a geometrical trap. When a single cell blocked this trapping channel, the flow resistance increased dramatically, causing other cells to move through the two other channels instead. These two other channels ended up in another functional trapping unit. The devices allowed flexible design of different configurations of trapped cells, which could be used to control interactions between single cells. The device was shown to effectively $(>85 \%)$ trap single HeLa cells and mouse embryonic stem cells, which could then be imaged using fluorescence microscopy.

Another example of contact-based trapping in geometrical structures in a microchannel was presented by Yesilkoy et al. Here, mammalian MIA $\mathrm{PaCa}-2$ cells were seeded into microfluidic channels containing arrays of nanoliter-sized chambers (400 traps on whole device, trapping efficiency $\sim 70 \%$ ). The cells remained viable for 2 days. ${ }^{11}$ A PDMS device employing a similar trapping strategy was published by Weng et al. ${ }^{12}$ The relatively simple device was aimed at monitoring cell membrane permeability to cryoprotective agents and was used as such. Butterfly-shaped traps were used effectively for trapping of individual rat hepatocytes and cells from a patientderived circulating tumor cell line under low-shear-stress, hydrodynamic pressure. Membrane permeability was assessed by monitoring the volumetric changes of the cells over time as cryoprotective agents were perfused through the device.

An alternative microconfinement-approach was presented by Son et al., ${ }^{13}$ in a device that was directed at the monitoring of release of specific molecules from cells. The roof of this device contained molded cell-sized microwells that were aligned with patterned, cell-capturing sites on a glass substrate. After cells were captured at these sites, antibody-covered sensing beads were flown in along with fluorescent, secondary antibodies. The roof was lowered, trapping individual cells along with 
sensing beads and secondary antibodies. The antibody-covered microbeads captured cell-secreted molecules and, after binding of the secondary antibody, became fluorescent. The fluorescence intensity was monitored over time, giving temporal information on the secretory activity of single cells. As examples, secretion of inflammatory cytokine by CD4 Tcells (trapping efficiency $\sim 45 \%$ ) and of exosomes by hepatocellular carcinoma cells was observed in this fashion.

Zhou et al. published a device that combined geometrical trapping of cells with microfluidic valves. ${ }^{14}$ Trapping was done by flowing a cell suspension through a channel lined with trapping units: a geometrical trap and a bypass channel, through which the suspension could flow if the trap was occupied. When trapping was complete, a chamber adjacent to trapped cells could be emptied and blocked, causing trapped cells to be released from their fixed position and forced into the bypass channel. After the cells flowed to the outlet of the chip, they could be retrieved. All valves were operated simultaneously in the current version, but if individual control would be exerted, selective retrieval of particular cells would be possible. As an example, murine embryonic stem cells were successfully trapped and imaged using photoactivated localization super-resolution microscopy.

Ohiri et al. presented a device that combines a parallelized array of trapping units, each consisting of a geometrical (weirtype) trap, a bypass channel (leading cells to the next unit if the trapping site is occupied), and a cellular compartment. ${ }^{15}$ Successful loading of the traps with single cancerous PC9 cells was achieved with a trapping efficiency of $80 \pm 5 \%$. After this geometrical, contact-based trapping step, gentle acoustic wave patterns were employed to guide the cells toward the cellular compartments. This larger compartment is more suitable for single cell analysis, as shear stress following from the flow of medium on the cells is lower here. This transfer of cells generated single-cell arrays with an efficiency of $67 \pm 4 \%$. No further chemical analysis of cells was shown.

Trapping and Sorting Using Hydrodynamic Flow Patterns. In addition to the confinement-based trapping and sorting methods described above, contactless approaches also exist. Hydrodynamic focusing using carefully tuned flow patterns continues to be successfully employed.

Zhao et al. published a simple, single-layer device, consisting of a PDMS microchannel on a glass substrate. ${ }^{16}$ Four different sheath flows focus the flow pattern of a sample both vertically and laterally. This allows particles or cells to be continually flowed through the channel one after another. An optical fiber was integrated perpendicular to one side of the channel, transferring light toward the sample flowing past. To focus the light, an air lens in the PDMS was used. Two optical fibers were placed in slots opposing the excitation fiber (relative angles of $13^{\circ}$ and $-60^{\circ}$ ) to count particles or cells in the sample flow. Cytometry of human basophils in the device was shown to be comparable to equivalent experiments in a commercial instrument.

Another approach toward flow-focusing of single cells is the use of laminar-flow vortices. The Di Carlo group has published many examples of this, applying the principle primarily to the capture of rare cells, like circulating tumor cells (CTCs). CTCs are very rare (1-10 per $\mathrm{mL}$ of blood), and monitoring their relative number is helpful in assessing patient prognosis as well as the effect of a chosen therapy. ${ }^{17} \mathrm{~A}$ commercialized microfluidic device, Vortex HT, was used in two recent publications (see Figure 1D). ${ }^{17,18}$ It features a network of parallel channels with series of lateral, rectangular reservoirs. A diluted sample $(10 \times)$ of blood and buffer are flowed through the channels. As a result, stable microvortices are generated in these reservoirs. High flow rates exert stronger fluidic forces on larger cells than smaller cells, and the larger CTCs are therefore captured in the lateral reservoirs, whereas smaller red and white blood cells flow through the main channel toward the outlet. To wash out the captured cells, sample flow is stopped, and the buffer flow rate is increased. The cycle can then be repeated to achieve increased CTC purity. The viability of the recovered CTCs was shown to be good, and as such this technique was combined with pharmacological and genetic studies. ${ }^{17}$ In the two recent papers, effective capture of CTCs from breast, lung, ${ }^{17}$ and prostate ${ }^{18}$ cancer patients was demonstrated with high throughput $(8 \mathrm{~mL}$ of $10 \times$ diluted blood $/ \mathrm{min}$ ). In a publication from the same group, Khojah et al. present a different device employing the same principle of microvortex based capture of cells. ${ }^{19}$ In this case, only one lateral chamber was available next to the main channel. By switching the flow rate in the main channel, distinct geometries of the cell or particle capture vortices were generated. Three different "phases" were described: Phase I $(100 \leq \operatorname{Re}<175)$, Phase II $(175 \leq \operatorname{Re}<225)$, and Phase III $(225 \leq \operatorname{Re}<300)$. In Phase I, larger clusters were captured in the center of the vortex, while smaller cells could exit the lateral chamber and flow toward the outlet of the chip. In Phase II (higher flow rate), both clusters and smaller cells escaped the lateral chamber while larger cells were trapped. Phase III (highest flow rate) led to the smallest cells being captured in the vortices. From the results, the Reynolds number for which particles with a certain diameter were captured in stable orbits was obtained. This was successfully applied in the tunable capturing of fluorescent breast cancer cells and cell clusters from blood samples. The principle was then translated to the Vortex HT commercial device, with a capture efficiency of $24 \%$. These techniques, if combined with a trapping system, could provide a powerful system to study CTCs. Dhar et al. presented a combination of the Vortex device with a droplet encapsulation system. ${ }^{20}$ This was used to first isolate rare CTCs from blood from prostate cancer patients. The cells were then individually encapsulated into droplets with fluorogenic reagents for the assessment of protease enzymes secreted by the CTCs. This assay was performed by imaging the droplets. The total process of isolation and encapsulation was completed within minutes. It was found that CTCs display higher protease activity than leukocytes from the same patient, and that the activity of CTCs between patients varied greatly. It was hypothesized that high CTC protease activity could influence invasion of cancer cells into the bloodstream and evade immune cells, processes involved with metastasis.

A system including a dedicated and cell-specific release system was presented by Yeo et al. ${ }^{21}$ Here, a viscous sheath flow pushed a cell suspension into a single-cell file along a bend in a microchannel channel. The bend was lined with passive trapping sites, which were filled with cells due to centrifugal force. Each of the traps was connected to a control channel, and by providing positive pressure, individual cells were forced back into the main channel and subsequently recovered at the outlet. By tagging them beforehand, selection of specific cells for recovery could be performed. The device was used to single out CTCs from a suspension of white blood cells. By cycling the sample, very high capture efficiencies of up to $100 \%$ were obtained. Captured lung adenocarcinoma cells (PC9) were 
individually retrieved from the chip and subjected to immediate single-cell genomic screening for relevant mutations. The results demonstrated applicability of this device in a relevant analytical workflow, albeit with less throughput than the commercial Vortex HT device.

Hydrodynamic flow patterns, controlled by microfluidics, can also be used to break up clusters of cells (tissue, tumors) into single cells. An example was published by Qiu et al., where a laser-micromachined polyimide film containing a branching network of channels was used. ${ }^{22}$ The channels featured many expanding and constricting regions with sinusoidal and sharkfin shapes. The film was held in between polyethylene terephthalate (PET) and acrylic layers containing in- and outlets, and suspensions containing small $(<40 \mu \mathrm{m})$ aggregates of cells were flowed through the channels. Due to the geometrical features and the deceleration and acceleration of the sample they cause, large differences in shear stress on the aggregates were exerted. This caused the aggregates to dissociate into single cells, especially if two devices were connected in series. Robust disassociation into single cells was shown with samples of mouse kidney tissue and human breast cancer (MCF7).

Droplet-Based Trapping and Sorting. Arguably, some of the most advanced and complex microfluidic devices that perform trapping and sorting of single cells use droplets. However, efforts have been made to make droplets more accessible to nonspecialized laboratories. $\mathrm{Li}$ et al., for example, published an open system, where droplets were formed based on the mutual repulsion of different phases. ${ }^{23}$ Aqueous liquids exclusively repelled silicone oil on PDMS surfaces, forming stable droplets $\left(\right.$ contact angle $\left.=180^{\circ}\right)$. Instead of using a channel-based, continuous-flow approach or the technically complex electrowetting-on-dielectric approach, ${ }^{24}$ droplets were actuated in this device using a pipet. The droplets were also used to encapsulate single cells and to create cocultures by selectively merging droplets containing cells and enriching samples of CTCs. Dyes could also be injected into the droplets (with minimal diffusion into the oil phase when using hydrophilic dyes) and cells could be imaged. As an example, CTCs and peripheral blood mononuclear cells were thus identified after pipetting $1 \mu \mathrm{L}$ of a 0.5 cell $/ \mu \mathrm{L}$ stained cell suspension into each well of a PDMS 384-well plate containing silicone oil.

Stationary droplets were used for single-cell analysis as well. In the work published by $\mathrm{Li}$ et al., a microfluidic chamber was accessed by means of a fused silica capillary. ${ }^{25}$ This was used to create and manipulate nanoliter-sized droplets of cell suspension. The ceiling of the chamber was closed off by an oil phase to prevent evaporation of the aqueous droplet. Droplets containing single or multiple cells were thus created. Using the capillary to add reagents, single cells could be lysed and their proteins digested. After this, the contents were transferred to a coupled LC-MS/MS and analyzed. Thus, proteomic analysis was performed on E. coli, HeLa cells, and mouse oocytes. In a single mouse oocyte, 355 proteins were identified.

$\mathrm{Ng}$ et al. employed droplet microfluidics to assess activities of six protease enzymes in single cells. ${ }^{26}$ This was achieved by mixing cell suspension with multicolored enzyme substrates via pinched-flow, after which droplets containing single cells were generated by trapping a volume of suspension in between oil. The substrate-protease reactions were monitored in a highthroughput fashion using fluorescence microscopy. After analysis, reaction rates were compared with those obtained using a conventional plate reader-based method. The method was tested in breast, lung, and leukemia cancer cell lines.

Moon et al. presented a device aimed at increasing the throughput (for improved statistical power) and reducing the barcoding error (to ensure correct relation of the sequenced information to a single cell) of the existing Drop-Seq single-cell RNA-sequencing (scRNA-seq) technique (see Figure 1C). ${ }^{27}$ Lysis buffer and oligonucleotide-barcoded beads were mixed with a cell suspension on-chip. Subsequently, the mixture was encapsulated into water-in-oil emulsion droplets by means of a microfluidic droplet generator, in such a way that each droplet contained a single cell. By applying a spiral-shaped microchannel to lead the beads toward the mixing site, an inertial ordering with uniform distances between beads occurred. This resulted in diminishing the occurrence of encapsulation of multiple beads per droplet ( $1-2 \%$ of droplets vs $20 \%$ without spiral channel). RNA-sequencing was performed off-chip after retrieval of the droplets from the device. The system was validated with human HEK293T and murine NIH3T3 cell lines.

Another droplet-based RNA-sequencing technique is found in the inDrops system. Zillionis et al. have provided a comprehensive overview of the construction of the platform. ${ }^{28}$ The inDrops uses the same principal technique as Drop-Seq (with Chromium ${ }^{29}$ and the nondroplet-based Fluidigm $\mathrm{Cl}^{30}$ being other commercially available alternatives). The principle is to fuse single cells with barcoded beads followed by lysis buffer in droplets, after which the contents are pooled and sequenced and the resulting information related back to the original cells. However, since a much higher fraction of the cells is actually barcoded in the inDrops system compared to the Drop-Seq system ( $75 \%$ vs $2-4 \%$ ), the former is more suitable when the input sample is very small ( $<200000$ cells). In the dedicated section later in this review, more examples of microfluidics-assisted single-cell sequencing will be presented, many of which rely on droplet trapping and sorting.

Other Techniques for Trapping and Sorting. As was already mentioned, ${ }^{15}$ acoustic waves can be used to guide, manipulate, and even trap particles and cells. Another recent example that employs acoustic manipulation of single cells was published by Antfolk et al. ${ }^{31}$ This publication describes separation and concentration of single CTCs (prostate cancer cells in peripheral blood mononuclear cell suspension) using fluidic structures and ultrasound. This was done in a rigid glass/silica chip. After this, concentrated CTCs were flowed into a PDMS chip that featured an array of cell-sized microwells with transparent indium tin oxide (ITO) electrodes at the bottom. By applying a potential, prostate cancer cells were effectively $(76.2 \pm 5.9 \%)$ trapped into these wells by dielectrophoresis. The (prestained) cells could then be imaged and identified.

A more complex example of acoustic manipulation was presented by Guo et al. ${ }^{32}$ Instead of focusing flows, this device can be used to manipulate single cells in three dimensions through a microfluidic chamber. This was achieved by means of phase-shifting of standing waves for in-plane movements and changing the amplitude for orthogonal movements. The device was used for micromanipulation and translation of cells and particles and for printing using precisely placed cells. Thus, far, they have not shown an analytical application for this device but have suggested their device can be used for manipulating cells into an area of analysis (e.g., for imaging). 
Huang et al. employed an altogether different technique to trap single cells. ${ }^{33}$ Their device consisted of a PDMS microchannel with a ceiling containing cell-sized microwells. These microwells were sealed off by a coverslip mounted on top of the device. A permanent magnet was used to effectively "pull" immunomagnetic-labeled human acute monocytic leukemia cells into the microwells. Other, nonlabeled cells were flushed away in a washing step after the trapping. The trapped cells could then be imaged. A specific analytical application has not been shown to date.

When trapping single cells for subsequent chemical analysis, one usually starts with a sample containing as many viable cells as possible. A device presented by Islam et al. employed a series of diagonal ridges in a microchannel through which a cell suspension is flowed to sort live and dead cells. ${ }^{34}$ This was done based on a difference in Young's modulus (i.e., stiffness) of live and dead cells. Stiff, unviable cells were compressed against the ridges and were directed along the ridge toward a channel. Softer, viable cells flowed toward the other channels via hydrodynamic flow patterns, leading to an enriched concentration of live cells at the outlets for softer cells. This device was applied to increase the concentration of viable, nucleated cells in human cord blood samples from $65 \%$ to $94 \%$. Ren et al. used the difference in stiffness of a breast cancer cell line and a noncancer breast cell line to differentiate between the two. ${ }^{35}$ This was based by tracking the velocity profiles in microchannels with several constrictions using a smartphone. In both cases, no direct applications for chemical analysis were shown to date.

Okumus et al. developed an advanced, automated single-cell imaging system based on microfluidic trapping using pneumatic valves. ${ }^{36}$ The microfluidics-assisted cell screening (MACS) platform featured a set of PDMS microchannels used to transport suspensions of cells (in this case Escherichia coli). The ceiling of these channels could be pneumatically forced down, gently trapping single cells in the field of view of a microscope. The system was compatible with total internal reflection fluorescence microscopy as well, allowing identification and numeration of rare proteins (single-molecule resolution) in cells. The MACS platform allowed for inclusion of an upstream growth chamber, from which a cell suspension could be sampled and imaged in an automated fashion. Using valving systems, automated cleaning of the chip in between imaging experiments was performed. Cells were made to flow through the device for constant imaging, and cells of interest were identified using real-time image analysis. A different set of valves could then be used to trap these cells of interest within an oil phase and retrieve them from the chip. Although the experiments shown in this paper were performed with $E$. coli, the authors claimed no extra changes need to be made in order to image other cells (e.g., mouse embryonic fibroblasts or red blood cells in whole blood samples).

Sample Analysis. As has been described above, a large and varied toolkit for microfluidic sorting and trapping of single cells exists. However, not every example described has led to an analytical application to date for the sample preparation or enrichment developed. In this section, recent advances in the field of microfluidics-assisted analyses will be reviewed that were not mentioned in the other sections. Special attention is given to the role microfluidics plays in the rapidly expanding field of single-cell sequencing and gene expression analysis.

Microfluidics-Assisted Sequencing and Gene Expression Analysis. As argued in the introduction of this review, heterogeneity of cells is of paramount importance to understanding biological responses on higher levels. Arguably, most information about this heterogeneity can be obtained by looking at the genome, transcriptome and/or epigenome of individual cells, as is also claimed by many recent reviews on the subject. ${ }^{37-42}$ Although single-cell sequencing protocols are often facilitated by nonmicrofluidic methods, such as fluorescence-assisted cell screening, microfluidics brings unparalleled throughput to the table. Some devices incorporating microfluidics for this have quite recently been reviewed elsewhere. ${ }^{43}$

As was already introduced before, a large part of these platforms relies on droplet microfluidics. Zheng et al. developed an 8-channel device for high-throughput single-cell RNA-sequencing (scRNA-seq). ${ }^{44}$ Comparable to systems described above, the principle relied on the coencapsulation of barcoded beads with single cells into droplets. In this platform, $80 \%$ of the droplets featured one barcoding gel bead. Combined with the Poisson-distributed cell loading, this resulted in a $50 \%$ cell capture rate. In each of the 8 independent channels of this chip, thousands of cells were encapsulated with beads per 6 min run. After cell lysis and barcoding, the droplets were pooled and the RNA sequenced. The system was applied to different cell lines and patientderived primary cells. Due to the high-throughput over relatively short time-scales, the system is especially interesting for researchers or clinicians studying particularly fragile cell samples, such as those derived after high-intensity chemotherapy.

Stephenson et al. developed an alternative to standard droplet-based sequencing platforms. ${ }^{45}$ The system contained a PDMS chip for actual droplet generation, but 3D-printed and miniaturized alternatives to bulky external hardware (e.g., syringe pumps and microscopes) to lower cost and footprint. After validation of the system against a conventional dropletbased sequencing platform, the system was applied for transcriptomal analysis of synovial tissue samples from rheumatoid arthritis patients. The RNA of more than 20000 cells from human synovial tissue was sequenced, based on which 13 different clusters of cells were identified.

Guo et al. presented a device directed at the sequencing of micro-RNA (miRNA). ${ }^{46}$ Again, single cells were encapsulated with reagents. In this droplet-based device, miRNAs were amplified using hairpin DNA sequences after lysis of each cell. The hairpin DNA sequences contained a fluorophore that increased in intensity as the miRNA was amplified. The overall reaction time of this hybridization was about $20 \mathrm{~min}$. The resulting intensity was measured on-chip, with a throughput of 300-500 cells per min. The miRNA expression level of three different cell types was compared: healthy MCF-10A cells and two breast cancer cell types MCF-7 and MDA-MB-231, with the latter being a more aggressive cancer cell type. It was found that the lower miRNA expression level of healthy cells was distinguishable from the cancer cell types, but also that MDAMB-231 cells had higher miRNA expression than MCF-7 cells.

Where most examples focus on sequencing of RNA, Chu et al. developed a PDMS device aimed at sequencing the DNA of single cells (whole genome sequencing). ${ }^{47}$ The complex (continuous-flow-based) design featured a structure for capturing single cells from a suspension and allowed lysis of single cells and separation of their double-stranded DNA. Using a network of control valves, the single stranded fragments were then partitioned over 24 reaction chambers, 
where the DNA was amplified. The DNA was then barcoded and sequenced. As a benchmark, the genome from three cells of the well-defined human fibroblast cell line PGP If was sequenced. The throughput was still very low, as a result of the complexity of the design, up-scaling and parallelization were difficult. Higher throughput ( $>50000$ cells per run of a few hours) was achieved by Lan et al. ${ }^{48}$ Here, barcode droplets were fused with hydrogel droplets containing encapsulated bacteria (each generated in microfluidic devices). After lysis, fragmenting and tagging of the genomes, the barcoded fragments were pooled and sequenced using off-chip PCR and Illumina DNA-sequencing. In this fashion, the genomes of single bacterial and fungal cells were assessed.

Vaninsberghe et al. demonstrated the design and use of a more multiplexed multilayer PDMS device. ${ }^{49}$ Similar to the work of Chu et al., this device featured cell traps and reaction chambers and a complex valving system instead of droplet generators. It was shown to be capable of performing quantitative polymerase chain reaction (qPCR) on 200 cells on one device. For this, the fluorescence intensity resulting from the PCR was measured using the prototype of a commercial device. To validate the system, well-defined RNA samples were measured as well as specific miRNAs in the K562 human erythroleukemic cell line and the murine $\mathrm{BaF} 3$ pro- $\mathrm{B}-$ cell line.

Kaiser et al. developed a microfluidic system that allows following gene expression through time by combining quantitative fluorescence time-lapse microscopy (QFTM) with specialized software. ${ }^{50}$ In the PDMS device, cells (E. coli in this case) were grown in a single file in growth channels that had diameters similar to that of the single cells. Via a twoinput channel system, cells could be exposed to well-controlled concentrations of medium components. As a demonstration, the device was used to follow the expression of E. coli's lac operon as a consequence of switching the carbon source from glucose to lactose and back in medium flowing through the device. When switched to lactose, expression of this lac operon occurs, which in this case was coexpressed with green fluorescent protein. Measurement of fluorescence intensity was done by taking a frame of the growth channels every 3 min. This measurement of expression and simultaneous measurement of cell growth was done over more than 10000 cell cycles for a total of more than 500000 individual cells (see Figure 1A).

A system presented by Rullan et al. combined the optogenetic photoregulation of a transcription factor with RNA quantification in single cells. ${ }^{51}$ This was done in order to study the effect of regulators on the dynamics of transcription in Saccharomyces cerevisiae. A so-called digital micromirror device was used to achieve micrometer-resolution illumination of targeted cells in a PDMS chip. This chip was specifically designed for long-term culturing and imaging of nonadherent cells, such as S. cerevisiae. After illumination of the cells and subsequent activation of a reporter gene, nascent RNA was formed which was engineered to result in fluorescence. Singlemolecule fluorescent in situ hybridization microscopy was used to quantify this and relate the intensity to the number of nascent RNAs. By combining the high spatial resolution of the micromirror array and microscopy technique with the fast kinetics of the photoregulator, transcription bursts and timing could be monitored at the single-cell level.

Other On-Chip Analyses. Some recent examples of on-chip analyses that have not been mentioned earlier in this review will now briefly be discussed. Liao et al. developed a nanowell array that was seeded with human neural and glial cells from induced pluripotent stem cells (iPSCs). ${ }^{52}$ The iPSCs were seeded by letting cell suspension gravitate into $\sim 100000$ nanowells which fit $0-2$ cells (assessed using microscopy) each. On average, 30000-40000 wells were occupied by single cells. After staining for viability and initial imaging, a glass slide covered with antibodies to capture amyloid $\beta$ and soluble amyloid precursor protein-alpha (factors involved in Alzheimer's disease) was placed on top of the nanowells. These proteins, secreted by individual cells, were thus captured, after which detection and fluorescent secondary antibodies were added. After washing, the glass slides were imaged. The cells were subsequently fixed and immunostained or individually retrieved using a micromanipulator after which expression of neuronal or amyloid precursor protein-related genes were assessed. This platform, which combined immunostaining, gene expression analysis, and antibody-based assays for secreted factors, all on single cells, made it possible to single out differences between subpopulations and individual cells in a clonally stable cell population.

Xia et al. demonstrated the use of an array of cell-sized, PDMS microwells coated with a $50 \mathrm{~nm}$-thick layer of gold for measurement of intracellular glucose. ${ }^{53}$ This was done by first loading the cells by gravity, after which the cells were lysed and exposed to glucose oxidase. Next, $200 \mu \mathrm{M}$ of the bright luminol analogue, L012, in PBS was added, which reacted with the hydrogen peroxide formed by the enzyme. Under application of a positive potential this resulted in luminescence, which was monitored with a charge-coupled device (CCD) and related to the intracellular glucose levels.

Zhou et al. presented an adapted version of their trapping device discussed above, ${ }^{14}$ leaving out the control channels that allow selective retrieval of single cells from the platform but including an array of electrodes that allow measurement of electrical impedance of individual cells. ${ }^{54}$ Mouse embryonic stem cells were captured and differentiated on-chip. Their impedances were measured after 0 (undifferentiated), 24 (transition) and $48 \mathrm{~h}$ (differentiated). It was found that the heterogeneity of cells was highest in the transition phase as well as an overall increase in impedance of cells as differentiation progressed.

Finally, Cermak et al. presented a microfluidic device that allowed the assessment of single-cell growth rates using mass sensors. ${ }^{55}$ Suspended microchannel resonators (SMRs) are cantilevers that contain a sealed microfluidic channel, and when cells flow through, the resonant frequency changes with the mass of the cells. In the presented device, an array of fluidically connected SMRs was used for precision mass measurements of individual cells. By measuring multiple times over time, growth rates could be assessed with a resolution 0.2 $\mathrm{pg} / \mathrm{h}$ and a throughput of 60 mammalian or 150 bacterial cells per hour. The device was successfully tested with (human) cell lines and primary cells, yeast cells, and bacteria. The growth rate of cancer cells was found to be related to their responsiveness to chemotherapy. ${ }^{56}$

\section{SUPER-RESOLUTION MICROSCOPY FOR IMAGING OF INDIVIDUAL CELLS}

Optical microscopy has played as a key role in the exploration of molecular organization inside single cells, despite its wellknown limitation of the diffraction of light, which states that the best obtainable spatial resolution is half of the wavelength 


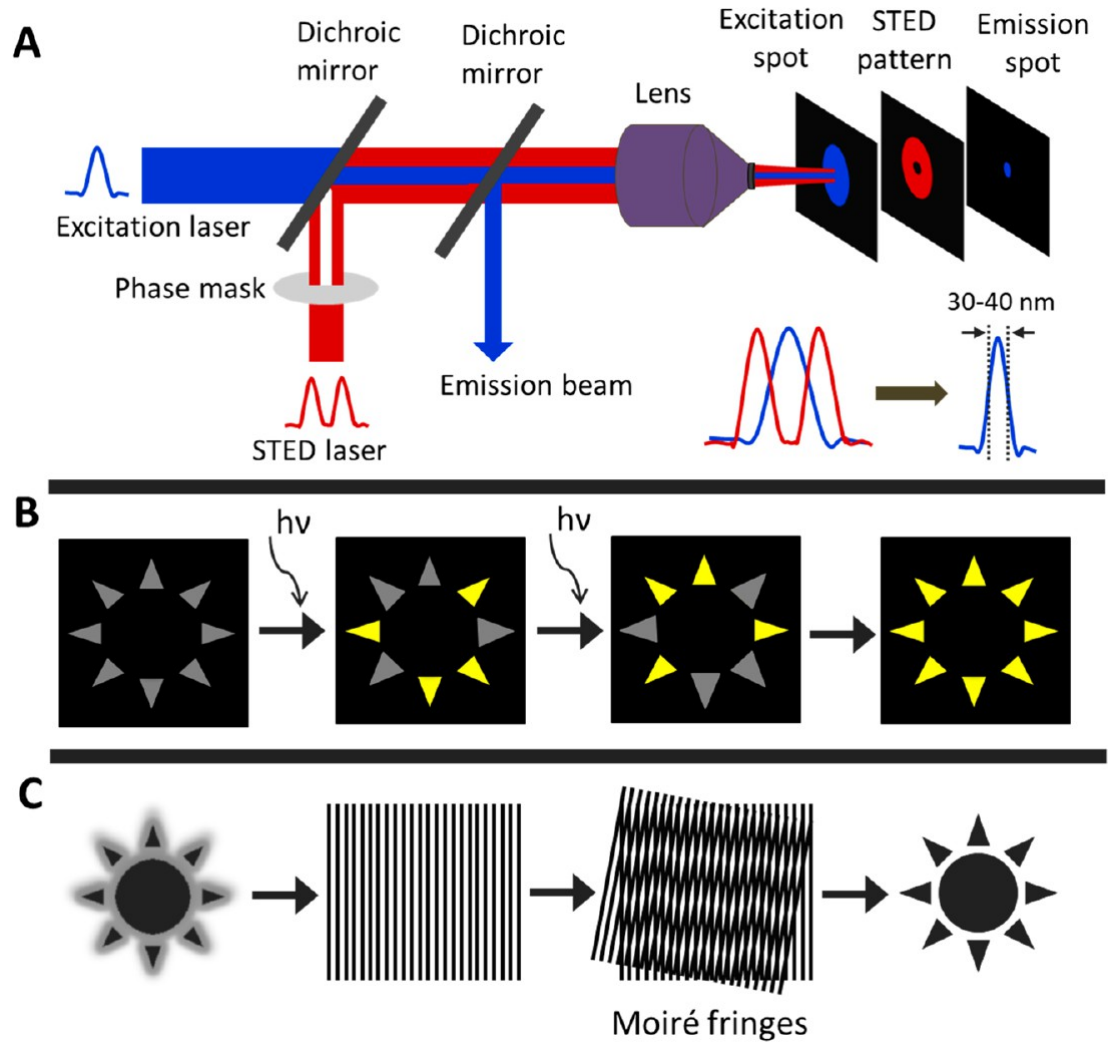

Figure 2. Principles of super-resolution microscopic techniques: (A) STED microscopy, (B) STORM/PALM microscopy, and (C) SIM.

of the illuminating light ( $200 \mathrm{~nm}$ for visible light). This classical diffraction limit was eventually surpassed by the breakthroughs of the three pioneers Eric Betzig, William Moerner, and Stefan Hell, who were awarded the Nobel Prize in 2014. The concept of super-resolution microscopy, or socalled nanoscopy, was realized since then. The most prominent approaches of super-resolution microscopy, including single molecule localization microscopy (SMLM), stimulated emission depletion (STED), and structure illumination microscopy (SIM), utilize switching between the "on", fluorescent state and "off", nonfluorescent state of the fluorophore, in order to discern the positions of molecules. Super-resolution microscopy has certainly become a powerful imaging tool in the field of cellular biology and has been developed to reach to the molecular scale.

In this section, we report on the latest achievements of super-resolution microscopic techniques for subcellular imaging. We also address recent labeling trends as well as the possibilities for further technical development of superresolution microscopy at single-cell and single-molecule levels.

STED Microscopy. STED utilizes switching the fluorescence emission of the fluorophore on and off at a preset spatial coordinate. The fluorophores are illuminated with two cocentered beams: an excitation beam to switch the fluorescent state on, and a doughnut-shaped depletion beam to switch it off. The depletion beam is characterized by a minimum (zero light intensity) at the doughnut center. As a result, only fluorophores located at the beam center, which is smaller than the diffraction limit, remain fluorescent (Figure 2A). In principle, the minimum could be narrowed down to detect single molecules. The beams gradually scan across the sample area with a pinhole, similar to confocal microscopy. The outcome of the imaging depends on several factors. The zero light intensity at the center of the depletion beam is critical for obtaining high sensitivity and high contrast of the image. In addition, the fluorophore must be bright, photostable, and switchable between fluorescent and nonfluorescent states. The labeling probe should be compatible with cells and be highly selective for the target protein. STED provides a routine lateral resolution of $30-40 \mathrm{~nm}$ and an axial resolution of approximately $500 \mathrm{~nm}$. To obtain three-dimensional (3D) imaging with STED, a second depletion beam is inserted along the $z$-direction to sharpen the fluorescence-emitting point axially. ${ }^{57}$ Alternatively, two opposing objective lenses (4Pi arrangement) are placed in a modified version of STED (isoSTED). ${ }^{58,59}$ The latter results in an axial resolution of $20-$ $30 \mathrm{~nm}$, while the lateral resolution is unaffected.

Recently, many applications of STED in the study of individual cells were reported. The nodes of Ranvier are the gaps along myelinated axons of neurons and are important for the propagation of the action potential along neurons. To investigate the nanoscale organization of the nodes of Ranvier of teased sciatic nerve fibers as well as the interaction between axons and glial cells at these nodes, 12 different proteins of cytoskeleton, ion channels, and axon-glia adhesion molecules were imaged using two-color STED microscopy. ${ }^{60}$ It was shown that axonal cytoskeletal proteins and proteins of potassium channels exhibited periodic longitudinal organization at the nodes, whereas axon-glia adhesion molecules formed periodic 2D hexagonal lattices with a dimension of 190 nm. The study emphasized a close functional relationship between the axons and glial cells, and their involvement in a wide range of neurodegenerative diseases.

Another study utilized multicolor and live-cell STED microscopy to investigate how synaptic strength, or neuronal plasticity, correlates to the molecular architecture of the 

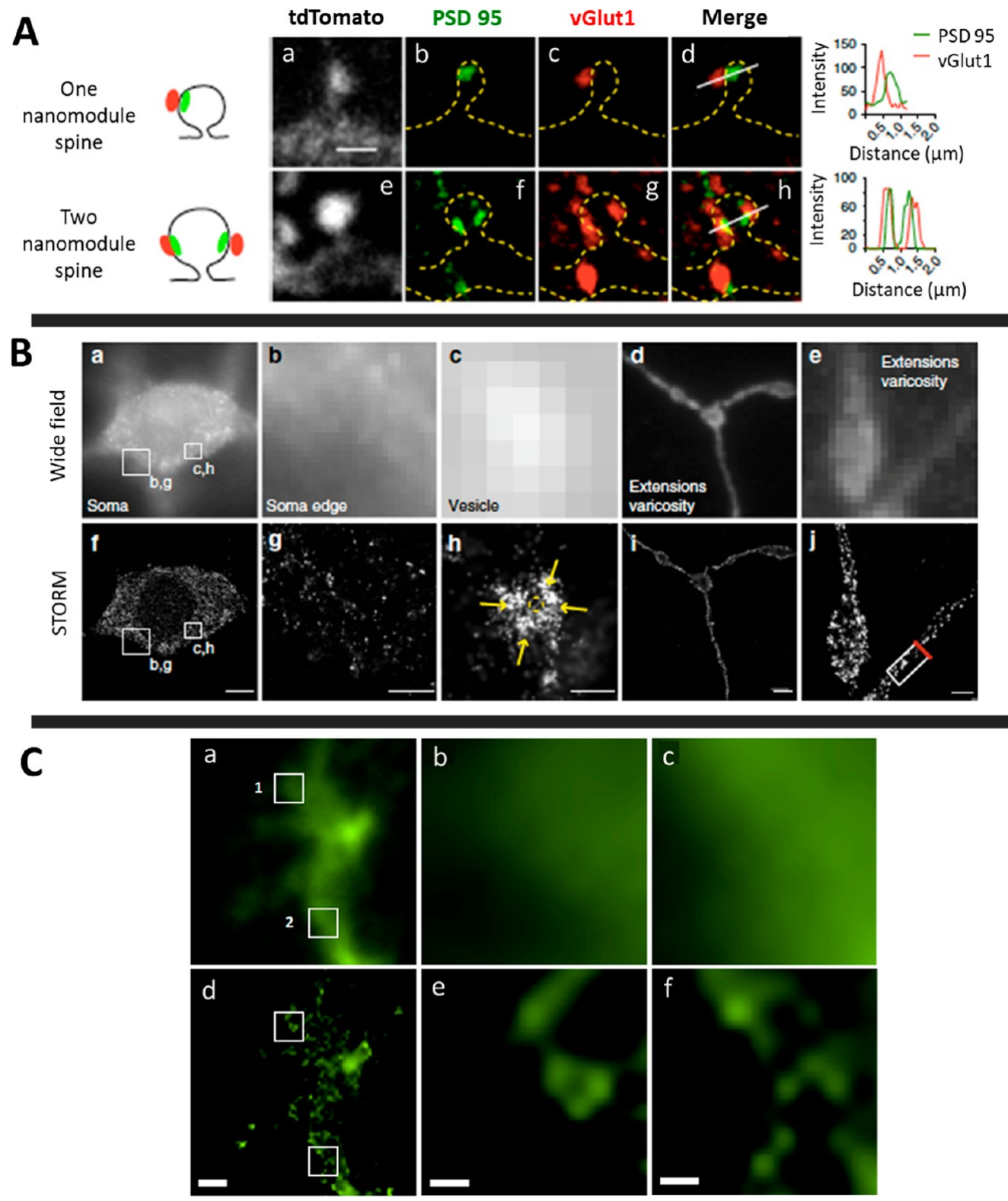

Figure 3. Applications of super-resolution STED, STORM, and SIM in single cell imaging. (A) STED imaging of molecular architecture of dendritic spine synapses of DIV21 cortical neurons. Schematics showing protein arrangement in individual spines (left); STED images of PSD 95 (green) and vGlut1 (red) proteins in individual spine (visualized by a confocal image of tdTomato) (middle). Line-scans of the white lines in parts $\mathrm{d}$ and $\mathrm{h}$ indicating high degree of alignment of these structures (right). Reprinted by permission from Macmillan Publishers Ltd.: NATURE NEUROSCIENCE, Hruska, M.; Henderson, N.; Le Marchand, S. J.; Jafri, H.; Dalva, M. B., Nature Neuroscience 2018, 21 (5), 671-682 (ref 61). Copyright 2018. (B) STORM imaging of DAT distribution in cultured dopaminergic neurons. (a, f) Widefield image and STORM image of the cell body. (b, g) Zoom-in widefield and STORM images of the soma edge. (c, h) Zoom-in widefield and STORM images of a putative vesicle. Yellow arrows demonstrate circular distribution of DAT. (d, i) Widefield and STORM images of an extension of varicosities and their zoom-in widefield and STORM images (e, j), respectively. Reproduced from Rahbek-Clemmensen, T.; Lycas, M. D.; Erlendsson, S.; Eriksen, J.; Apuschkin, M.; Vilhardt, F.; Jorgensen, T. N.; Hansen, F. H.; Gether, U. Nature Communications 2017, 8 (1), 740 (ref 63) under a Creative Commons 4.0 International License (http://creativecommons.org/licenses/by/4.0/). (C) Localized plasmonic SIM (LPSIM) imaging of Fzd3 receptors labeled with tdTomato in a fixed neuron of rat. (a, d) Widefield and LPSIM images indicating significant improvement in lateral resolution of LPSIM. (b, e) Zoom-in widefield and LPSIM images of area 1 in part a, respectively. (c, f) Zoom-in widefield and LPSIM images of area 2 in part a, respectively. Reproduced from Ponsetto, J. L.; Bezryadina, A.; Wei, F.; Onishi, K.; Shen, H.; Huang, E.; Ferrari, L.; Ma, Q.; Zou, Y.; Liu, Z., ACS Nano 2017, 11 (6), 5344-5350 (ref 67). Copyright 2017 American Chemical Society.

synapses of rat and mouse (Figure 3A). ${ }^{61}$ Proteins of the dendritic spine, PSD95, the presynaptic proteins Bassoon and glutamate receptor vGlut1, and vesicular protein synaptophysin were labeled and were found to be spatially well-aligned. These proteins form a cluster whose size was found persistent at the spines. As the synaptic strength changed, the size of the dendritic spines changed corresponding to the number of protein clusters. These examples are the most recent demonstrations of the single-molecule imaging capability of STED microscope in biological applications.

Single Molecule Localization Microscopy (STORM, PALM). Stochastic optical reconstruction microscopy/photo- 
activated localization microscopy (STORM/PALM) stochastically switches the fluorescence emission of a subset of fluorophores on and off. This random approach effectively avoids the simultaneous emission of molecules located within the diffraction limit, allowing the identification of the positions of individual fluorophores. The collected positions of all fluorophores, obtained from thousands of images of different subsets of fluorophores on the entire sample area, is eventually used to reconstruct the final molecular image (Figure 2B). ${ }^{62} \mathrm{~A}$ high number of photons is needed to generate an image with sufficient resolution (approximately $10 \mathrm{~nm}$, laterally) to localize each fluorophore. Most importantly, the fluorophores suitable for STORM/PALM must be photoactivatable and stable through many imaging cycles. The technique prevents fluorophores from photobleaching by using lower intensity light compared to STED. However, as a consequence of the necessary thousands of imaging cycles, the method is more time-consuming.

Dopamine transporter (DAT) is a well-known transmembrane protein responsible for the reuptake of dopamine during neurotransmission. To understand the molecular mechanism of the tight regulation of DAT on dopamine signaling, PALM and STORM were used to study the spatial distribution of DAT in CAD (mouse neuron-like) cells and rat dopaminergic neurons and its dynamic changes following neuronal excitation. ${ }^{63}$ The photoswitchable dye Dronpa was coupled to DAT to be observed with PALM or a pair of dyes, Alexa405 and Alexa647, was used to immunostain DAT for visualization using STORM (Figure 3B). Nanodomains of DAT (approximately $70 \mathrm{~nm}$ in diameter) were found localized in discrete and cholesterol-dependent regions where the proteins tyrosine hydroxylase and vesicular monoamine transporter (VMAT2) were present. In addition, the DAT nanodomains were shown to be dynamically mediated by NMDA receptor stimulation. PALM/STORM was also successfully applied to study the 3D arrangement of proteins at a ciliary transition zone to understand the molecular defect in ciliopathies ${ }^{64}$ and to reveal the molecular cues of how noncoding RNA selectively spreads only to the inactive $\mathrm{X}$ chromosome of a pair of X chromosomes. ${ }^{65}$

Structured Illumination Microscopy. In SIM, the sample is illuminated with a periodic sinusoidal light pattern consisting of different lateral frequency components, which is generated by passing excitation light through a movable diffraction grating. The obtained raw data are then computationally reconstructed to produce a final image (Figure 2C). The advantage of SIM is that conventional fluorophores and sample preparation for standard fluorescence microscopy can be readily used, and multicolor imaging up to four colors is easily performed. The lateral resolution, however, is only 2 times better than conventional fluorescence microscopy, since the illumination pattern itself is diffraction limited. ${ }^{66}$ The image reconstruction is also heavily dependent on sophisticated computational process and operator experience to avoid artifacts during the reconstruction. Efforts have been made to improve the lateral resolution of SIM. A typical example is the use of surface plasmon polaritons or localized plasmonic field in SIM (LPSIM), producing higher spatial frequency of the illumination pattern than the wavenumber of the excitation light. ${ }^{67}$ The use of this method was demonstrated by localizing Fzd3 protein labeled with the fluorescent protein tdTomato in fixed neurons of rats (Figure 3C). Subcellular features could be resolved at a resolution of approximately $80 \mathrm{~nm}$. Three-color
SIM and the newly developed statistical method Statistical Object Distance Analysis (SODA) were used to image primary hippocampal neurons and characterize the spatial organization of thousands of synapses. ${ }^{68}$ It was found that the dendritic molecules Homer and PSD95 localize in nanodomains and position in triangle with presynaptic protein Synapsin.

Challenges and Recent Developments in SuperResolution Microscopy for Single-Cell Imaging. Although in theory single-molecule imaging could be achieved by super-resolution microscopy, several challenges have come along when it found applications in cellular and molecular biology. Particularly, the demand for reduced photobleaching from light exposure, multicolor imaging, and live-cell imaging. Recent method developments have mitigated these challenges, enabling detailed capture of the cellular structure, the interaction of biomolecules, and their quantification.

Reduction of Photobleaching. Photobleaching has been the main challenge that prevents super-resolution microscopic techniques from reaching down to the molecular level. As the localization precision of individual fluorescent molecules depends on the photon budget of each fluorophore, a high and long-lasting photon budget would allow imaging and longterm tracking of single biomolecules in live cells. Superresolution microscopy often utilizes high intensity lasers in order to efficiently excite fluorophores. This is especially the case for STED, which uses an additional depletion laser for quenching the fluorescence of all fluorophore within the doughnut rim during a temporal window of a few nanoseconds. This causes extreme photobleaching and possible phototoxicity, which could damage living cells during in vivo imaging. Different modifications have been proposed to reduce photobleaching; ${ }^{69,70}$ the most noticeable improvements are the Hessian deconvolution algorithm for SIM, and time-gated, MINFIELD, and MINFLUX for STED. ${ }^{71-74}$

To reduce photobleaching in STED, Göttfert and coworkers $^{72}$ introduced the MINFIELD concept, which restricts the imaged area to the size of a subdiffraction-limit region around the zero-intensity center of the doughnut. In this case, the fluorophores are not exposed to the strong-intensity light at the doughnut rim of the depletion beam, which significantly reduces the irradiation dose and therefore photobleaching. It was successfully demonstrated by visualizing proteins nucleoporins Nup93 and Nup98 in the nuclear pore complexes (NPC) of Xenopus laevis X177 cells. Bleaching was reduced 100 times compared to the conventional recording. Moreover, the method was shown to be compatible with labeling with nanobodies, giving more accurate information on the substructure of the protein complexes (lateral resolution, approximately $25 \mathrm{~nm}$ ) compared to conventional, indirect immunostaining. Another strategy, DyMIN (Dynamic Intensity Minimum), relies on adjusting the intensity of the STED beam during scanning at different sample positions, to avoid continuously exposing the sample with the full-power doughnut beam. ${ }^{75}$ Fluorescence signal at an illuminated position is first measured without or with low STED beam intensity. If the signal is above a threshold (meaning a fluorophore is present), the STED beam intensity is incrementally increased to obtain better resolution. Each step, the fluorescence signal is evaluated for further increase. If the signal is lower than the threshold, the beams move to the next position with low STED beam power. Full resolution is reached as maximum STED beam power is applied when the fluorophore is at the zero-intensity center of the STED beam (Figure 4A). The method was 

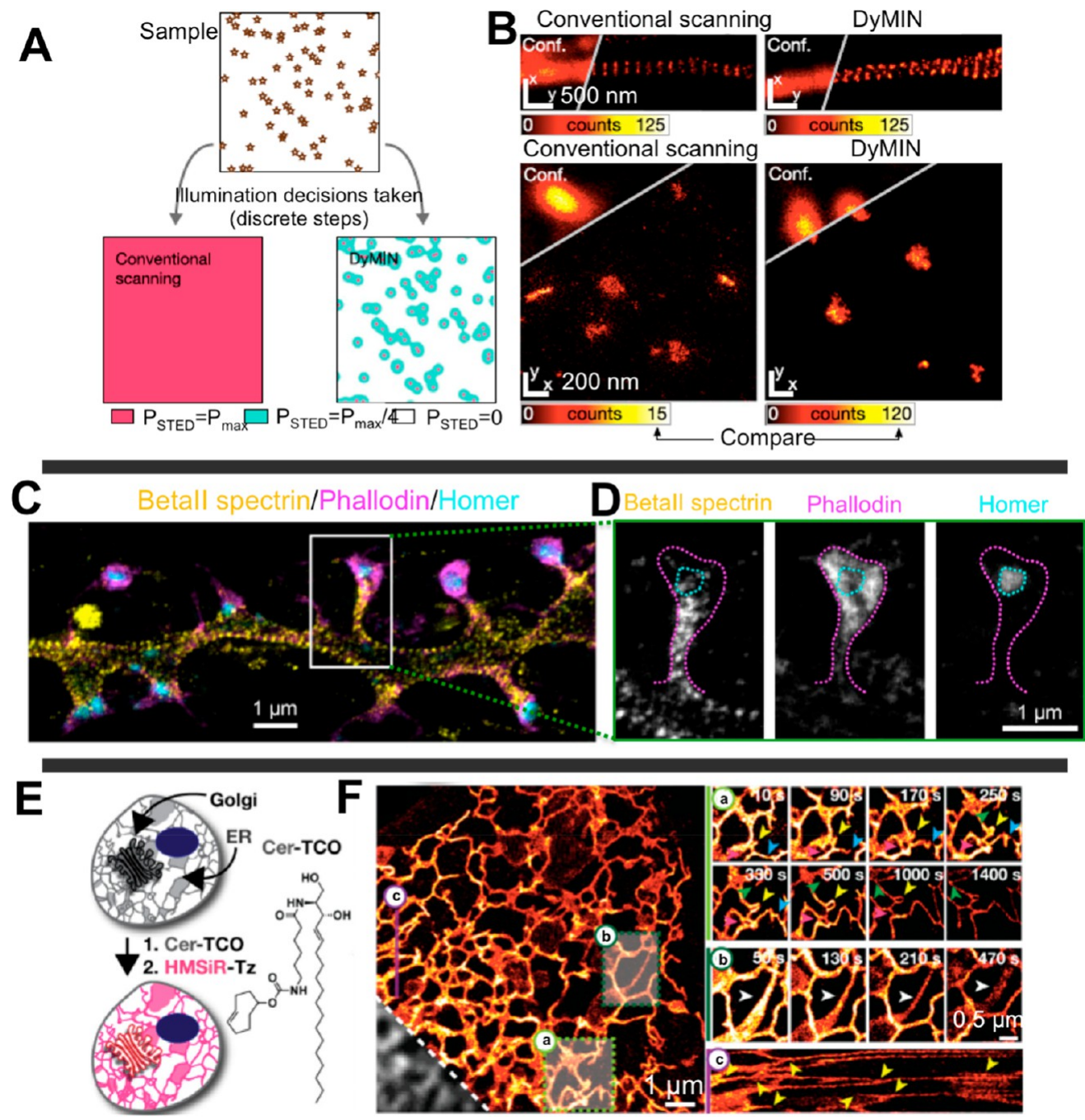

Figure 4. Examples of improvements in super-resolution microscopy. (A,B) DyMIN for reduction of photobleaching in STED imaging. (A) Simulation of a sample with various fluorophores scanned by the conventional and DyMIN approaches. (B) Improved brightness and resolution in DyMIN STED compared to conventional STED. Spectrin-II protein along the axon of rat hippocampal neurons (top). Scaffolding protein gephysin at inhibitory neuronal synapses (bottom). (C,D) Multilevel three-color STED imaging of the subcortical cytoskeletal proteins. (C) BetaII spectrin (yellow), phallodin (magenta), and homer (cyan) shows periodic spectrin organization at the spine. (D) Zoom-in image of a spine selected in part C. The magenta and cyan dashed lines indicate the boundary of the spine and PSD position, respectively. (E,F) Live imaging of endoplasmic reticulum (ER) dynamics in Hela cells using HIDE probe. (E) Schematics showing the labeling of ER using Cer-HMSiR probe. (F) Live STORM/ PALM imaging of ER dynamics over a period of $25 \mathrm{~min}$. A snapshot of ER from a 25 min movie (left) and the time-lapse images of the selected areas (right). (a) The dynamics of the ER regions as indicated by arrowheads. (b) Transition of sheet-like ER into tubular ER. (c) A line-scan of the line in the left figure. Each image was reconstructed from 800 frames, recorded for 2 s. Panels A and B, Reproduced and adapted with permission from Proceedings of the National Academy of Sciences USA Heine, J.; Reuss, M.; Harke, B.; D'Este, E.; Sahl, S. J.; Hell, S. W., PNAS 2017, 114 (37), 9797-9802 (ref 75). Panels C and D, Reproduced and adapted from Sidenstein, S. C.; D’Este, E.; Bohm, M. J.; Danzl, J. G.; Belov, V. N.; Hell, S. W., Scientific Reports 2016, 6, 26725 (ref 79) under a Creative Commons 4.0 International License (http://creativecommons.org/licenses/ by/4.0/). Panels E and F, Reprinted and adapted by permission from Macmillan Publishers Ltd.: NATURE BIOTECHNOLOGY, Takakura, H.; Zhang, Y.; Erdmann, R. S.; Thompson, A. D.; Lin, Y.; McNellis, B.; Rivera-Molina, F.; Uno, S. N.; Kamiya, M.; Urano, Y.; Rothman, J. E.; Bewersdorf, J.; Schepartz, A.; Toomre, D., Nature Biotechnology 2017, 35 (8), 773-780 (ref 88). Copyright 2017.

applied to visualization of the organization of protein spectrinII along the axons of rat hippocampal neurons, the scaffolding protein gephysin of inhibitory synapses of the neurons (Figure 4B) and also to imaging of tubulin of mouse spermatozoa axonemes in three dimensions. Bleaching was reduced up to 20 times compared to conventional imaging, together with brighter image acquisition with a resolution of approximately $30 \mathrm{~nm}$ laterally and $60 \mathrm{~nm}$ axially.

A new version of STED approach named MINFLUX was developed for localizing photon emitters, using a combination of stochastic photoswitching and the doughnut-shaped laser used in STED. ${ }^{73}$ Unlike STED, MINFLUX employs a doughnut-shaped excitation beam, which produces zero excitation intensity in its center. Thus, when the center overlaps with the emitting molecule, it is not excited, resulting in an absence of fluorescence. The location of the molecule is then defined as the position of the doughnut center. Rapidly moving the doughnut laser to image four points located around and adjacent to the molecule produces a distance related fluorescence profile. This can be used to accurately determine an emitting molecule's position. As the localization precision is not based on the number of photons detected from the 
emitter, the imaging rate is improved significantly. MINFLUX provides a spatial resolution of $6 \mathrm{~nm}(1 \mathrm{~nm}$ precision $)$. As MINFLUX requires fewer photons for localization, molecular positions can be determined in shorter time. The photon efficiency is 20 times and the temporal resolution is 100 times greater than other super resolution techniques. The technique has been used to detect the movement of DNA origami, which was coupled to the Atto647N dye, with a temporal resolution of $400 \mu \mathrm{s}$ and a localization precision of approximately $2 \mathrm{~nm}$ for the average counts of approximately 168 photons. $^{76}$

The Hessian deconvolution algorithm was developed for SIM to reduce the photon dose used for imaging and to increase the temporal resolution in live-cell imaging. ${ }^{74}$ The method is based on the continuity of biological structures in various dimensions as a guideline for reconstructing the image and minimizing artifacts. Hessian-SIM was used to image actin filaments in human umbilical vein endothelial cells (HUVEC) with an exposure time of $0.5 \mathrm{~ms}$, which reduced background noise more efficiently compared to the $7 \mathrm{~ms}$ exposure time using the conventional Wiener deconvolution method. This means that the photon dose was reduced to $1 / 12$ of that used by the Wiener method. The densely packed cytoskeletal proteins actin and tubulin in live HUVEC and insulin-secreting INS-1 cells were also well resolved with a temporal resolution of only approximately $49 \mathrm{~Hz}$. In addition, rapid movement and membrane fusion of synaptic vesicles INS-1 cells were successfully captured in vivo over a $10 \mathrm{~min}$ period at a frame rate of $97 \mathrm{~Hz}$.

Multicolor Imaging. Biological and cellular processes often involve complex interactions between various biomolecules. In order to understand their functions in relation to each other, simultaneous observation of the organization of as many different molecules as possible is necessary. Multicolor imaging can be realized by improving the optical setup to separate spectral lines of different fluorophores, using suitable dyes, developing data-processing methods to differentiate between individual fluorophore signals from a mix of spectral information, and by developing robust sample preparation and immunolabeling procedures. As of yet, it is possible through technical developments of the microscope and acquisition software to perform four-color imaging, although a complex optical setup is required to do so. Alternatively, the sample preparation and labeling strategy can be modified, which enables up to eight-color sequential imaging.

Respiratory syncytial virus (RSV) infects human lung epithelial A459 cells by forming pleomorphic virus particles which spread into uninfected cells. To investigate the interaction between the virus particles and uninfected cells, three-color STED was utilized with the white light excitation laser and three STED lasers. ${ }^{77}$ This optical configuration allows excitation and emission at the specific wavelengths of each fluorophore. It is critical to choose dyes in such a way that they do not cause spectral overlap and are suitable for the available STED lasers. Three dyes, AlexaFluor488, rhodamine phalloidin, and Atto67N, were selected to label the filament of the RSV virus, F-actin, and $\beta$-tubulin of the infected A549 cells, respectively. The corresponding STED lasers for these dyes were 775,660 , and $592 \mathrm{~nm}$. The images were acquired sequentially showing that the RSV virus particles were transported to the neighboring cells by filopodia which are composed of F-actin.

To simplify the optical system, sample preparation and labeling procedures could be developed and optimized for multicolor imaging. This approach is generally not preferable as it is often elaborate and time-consuming. However, one noticeable example is the so-called DNA exchange imaging method for sequential multiplexing. The method is characterized by the use of a single step of immunostaining with all DNA barcoded antibodies, followed by several sequential steps of binding with fluorescent imagers, the DNA strands conjugated with fluorophores. In each sequential step, only one type of imagers is allowed to bind to the selected antibodies. $^{78}$ The details of this approach will be introduced in the next section. With this method, eight-color images have been achieved for different proteins in mouse hippocampal neurons. The method is applicable to various super-resolution microscopic platforms such as STED, STORM, and SIM.

A method for multilevel three-color STED imaging using a single STED beam has been demonstrated for the study of the organization of subcortical cytoskeleton in rat hippocampal neurons. ${ }^{79}$ In this method, the energy of the STED beam was adjusted to different levels during the imaging to optimize the resolution and brightness facilitating the emission of individual fluorescence dyes. The subcortical proteins beta II spectrin and actin were labeled together with presynaptic Bassoon protein or postsynaptic Homer protein (Figure 4C,D). Besides a common dual color dye pair AlexaFluor488-Atto532, a long Stokes shift dye Atto430LS was used as a third color. Three excitation lasers were used for the dyes, but only one STED beam was needed. It was shown that the actin and beta II spectrin lattice was localized in the neurites of neurons, however, not at the pre- and postsynaptic active zones. The absence of the rigid beta II spectrin/actin lattice might be necessary for the frequent rearrangement of the neuronal membrane at the active zones during vesicular fusion.

Another approach, called Hyperspectral STED (HyperSTED), allowed up to four-color imaging and is based on the differentiation of individual signals from the mixed emission spectra over the range of $620-750 \mathrm{~nm} .^{80}$ The significant feature here is the simplicity of the optical setup, owing to the use of a single excitation and a single STED beam. The minimum distance between the maximum emission wavelengths of the two dyes was $20 \mathrm{~nm}$. HyperSTED was used to image the proteins peroxisomes, vimentin, giantin, and nuclear pores in fixed Vero cells. Crosstalk between channels was less than $20 \%$. It was also used to image tubulin, endoplasmic reticulum marker, and endosomes in living U2OS cells, for which the crosstalk was less than $16 \%$. The crosstalk increased when adding a fourth protein labeling mitochondria; however, the structures of these organelles were clearly distinguished.

Live Cell Imaging. Understanding cellular dynamics, molecular interaction, and transformation in live cells has always been a main goal in cellular and biological research. Super-resolution microscopy has therefore been developed to accommodate this need. However, two challenges that remain are the speed of imaging, which must be sufficiently high in order to capture the dynamics of the observed phenomenon and limiting the effect of incident light on cell physiology. In addition, fluorophores must be biocompatible, very bright, and extremely stable for tracking the labeled molecules over an extended period of time. Several methods reducing photobleaching and photon dose discussed above are very useful for live imaging applications. Besides, mathematical simulations have also been employed to optimize experimental conditions, improving the imaging speed. ${ }^{81}$ In addition, the choice of dyes 

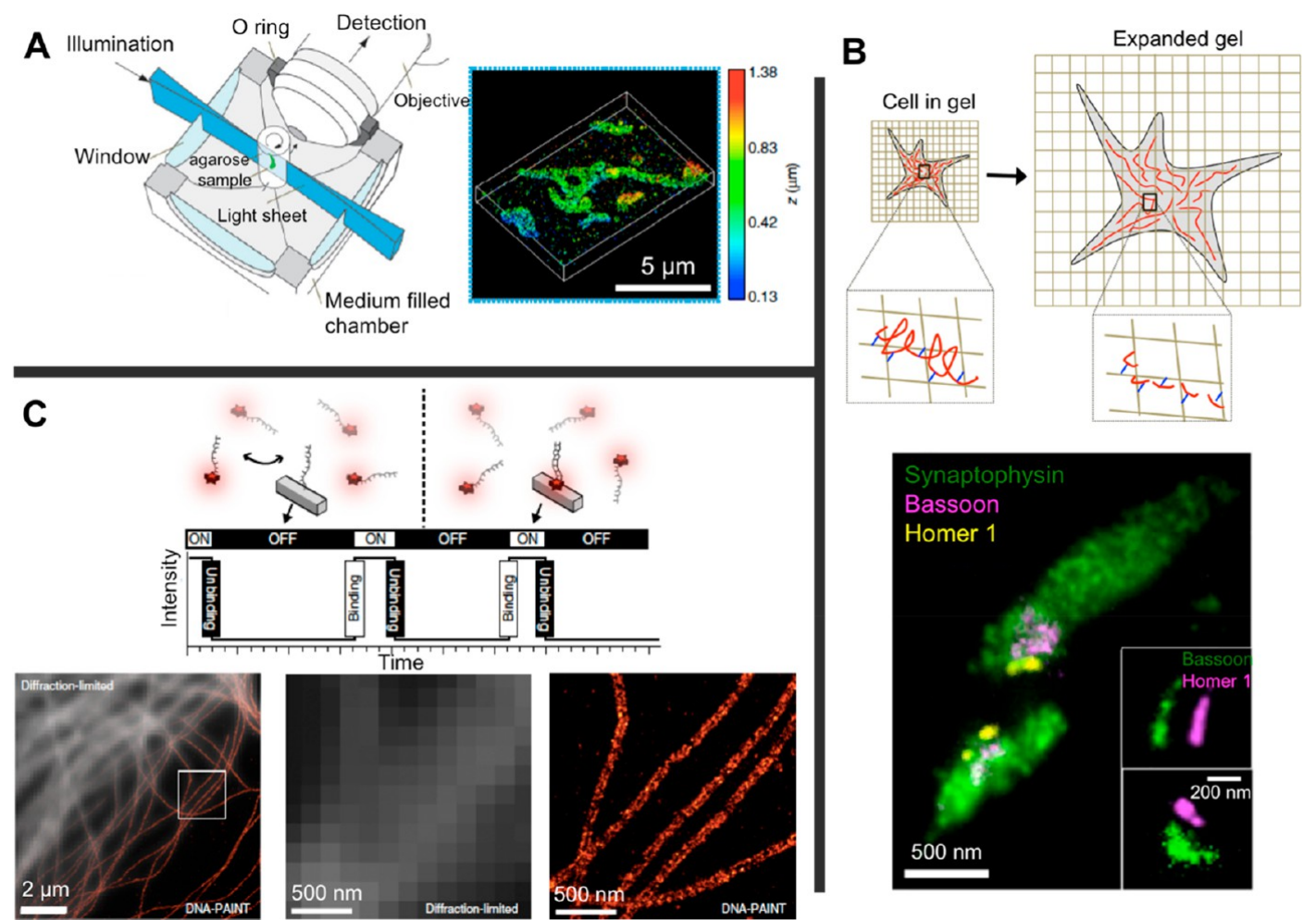

Figure 5. Other super-resolution microscopic techniques and their selected examples. (A) Schematic of the imaging chamber of light sheet microscopy (left) and a 3D super-resolution image of mitochondrial protein TOM20 in Hela cell obtained by tilted light sheet microscopy (right). (B) Schematic of the gel expansion for expansion microscopy imaging (top) and a three-color image of a synaptic structure with synaptophysin (green), presynaptic active zone bassoon (magenta), and postsynaptic densities homer 1 (yellow), and zoom-in images showing the alignment of presynaptic and postsynaptic proteins. (C) DNA-PAINT: Transient binding of the dye coupled DNA strands as imagers to the target molecules, and the intensity versus time trace showing the blinking ability for super-resolution imaging (top). Diffraction limited and super-resolution DNAPAINT image of $\alpha$-tubulin in cultured cells (right) and zoom-in diffraction limited and highly resolved DNA-PAINT images of the selected area. Panel A, Reproduced and adapted from Gustavsson, A. K.; Petrov, P. N.; Lee, M. Y.; Shechtman, Y.; Moerner, W. E., Nature Communications 2018, 9 (1), 123 (ref 95) under a Creative Commons 4.0 International License (http://creativecommons.org/licenses/by/4.0/) and with permission from Olarte, O. E.; Andilla, J.; Gualda, E. J.; Loza-Alvarez, P., Advances in Optics and Photonics 2018, 10 (1), 111 (ref 96) [The Optical Society]. Panel B, Reproduced and adapted from Truckenbrodt, S.; Maidorn, M.; Crzan, D.; Wildhagen, H.; Kabatas, S.; Rizzoli, S. O., EMBO Report 2018, e45836 (ref 97) under a Creative Commons 4.0 International License (http://creativecommons.org/licenses/by/4.0/). Panel C, Reprinted and adapted by permission from Macmillan Publishers Ltd.: NATURE PROTOCOLS, Schnitzbauer, J.; Strauss, M. T.; Schlichthaerle, T.; Schueder, F.; Jungmann, R., Nature Protocols 2017, 12 (6), 1198-1228 (ref 98) Copyright 2017.

is also critical, as it determines the photon emission rate and therefore the localization accuracy and speed of data acquisition. There has been a number of works investigating a new generation of fluorescent probes suitable for live imaging with super-resolution microscopy. For example, a far-red emitting protein mNeptune 2 was found suitable for in vivo STED imaging of cultured cells and living tissues. It demonstrates less phototoxic stress to cells, better depth penetration for tissue imaging, and low autofluorescence in tissue. $^{82}$ The protein was used to visualize actin filaments in live rat hippocampal neurons at a resolution approximately 80 $\mathrm{nm}$ and to track the dynamic structure of actin in the cortex of living mouse for up to an hour.

Nanoparticles (NPs) have been potential materials for fluorescence probes, owing to their high absorption coefficient and quantum yield, high photostability, blinking stability (for STORM/PALM), and biocompatibility. ${ }^{83}$ Protein-based nanoparticles coupled to the organic dye atto647N, such as transferrin-based NPs-atto647N, were synthesized and tested on live HeLa cells using STED. ${ }^{84}$ Carbon dots (CDs) were conjugated to antimouse antibodies and were shown to outperform other common dyes and quantum dots (QDs) in terms of the blinking stability, duty cycle, and photon output using STORM/PALM. ${ }^{85}$ The CDs were then shown to discern the microtubular network and clusters of $G$ protein-coupled receptor CCR3 inside HeLa cells. Another interesting characteristic of the CDs is that the optical properties, particularly the optical band gap energy and fluorescence emission, change according to their particle sizes. ${ }^{86}$ This makes CDs well-suited for multicolor imaging by selecting different particle sizes.

Thompson et al. have developed a new fluorescence probe for labeling plasma membrane lipids, so-called high-density environment-sensitive (HIDE) probes. This facilitates the study of membrane dynamics using super-resolution microscopy. ${ }^{87}$ A HIDE probe, DiI-SiR, consists of a trans-cyclooctene-containing high-density membrane lipid probe DiITCO conjugated to a silicon-rhodamine dye via tetrazine chemistry reaction. The probes have been used to image the plasma membrane of HeLa cells with STED with a temporal resolution of $0.5 \mathrm{~s}$ for $25 \mathrm{~min}$ and mouse hippocampal neurons with a temporal resolution of $2 \mathrm{~s}$ for $9 \mathrm{~min}$. This is superior in terms of photostability, compared to a common membrane protein marker Smo-Halo conjugated to silicon-rhodamine 
dye, which photobleached within $1 \mathrm{~min}$. Individual filopodia on the neurites could be clearly resolved with a resolution of $90 \mathrm{~nm}$, and their movement, contraction, and extension could also be observed at different time points. Two other, photoswitchable HIDE probes, Cer-HMSiR and RhoBHMSiR, have been successfully applied to the visualization of dynamic structures of endoplasmic reticulum (ER) and mitochondria, respectively, using STORM/PALM (Figure 4E,F). ${ }^{88}$ Moreover, a lateral resolution of $50 \mathrm{~nm}$ and temporal resolution of $2 \mathrm{~s}$ could be achieved with $2 \mathrm{D}$ and $3 \mathrm{D}$ live imaging of the ER of HeLa cells over 20 and $15 \mathrm{~min}$, respectively.

Specific detection of biochemical activity at super resolution inside living systems has been a great challenge due to lack of photoactivability and high selectivity. A dual photoactivable probe has been developed to detect the activity of the esterase enzyme at the single-molecule level using STORM/PALM. ${ }^{89}$ This diazoindanone-based probe remains dark in the absence of esterase activity. However, when the probe is activated by carboxylesterases, its acetyl group is removed and it transforms into a fluorescent rhodol emitter. Using the probe, the dynamics of esterase activity and its nanodomains could be localized in live HeLa cells. Organic fluorescent protein markers which are permeable to live cells have also been introduced, e.g., lysosomal probes, and dyes for microtubules and tracheoles. ${ }^{90,91}$

Other Super Resolution Microscopic Techniques for Single Cell Imaging. Besides the well-known established techniques mentioned above, several newly emerging microscopic techniques have shown potential for super-resolution imaging.

Super-Resolution Light Sheet Microscope. Selective-plane illumination microscopy, or commonly light sheet microscopy (LSM), uses a thin excitation illumination plane, focusing on the focal plane, which is orthogonal to the detection optics. This configuration only illuminates the fluorophores at the focal plane and therefore effectively reduces photobleaching as well as out-of-focus fluorescence. Optical sectioning at different depths or different angles of the sample can be obtained by moving or rotating the sample (Figure 5A). Huisken et al. ${ }^{92}$ first demonstrated LSM to obtain multidimensional images of muscles in the transgenic fish Medaka's embryo and to observe the embryonic development of Drosophila in vivo. A lateral resolution of $6 \mu \mathrm{m}$ and depth penetration of $500 \mu \mathrm{m}$ were achieved. Conventional LSM does not reach super resolution, however combination approaches between LSM and other imaging techniques for obtaining subdiffraction limit have recently been demonstrated. ${ }^{93}$ For example, integration of LSM and polarization-based differential interference contrast microscopy (DIC) has been applied to the localization of gold nanorods (AuNRs) and the tracking of their dynamics in single live HeLa cells. ${ }^{94}$ AuNRs have been widely used as drug carriers or delivery agents into target cells. However, the localization at individual particle level has remained a difficult task. Using the integrated LSM and DIC, individual AuNRs in the aggregate could be resolved in $3 \mathrm{D}$, with a lateral resolution of $40 \mathrm{~nm}$. The orientation of the AuNRs was also identified. Another configuration utilizes tilted light sheet illumination with 3D point spread functions to obtain super-resolution 3D images of mitochondria and the whole nuclear lamina in mammalian cells (Figure 5A). ${ }^{95}$ A high localization precision of approximately $16 \mathrm{~nm}$ in the $x y$ direction and $23 \mathrm{~nm}$ in the $z$ direction was achieved. While preventing photobleaching of the fluorophores is still the main advantage of the conventional LSM, this method allows imaging through thick cells down to the coverslip while using high numerical aperture, which is necessary for high spatial resolution.

Super Resolution Optical Fluctuation Imaging. Super resolution optical fluctuation imaging (SOFI) was introduced by Dertinger et al. ${ }^{99}$ This method relies on high-order statistical analysis of the temporal fluctuation of fluorescence emitters, which independently and stochastically blink over time. The high-order statistical analysis filters the signal in such a way that only the highly correlated fluctuation remains and the low correlated surrounding signal is removed. This strategy provides subdiffraction-limit resolution as well as improved signal-to-noise. A resolution of half the diffraction limit was obtained. The main advantage of SOFI is that it allows higher imaging speed (several tens of seconds) compared to STORM/PALM, and it can be combined with any other microscopic techniques. For instance, PALM-SOFI was used to image the focal adhesion, a dynamic protein structure close to the cell membrane. ${ }^{100}$ STORM-SOFI was used to image axonal neurofilaments, myelin, and astroglial processes in the white matter of human, rat, and mouse brain tissue. ${ }^{101}$

Super Resolution Imaging Using Expansion Microscopy. Expansion microscopy was first introduced by the Boyden lab to obtain subdiffraction resolution by physically enlarging the samples instead of modifying the optics or data analysis strategy. ${ }^{102}$ In this method, the cells or tissues are first fixed, immunostained, and embedded in a hydrogel which is composed of acrylamide and sodium acrylate with $N-N^{\prime}$ methylenebis(acrylamide) as the cross-linkers. The fluorescently immunostained proteins are covalently linked to the gel network and digested or denatured before the gels are dialyzed in water for expansion. The digestion or denaturation is needed before expansion in order to loosen up the tight structures of proteins, helping the entire sample to expand evenly and proportionally with the gel network. After expansion, the sample structure disappears and the digested products of digestion are washed away during the dialysis step. However, the fluorophores covalently bound to the gel retain their relative positions in the gel (Figure 5B). Originally, an expansion magnitude of approximately $4.5 \times$ in all dimensions could be obtained. Recently, there have been further improvements that provide a magnitude of up to $10 \times$ by modifying the gel ingredients ${ }^{97}$ or up to $20 \times$ by expanding the $4.5 \times$-expanded gel a second time. ${ }^{103}$ This results in a resolution of approximately $20-30 \mathrm{~nm}$, which is comparable to STED and STORM/PALM. This sample-treatment method offers a valuable tool for obtaining super resolution using simple conventional fluorescence microscopes.

Expansion microscopy (ExM) also shows potential for combination with other super-resolution microscopic techniques to produce a spatial resolution superior to that of conventional super-resolution microscopy techniques alone. Most recently, the combination of ExM and STED (ExSTED) was performed, resulting in a resolution of $<10 \mathrm{~nm} .{ }^{104}$ The approach was successfully applied to the visualization of tubulin doublets at the cross section of primary cilium of epithelial MDCK cells. ExM combined with SIM (ExSIM) was used to image the cytoskeleton of the microbe Giardia lamblia, with a spatial resolution of approximately $30 \mathrm{~nm} .^{105}$

Super-Resolution Microscopy Implemented with DNA$P A I N$ and Exchange-PAIN. Another alternative approach to super-resolution imaging is a modification of the labeling 
approach, namely, point accumulation for imaging in nanoscale topography (PAINT). ${ }^{106}$ It is similar to stochastic blinking in STORM, yet this method relies on repetitive, transient binding of fluorescently labeled oligonucleotides, which function as imagers, to the complementary docking strands located on the DNA targets. The fluorescence signal of the DNA target is only observed when the docking strands are bound to the imagers (Figure 5C). To label specific target proteins, the docking strands are conjugated with antibodies using streptavidin as a linker. This approach also enables multiplexed imaging by sequentially exchanging different orthogonal imagers, which only bind to their corresponding conjugated docking strands on specific proteins (Exchange-PAINT). The imaging can be performed using total internal reflection (TIR) or highly inclined and laminated optical sheet (HILO). A spatial resolution $<5 \mathrm{~nm}$ and a localization precision of approximately $1 \mathrm{~nm}$ was demonstrated. ${ }^{98}$ The method eliminates the need of different fluorescence dyes and the problem of photobleaching, as the imagers are constantly supplied from the solution. DNAPAINT has been used with STORM, STED, and SIM to sequentially visualize the proteins $\alpha$-tubulin in the cytoskeleton structure (Figure 5C), LaminB in the cell nucleus, and TOM20 in the outer mitochondrial membrane of fixed cells. ${ }^{107}$ Another outstanding example is the combination of DNAPAIN and Exchange-PAINT with spinning disk confocal (SDC) microscopy to obtain $2 \mathrm{D}$ and $3 \mathrm{D}$ images of various cellular biomolecules. These include proteins, DNA and RNA in HeLa cells, mouse embryonic fibroblasts, and human lung fibroblasts, respectively. ${ }^{108}$ The use of SDC offers the advantage of efficient optical sectioning which can be deep inside the samples, while maintaining the camera as a spatial detector. This enables excellent 3D imaging of whole cells. The combination provided a resolution of $20 \mathrm{~nm}$ laterally and 80 $\mathrm{nm}$ axially. Localization of the proteins TOM20 at the outer mitochondrial membrane and HSP60 in the mitochondrial matrix was achieved. Moreover, the structures of the nuclear proteins LaminB, nucleophosmin, heterochromatin in HeLa cells, as well as those of major satellite, minor satellite, and telomere regions in mouse embryonic fibroblasts were well resolved in the nuclear area. Exchange-PAINT and DNAPAINT have shown great potential toward multiplexing of super-resolution microscopy and are applicable to a wide range of biological and cell research.

Fluorescence Labeling for Super-Resolution Microscopy. The success of super-resolution microscopic techniques is heavily dependent on the use of labeling probes and methods. Although numerous fluorescent probes have already been developed, the demands for bright, highly selective and cell-penetrating, biocompatible, and super photostable probes have been hardly met. A large variety of probes is available, including fluorescent proteins, conventional antibodies, nanobodies, small organic dyes, genetically coded labeling probes, SNAP-tags, and nanomaterials. The most recent developments will be discussed here.

In order to achieve efficient labeling of targets with practical resolution, a fluorescent probe should be able to migrate through densely packed proteins in the cell. One of the main criteria of fluorescent probes is therefore that they must be small in size. Besides nanobodies, small organic dyes are of great interest. Aptamer-functionalized fluorescent silver cluster (AS1411) was synthesized and used for STED microscopy to visualize the protein nucleolin in the plasma membrane of HeLa cells. ${ }^{109}$ The aptamer specifically labels nucleolin, and the silver cluster helps efficient depletion with STED. The images were well resolved and the photostability was improved compared to the common dyes Alexa Fluor594 and Atto594. The PhoxBright 430 dye was designed and employed to image microtubulin using STED. ${ }^{110}$ The dye was characterized as super photostable compared to Alexa Fluor 430, Atto 425, and Abberior STAR440SX, and highly bright and soluble in water. The coupling of the dye with protein-tags such as SNAP and HALO-tag would be promising for long-term 3D live-cell imaging. Multicolor imaging in live cells has been a great challenge for fluorescence microscopy, due to the lack of dyes which are cell-permeable and suitable for simultaneous imaging without cross-talk between different color channels. Butkevich et al. ${ }^{111}$ has introduced a series of large-Stokes-shift dyes: 9iminoanthrone, 9-imino-10-silaxanthone, and 9-imino-10germaxanthone fluorophores. These can be used complementarily with small-Stokes-shift dyes to obtain up to four-color live-cell imaging. The dyes have shown to penetrate intact cell membrane of living cells well, and thus cell transfection was not needed. The dyes were used to simultaneously image tubulin, actin, mitochondria, and endosome in living human fibroblasts and visualize tubulin, actin, mitochondria, and neurofascin in living rat hippocampal neurons. Multimodal microscopy imaging is also possible using multimodal probes that are compatible with different techniques. Ir(III)-based small-molecule complexes have been used as probes for transmission electron microscopy (TEM) and super-resolution microscopy to image mitochondria in HeLa cells. ${ }^{112}$ The probe is highly specific to mitochondria, as $3 \mathrm{D}$-SIM showed good colocalization with the common mitochondria tracker MitoTracker Orange. In addition, TEM images of the cells showed high contrast. The organelle membrane and mitochondria cristae were well resolved. More examples of newly developed organic dyes can be found in selected literature. $^{113-115}$

Nanomaterials have been at the center of attention in the development of new labeling probes. The use of a large collection of nanomaterials has been successfully demonstrated in super-resolution microscopy for subcellular imaging, for example, semiconductor quantum dots (QDots), ${ }^{116}$ carbon dots (CDs), ${ }^{86}$ polymer dots, ${ }^{117}$ upconversion nanoparticles, and nanoparticles. ${ }^{118}$ Several nanomaterial-based probes have been introduced previously for live-cell imaging. $\mathrm{CaPbBr} 3$ QDots were tested as fluorescence probe for STED imaging. It was shown that the QDots exhibited high quantum yield and superior resistance to photobleaching after irradiation with a depletion laser for $200 \mathrm{~min} .{ }^{116}$ A lateral resolution of $\sim 20 \mathrm{~nm}$ was obtained on a single nanoparticle. Nanoparticles coated with fluorescently doped silica were designed and applied in STED imaging. ${ }^{119}$ The probes exhibited a low rate of photobleaching compared to other common STED dyes, along with high solubility in water. The resolution was improved approximately 3-fold $(75 \mathrm{~nm})$ and show great potential for subcellular imaging. Two types of photoblinking polymer dots with different colors, blue $\mathrm{PFO}$ and carmine PFTBT5, have been introduced for dual-color SOFI. ${ }^{117}$ Bioconjugation of these polymer dots with streptavidin and specific immunolabeling of microtubule filaments, the mitochondrial outer membrane, and clathrin-coated vesicles in monkey kidney epithelial cells BS-C-1 was demonstrated. The dots exhibited better resolved localizations of these structures compared to conventional wide field imaging, particularly a 1.9-fold enhancement in spatial resolution. 
Their brightness was also 2.4- and 4.3-fold higher for PFTBP5 and PFO, respectively, compared to other common dyes for SOFI, such as Alexafluor405 and QDots655.

Besides these main trends, new fluorescent proteins have also been investigated, such as a reversibly switchable fluorescent protein developed from the bacterial photoreceptor $\mathrm{YtvA}^{120}$ or a far-red emitting fluorescent marker protein mGarnet2. ${ }^{121}$

\section{MASS SPECTROMETRIC ANALYSIS OF INDIVIDUAL CELLS}

While single cell technologies such as flow cytometry, singlecell PCR, single-cell RNA sequencing, immunofluorescence, and electrochemistry have been developed and applied successfully, most of these single-cell techniques require the chemical of interest (usually large molecules, such as DNA, RNA, peptides, and proteins) to be labeled, amplified, or electrochemically detectable. Furthermore, simultaneous detection of these large molecules and small molecules such as saccharides, lipids, transmitters, and metabolites are even more challenging due to the lack of specific labeling and/or amplification methods for every individual molecule. Therefore, mass spectrometry (MS) has become an enabling and rapidly developing technique for single-cell analysis, due to its sensitive and specific detection along with structural identification capabilities of cellular biomolecules in a wide spectral range.

A number of MS techniques have been used for either profiling of biomolecules from individual cells or imaging of a single cell surface and subcellular compartments. The minute sample volumes and small quantity of analytes in cells, along with the variety of cellular constituents with distinct ionization characters, led to the use of several ionization and/or ablation methods for profiling and/or imaging mass spectrometry of individual cells. Laser desorption/ionization (LDI) and electrospray ionization (ESI) are mainly soft-ionization techniques (usually when it is used with a matrix for LDI) suitable for the routine analysis of a variety of intact molecules, including metabolites, lipids, peptides, and proteins. While the lateral resolution is limited for cell-surface imaging experiments with ESI, it is suitable for enhanced-molecular-coverage individual cell analysis in ambient conditions when coupled with advanced cell sampling techniques, such as the nanospray tip, and separation methods, such as microscale liquid chromatography (LC), ion mobility separation (IMS), and capillary electrophoresis (CE). LDI and/or matrix-assisted laser desorption/ionization (MALDI) was used for cell-surface imaging using high-performance focusing optics with low- or submicrometer laser spot sizes or for high-throughput molecular profiling of individual cells using a coupling technique, e.g., cell trapping or optically guided cell targeting. Time-of-flight (TOF) secondary ion mass spectrometry (SIMS) and NanoSIMS are often applied for imaging with submicrometer lateral resolution and nanometer-depth profiling of metabolites, lipids, pharmaceuticals, and elements. This is due to the easy focusing of the ion beams in the vacuum and high surface sensitivity associated with these techniques. While early studies performed with traditional primary ion beams induced chemical damage on the surfaces of biological samples, newly developed gas cluster ion beams allowed the desorption and ionization of larger intact molecular ions (e.g., gangliosides, small peptides) on a subcellular scale with higher analyte ion yields.
Most MSI and profiling MS techniques are nontargeted and label-free, allowing mainly the detection of abundant compounds. Mass cytometry is a high-throughput and highly specific technique for low-abundance cell components, such as particular cell surface receptors which are not detectable with current, nontargeted MS techniques. The technique utilizes the antibodies tagged with rare-earth elements that specifically form complexes with target molecules within the cells. This is coupled with flow cytometry and inductively coupled plasma (ICP) MS analysis for separation of the complexes and ionization and detection of the rare-earth elements, respectively.

While modern instruments with widely available ionization sources, mass analyzers, and detectors are capable of nontargeted analysis of a wide range of abundant cell components, a single cell is composed of a myriad of biochemical compounds with enigmatic regional roles. Therefore, advanced MS methods and techniques are still required for high-throughput profiling and imaging of single cells. Several reviews of this area have been published recently. ${ }^{122-125}$ Herein, we briefly review the recent advances and progress in single cell profiling and mass spectrometry imaging within the last 2 years.

Mass Spectrometric Analysis of Individual Cells Based on Electrospray Ionization. Electrospray ionization is a widely used ionization technique in biochemical analysis including single cell mass spectrometry. Its high ionization efficiency and the feature of easy coupling with separation methods such as CE, LC, and IMS allows mass spectrometric identification and quantification of biomolecules including small metabolites, lipids, peptides, proteins, and large noncovalent complexes on trace amounts in a high-throughput fashion. ESI involves the generation of ions from charged liquid droplets after a high voltage is applied to a liquid to create an aerosols in which the solvated ion(s) are expelled from evaporation-shrinked droplets when the field strength at their surface is sufficiently large. ${ }^{126}$ The ionization of the molecules from the liquid phase makes ESI suitable for ambient single-cell MS and for coupling cell-content removal or extraction techniques which provides rapid, direct MS analysis of living cells.

NanoESI is well-suited for MS of single cells due to its associated low sample consumption, tolerance to high levels of salts, and capability to detect a wide range of molecules. Yin et al. achieved the extraction (via electroosmotic drag) and detection of several metabolites including sugars and flavonoids from the cytoplasm of individual Allium cepa cells using two electrodes and a finely pulled nanopipet (with a tip diameter of $<1 \mu \mathrm{m}$ ) which was coupled to a nanoESI source for quantitative MS analysis. ${ }^{127}$ Quantification of glucose extracted from single cells without prior separation was achieved using sequential extraction of a known volume of aqueous solution containing glucose- $\mathrm{d}_{2}$ standard of known concentration.

Acquiring data from single cells in their native environment to gather knowledge about their physiological activities is an important objective of single-cell mass spectrometry. To tackle this, Zhu et al. combined enhanced nanoESI-MS and a patch clamp system to analyze nanoliter-scale samples of the cytoplasm of single neurons taken from mice brain slices. ${ }^{128}$ Briefly, the method involves patching the cell, recording the electrophysiological signal, and performing induced nanoESI for mass spectrometric analysis. Induced nanoESI technique 


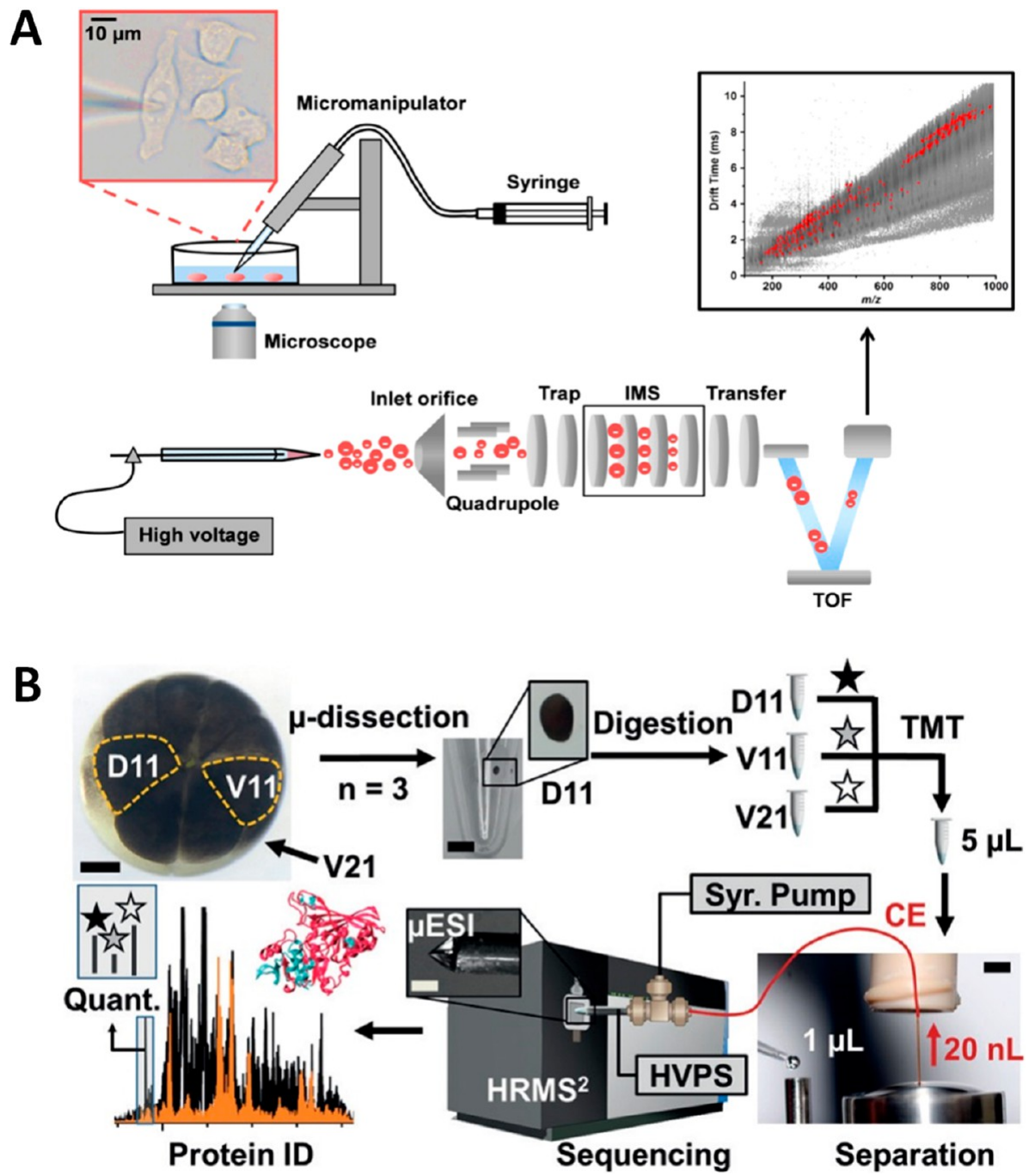

Figure 6. (A) Schematic representation of experimental setup for single cell analysis using capillary microsampling ESI-IMS-MS. A pulled capillary, held by the micromanipulator, is inserted into the single cell while observed through an inverted microscope. The corresponding microscope image, shown in the inset (scale bar is $10 \mu \mathrm{m}$ ). Cell content is extracted by a syringe connected to the capillary. The capillary is backfilled with electrospray solution, and the assembly is placed in front of the mass spectrometer inlet. A platinum wire is inserted into the solution, and high voltage is applied to produce the electrospray. The ions generated from the cell content are separated by the IMS system according to their drift time (DT) and are analyzed by the mass spectrometer. A separate DT vs $m / z$ plot is produced for every cell. Reproduced from Zhang, L.; Vertes, A., Anal. Chem. 2015, 87 (20), 10397-10405 (ref 134). Copyright 2015 American Chemical Society. (B) Microanalytical pipeline enabling multiplexed proteomic quantification of single embryonic cells in the 16-cell Xenopus embryo using microdissection, microscale bottom-up proteomics, and a custom-built single-cell CE- $\mu$ ESI platform for a high-resolution tandem mass spectrometer (HRMS2). Key: HVPS, high voltage power supply; Syr. Pump, syringe pump. Scale bars: $150 \mu \mathrm{m}$ (embryo and $\mu \mathrm{ESI}$, left-middle panels), $250 \mu \mathrm{m}$ (microcentrifuge vial), $1.5 \mathrm{~mm}$ (separation, right panel). Reproduced from Single-cell Mass Spectrometry for Discovery Proteomics: Quantifying Translational Cell Heterogeneity in the 16-cell Frog (Xenopus) Embryo, Lombard-Banek, C.; Moody, S. A.; Nemes, P., Angewandte Chemie International Edition 2016, 55 (1), 2454-2458 (ref 135). Copyright 2016 Wiley.

was used to avoid clogging to alleviate matrix effects from single cell analysis. An alternating current (ac) voltage with an amplitude of $3 \mathrm{kV}$ at $\sim 200 \mathrm{~Hz}$ at an electrode the outside spray emitter was applied different than conventional nanoESI to drive the pulsed ESI process which ameliorates the clogging and increases the detection and the signal-to-noise ratio in MS. The technique allowed rapid and accurate chemical profiling of the cytoplasmic constituents (over 50 metabolites) of a single neuron. ${ }^{128}$ Nakashima et al. used another approach for the MS analysis of single stalk and glandular cells, two adjacent cell types in intact trichomes (small often single cell hair-like growths from plant cells) of tomato plants (Solanum lycopersicum). ${ }^{129}$ A pressure probe ESI-MS with an internal capillary was developed, which enabled cell sampling with high spatial resolution, precise postsampling manipulation, and high detection sensitivity. This technique allowed the detection of amino acids, organic acids, carbohydrates, and flavonoids from less than a picoliter of sap from a single stalk cell. Furthermore, the precise postsampling manipulation enabled profiling of metabolite changes in adjacent cells in the same trichome.

Despite the high abundance of lipids and certain metabolites in cells, the structural diversity of these molecules and their distinct ionization polarities limit comprehensive lipid and metabolite profiling within a single MS analysis. Hu et al. developed a synchronized polarization induced electrospray ionization method for dual polarity MS profiling of PC-12 cells and Alium cepa cells. ${ }^{130}$ A periodic, alternating current square wave voltage was applied to induce bipolar spray, synchronized 
with the mass analyzer. This resulted in positive-ion and negative-ion mass spectra for several metabolites and lipids. Furthermore, an ultralow spray flow rate was achieved (picoelectrospray ionization, $\mathrm{pESI}$, flow rate $<1000 \mathrm{pL} / \mathrm{min}$ ) that enabled tandem MS analysis for the structural identification of the cell components.

While current single cell MS methodologies enable detection and identification of several cellular molecules, low-abundance metabolites, peptides, or proteins are usually undetectable using commercially available MS instruments owing to the low sample volume of single cells. Si et al. developed a method called "repeated ion accumulation" by use of ion trap MS. ${ }^{131}$ This provides enhanced sensitivity by selective and repeated accumulation of ions in a linear ion trap for up to 25 cycles. The technique involves a modified scan function for tandem MS. Isolated precursor ions are made without collisioninduced dissociation (CID) and stored in the high-pressure ion trap. This is followed by the injection of another batch of ions (matrix ions free), also stored in the high-pressure ion trap. Finally, the product ions were generated by CID from the accumulated precursor ions, which yielded stronger signals. This technique improved the detection sensitivity of adenosine triphosphate by 22-fold within 1.8 s. Furthermore, lowabundance ions were detected, such as 5-methylcytosine hydrolyzed from a sample equivalent to $\sim 0.2$ MCF7 cells.

Molecular information from within cellular components of living cells can provide detailed insights into the roles of cellular biomolecules. To this end, $\mathrm{Xu}$ et al. established an electrosyringe-assisted ESI-MS method to achieve intracellular sampling from axons or dendrites in living neurons. ${ }^{132}$ They inserted an $\sim 130 \mathrm{~nm}$ capillary tip into one axon or dendrite to extract cytosol for MS analysis through electro-osmotic flow. This technique revealed that the amounts of pyroglutamic acid and glutamic acid were higher in axons compared to the cell body and dendrites, which is in line with the accumulation of neurotransmitters in the axon for information delivery. Zhang et al. achieved the sequencing of peptides from the cytoplasm and nucleus of single neurons from the mollusk Lymnaea stagnalis using capillary microsampling mass spectrometry coupled with ion mobility separation. ${ }^{133}$ The technique, ESIIMS-MS, involved a pulled capillary held by the micromanipulator which was inserted into a single cell while observed through an inverted microscope. Cell content was extracted by a syringe connected to the capillary, which was backfilled with electrospray solution. The assembly was placed in front of the mass spectrometer inlet. The ions generated from the cell content were separated according to their drift times (DT) after high-voltage application (via a platinum wire) by the IMS system and analyzed by the mass spectrometer. ${ }^{134}$ This is shown in Figure 6A. ESI-IMS-MS allowed relative quantification of nine neuropeptides in the cytoplasm, while six of these peptides were also detected in the nucleus at different abundances. Furthermore, sequencing of a new 28-residue neuropeptide was achieved using tandem MS. ${ }^{133}$

A cell is a complex mixture of thousands of proteins, lipids, and metabolites which makes the direct analysis of a single cell limited due to ion suppression effects, isobaric interferences, and the complexity of acquired MS spectra. Hyphenated techniques have been useful for resolving the complex molecular mixture of a single cell. An integrated separation method prior to MS analysis is advantageous for specific, sensitive detection and quantitative analysis of the biomolecules in individual cells. Lombard-Banek et al. introduced an instrument design (CE- $\mu$ ESI-HRMS) which combines CE, ESI, and a tribrid ultrahigh-resolution mass spectrometer (HRMS) which enabled untargeted, quantitative proteomics ( $\sim 25$ amol lower limit of detection) in individual embryonic cells. ${ }^{135}$ In a bottom-up proteomic workflow, single blastomeres (a type of cell produced after cell division of the zygote after fertilization) were isolated from 16-cell frog (Xenopus laevis) embryos using microdissection, followed by digestion and a CE-microflow electrospray ion source ( $\mu \mathrm{ESI})$ leading to a high-resolution tandem mass spectrometer. CE- $\mu$ ESI-HRMS enabled the identification of 500-800 proteins with about 150 of them quantified in all the cells from multiple axes of the embryo, which indicated significant translational cell heterogeneity. ${ }^{135}$

To correlate subtle biological differences in individual cells with the molecular profiling information, fluorescence staining can be coupled with single-cell mass spectrometry. Zhang et al. combined fluorescence microscopy and capillary microsampling ESI-IMS-MS to investigate metabolite and lipid levels in individual hepatocellular carcinoma cells in distinct mitotic stages (including prometaphase, metaphase, anaphase, and telophase) together with cytokinesis. ${ }^{136}$ Cellular DNA was stained with Hoechst 33342, and the endoplasmic reticulum was counterstained with DiOC6(3) to identify the mitotic stages. A micropipet (tips with approximately $1-\mu \mathrm{m}$ openings) was used to aspirate the content from individual cells, which was connected to ESI-IMS-MS for ionization, separation, and detection of the ionized metabolites and lipids. The data revealed that the cellular energy is higher in metaphase compared to prometaphase and slightly declines in anaphase, telophase, and cytokinesis and that the $[\mathrm{GTP}] /[\mathrm{GDP}]$ ratio in cytokinesis is significantly higher than in prometaphase and anaphase.

Mass Spectrometry Profiling and Imaging of Individual Cells Based on Laser Desorption Ionization. The search for biological applications of LDI-MS was started several decades ago. For instance, a frequency-doubled ruby laser $(\lambda=347 \mathrm{~nm})$ was used by Hillenkamp et al. ${ }^{137}$ in 1975 for creating a microplasma to sensitively detect and image elements with LDI-TOF-MS. In their report, the authors were already anticipating today's incredible advances made in the biological applications of LDI-MS, e.g., its use on tissue sections and individual cells. Although follow up studies using UV-LDI-MS reported the detection of free fatty acids and large molecular fragments along with chemical elements, the detection of intact molecular ions often suffered from high molecular fragmentation as a result of intramolecular bondbreaking induced by high photon energies. Therefore, softer and sensitive LDI strategies for high-throughput molecular profiling and imaging of individual cells have been rapidly developing.

One of the attractive features of LDI is that it does not require matrix-assistance for the ionization and/or desorption of the analytes, which minimizes the spectral interferences and ion suppression in the lower mass range. Stopka et al. recently reported the use of a nanophotonic laser desorption ionization platform $^{138}$ for LDI-MS analysis of individual human hepatocytes. ${ }^{139}$ HepG2/C3A human hepatocarcinoma cells were cultured directly on highly uniform silicon nanopost array (NAPA) chips and analyzed using a linear ion trap-orbitrap hybrid mass spectrometer with a MALDI ion source (MALDI LTQ-Orbitrap XL, equipped with a nitrogen laser $(337 \mathrm{~nm})$ ) (Figure 7A,a). This allowed ionization and detection of 

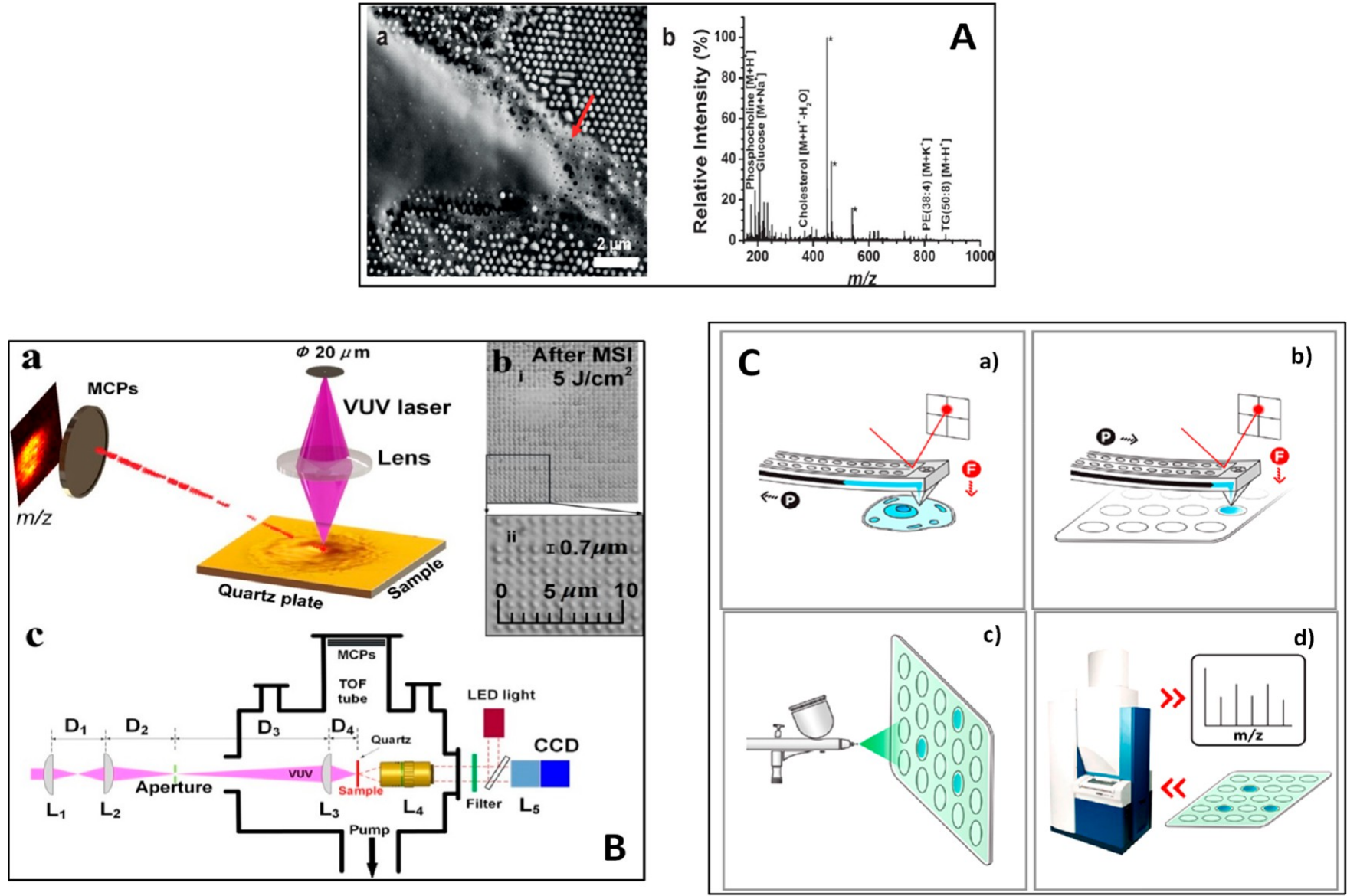

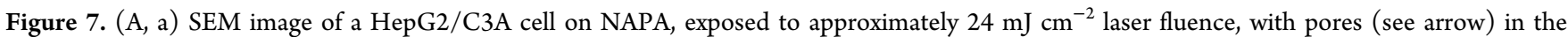
lamellipodia induced by the irradiated nanoposts. (b) Corresponding mass spectrum indicates metabolite and lipid ions originating selectively from the lamellipodia. Background ions from NAPA are marked by *. Reproduced from Molecular Imaging of Biological Samples on Nanophotonic Laser Desorption Ionization Platforms, Stopka, S. A.; Rong, C.; Korte, A. R.; Yadavilli, S.; Nazarian, J.; Razunguzwa, T. T.; Morris, N. J.; Vertes, A., Angewandte Chemie International Edition Volume 55, Issue 14 (ref 139). Copyright 2016 Wiley. (B) VUVDI-MSI system and workflow. (a) Concept of VUVDI-MSI with submicrometer craters. (b) i, Optical image of HeLa cell after VUVDI-MSI; ii, the magnification of black box shown in part b (i). The regular ablated craters with a diameter of $\sim 700 \mathrm{~nm}$. (c) Experimental setup used to focus and characterize the VUV laser beam. The VUV laser was focused with an aspherical $\mathrm{MgF}_{2}$ lens and was used to irradiate the sample. Reproduced from Wang, J.; Wang, Z.; Liu, F.; Cai, L.; Pan, J.; Li, Z.; Zhang, S.-C.; Chen, H.-Y.; Zhang, X.; Mo, Y., Anal. Chem. 2018, 90 (16), 10009-10015 (ref 144). Copyright 2018 American Chemical Society. (C) Schematic of the method for single-cell metabolic analysis using FluidFM and MALDI-TOF MS. (a) Metabolite sampling using FluidFM, (b) dispensing of the cytoplasmic extract onto a selected MAMS spot, (c) spraying of the 9AA matrix, and (d) acquisition of MS spectra. Reproduced from Guillaume-Gentil, O.; Rey, T.; Kiefer, P.; Ibáñez, A. J.; Steinhoff, R.; Brönnimann, R.; Dorwling-Carter, L.; Zambelli, T.; Zenobi, R.; Vorholt, J. A.,Anal. Chem. 2017, 89 (9), 5017-5023 (ref 149). Copyright 2017 American Chemical Society.

metabolites and lipids in lamellipodia of human hepatocytes (Figure $7 \mathrm{~A}, \mathrm{~b}) .{ }^{139}$

A new MS technique named laser desorption/ionization droplet delivery-mass spectrometry (LDIDD-MS) was recently developed by Lee et al. and applied for the single-cell analysis of apoptotic HEK cells along with real-time, direct measurements of live-cell exocytosis in PC12 cells in ambient conditions. ${ }^{140}$ The technique utilizes a pulsed UV laser beam $(266 \mathrm{~nm})$, focused on a surface of an individual cell to trigger desorption and ionization. To aid the capture and transfer of the ionized analytes to the mass spectrometer in ambient conditions, a spray of liquid droplets was simultaneously directed onto the laser-focused surface region. This technique enabled the detection of fatty acid and phospholipid changes during apoptosis of HEK cells and biogenic amines such as dopamine, phenethylamine, and tyramine from live PC12 cellsexocytosis.
An efficient imaging mass spectrometry with LDI is even more challenging considering the general trade-off between the spatial resolution and the molecular information. For high spatial resolution and depth profiling, extreme ultraviolet (EUV) single shot laser $(\lambda=46.9 \mathrm{~nm}$ or single photon energy $26.4 \mathrm{eV}$ ) scanning has also been used as a LDI source (EUVDI) by Kuznetsov et al. for 3D IMS, which allowed a lateral resolution of $75 \mathrm{~nm}$ and a depth resolution of $20 \mathrm{~nm} .{ }^{141}$ While this suggests the opportunity of nanoscale imaging of single cells with LDI-IMS, the associated high photon energies resulted in severe molecular fragmentation and only allowed the detection of small molecular ions.

To ameliorate the molecular fragmentation while preserving high-spatial resolution, Wang et al. recently introduced a new LDI-TOF-MS instrument which utilizes vacuum ultraviolet (VUV) light in the range of 120-150 nm (photon energies 10.3-8.3 eV suitable for ionization of many biomolecules), which can provide a spatial resolution of $\sim 100 \mathrm{~nm}$ according 
to the theoretical diffraction limit $(\sim \lambda / 2) .{ }^{142} \mathrm{~A}$ VUV laser at $125.3 \mathrm{~nm}$ providing an $\sim 4 \mu \mathrm{m}$ spatial resolution was prepared $^{142}$ and used for the LDI-IMS analysis of intact cholesterol in mouse zygotes. ${ }^{143}$ While a more recent advancement in the focusing system of the VUV laser allowed submicrometer ablation craters and was utilized to image small individual HeLa cells, the technique so far suffered from low mass resolution and low sensitivity (Figure 6B). ${ }^{144}$

A sensitive and high-throughput LDI-MS technique, matrixassisted LDI (MALDI) was discovered in the 1980s. ${ }^{145,146}$ It utilizes a photon-absorbing and laser desorption/ionizationenhancing matrix, allowing the detection of a wide range of molecules with minimal fragmentation. In spite of the fact that the ionization mechanisms in MALDI are still not fully understood due to the complexity of the ionization processes within the laser-induced plumes, an extensive survey for new matrix compounds and matrix application strategies significantly improved the detection limits, selectivity, and the detectable range of molecules. On the other hand, unlike LDI, MALDI requires advance matrix application strategies providing optimal desorption-ionization of the analytes, while minimizing the sample perturbation, which is relevant for biological applications. Therefore, MALDI has rapidly become an enabling technique for high-throughput single-cell molecular profiling when combined with cell trapping, microscopy, and/or intracellular content withdrawal methods, while the application is more challenging for mass spectrometry imaging of single cells.

High analytical throughput is an important objective for single-cell mass spectrometry. Cell-trapping technologies have been developed, such as functional high-density microarrays for mass spectrometry (MAMs). ${ }^{147}$ MAMs enables rapid picoliter-volume aliquoting and ultrasensitive analysis of multiple microscale samples including single cells by trapping them in arrays of hydrophilic microwells patterned on an omniophobic surface for MALDI-MS analysis. Krismer et al. recently used the MAMs technique to investigate the correlation between genetic diversity and phenotypic variation in the nitrogen-limited microalga Chlamydomonas reinhardtii. ${ }^{148}$ They were able to monitor the impact of nitrogen limitation on the molecular compositions (lipids and pigments) of thousands of individual cells of the genetically diverse wild-type strain CC-1690 and two isoclonal isolates from CC-1690 (ANC3 and ANC5) at different time points. While this technique enables high analytical throughput, the laser ablation results in perturbation and consumption of the whole cell bodies. Recently, fluidic force microscopy (FluidFM) was coupled with MAMs to enable nondestructive and quantitative withdrawal of intracellular fluid from the cytoplasm for MALDI-MS analysis (Figure 7C). ${ }^{149}$ FluidFM is comprised of a cantilever probe driven by an atomic force microscope to extract $1-3 \mathrm{pL}$ of the intracellular fluid and dispense it onto the MAMs well with minimal perturbation and without affecting cell viability. The developed method was utilized for the detection and identification of 20 metabolites from the cytoplasm of individual HeLa cells and further validated in ${ }^{13} \mathrm{C}$ feeding experiments, which showed incorporation of labeled carbon atoms into different metabolites. ${ }^{149}$

Phelps et al. introduced another cell-content withdrawal technique for minimally invasive single-cell MS analysis. ${ }^{150} \mathrm{It}$ combines a dual-positioner nanomanipulator for both extraction of organelle content from living cells and its precise codeposition with a matrix solution which was followed by
MALDI-MS analysis. The nanomanipulator was equipped with two nanopositioners with translational resolution, each fitted with a nanospray emitter: one for the direct microextraction of the contents of lipid droplets in individual living 3T3-L1 adipocytes and the second for matrix codeposition followed by MALDI-LTQ-XL-Orbitrap analysis at 100000 resolution (at $m / z 400)$. The technique is significant, as it allows acquisition of specific organelle-level spatial information and of individual lipid droplet triacylglycerol (TAG) profiles, which were further identified using MS/MS analysis.

Another objective of single-cell MS analysis is enhanced molecular coverage. While MALDI-MS enables ionization and detection of multiple biomolecules within a single analysis, the instrumental parameters and/or choice of matrix molecule along with the matrix application conditions dictates the ionization of distinct molecules. In this regard, Do et al. recently developed an optically guided single-cell profiling MS method using sequential MALDI-MS analysis (using UltrafleXtreme MALDI-TOF/TOF mass spectrometer equipped with Nd:YAG (355 nm) laser) to detect lipids, peptides, and proteins. ${ }^{151}$ A matrix molecule, 2,5-dihydroxybenzene (DHB), which can assist ionization of lipids, peptides, and proteins, was chosen and sprayed over the dispersed cells on indium tin oxide (ITO) glass. This was followed by optically guided sequential MALDI-MS analysis at low and high laser fluence for the analysis in low-mass and high-mass range, respectively. The method enabled the detection of phospholipids (e.g., phosphatidylcholines) and proteins (e.g., myelin basic protein $S$, vimentin, and neurofilament) in individual dorsal root ganglia (DRG) cells. Subsequent statistical analysis of the mass spectra allowed identification of peptide and protein heterogeneity in DRG population according to cellular morphology and, presumably, major cell types. ${ }^{151}$ Using a similar microscopy-guided single cell MALDI-MS protocol, Jansson et al. characterized single-cell heterogeneity of rat islets of Langerhans. ${ }^{152}$ Two levels of chemical heterogeneity were observed from the analysis of more than 3000 individual cells. Within a single islet, cellular heterogeneity was evident from the exclusive expression of the canonical biomarkers glucagon, insulin, pancreatic polypeptide (PP), and somatostatin within $\alpha$-, $\beta$-, $\gamma$-, and $\delta$-cells, respectively. Heterogeneity in cell composition was also observed between islets, as evidenced by a 50-fold larger $\alpha$-cell population in islets of the dorsal pancreas compared to the ventral-derived pancreatic islets.

Biogenic amines are important messenger molecules in cellcell communications. However, while untargeted MALDI-MS analysis allows detection of a wide range of molecules, analysis of small polar compounds (e.g., neurotransmitters) with MALDI-TOF-MS is usually hindered by low-detection sensitivity, poor ionization efficiency, ion suppression, and background spectral interferences from either the MALDI matrix and/or endogenous analyte components. Therefore, Diesner et al. recently developed a workflow for the targeted detection and quantification of biogenic amines (e.g., octapamine and tyramine) via chemical derivatization in individual cells from the brain of the fruit fly Drosophila melanogaster. ${ }^{153}$ Single cells were isolated from the intact brains of $D$. melanogaster via GFP-guided single-cell microdissection. This was followed by on-plate chemical derivatization via a Schiffbase reaction between biogenic amines, octapamine (OA), tyramine (TA), and their isotopically marked internal standards, with 4-hydroxy-3methoxycinnamaldehyde (CA) or 2,5- 
dimethyl-1H-pyrrole-3,4-dicarbaldehyde (DPD), for enhanced ionization and increased ion stability.

One important objective of single-cell MS is to map molecular distributions of a wide range of biomolecules within an individual cell in its native environment using untargeted, sensitive, and chemically specific methods with high spatial resolution. MALDI-IMS of individual cells is challenging due to the reduced focus depth at subcellular lateral resolutions, which decreases the sensitivity and surface specificity. Furthermore, uniform, small crystal-size matrix application for such small delicate cell surfaces is difficult. ${ }^{154}$ In this regard, Kompauer et al. engineered an atmospheric pressure (AP) MALDI source with a long-distance laser triangulation system, which can correct for variations in sample height and which is coupled to a high-resolution Orbitrap mass analyzer. ${ }^{155}$ Recently, the same group used improved laser-focusing optics coupled to an Orbitrap system, along with optimization of matrix application for high-mass resolution AP-MALDI mass spectrometry imaging of tissues and cells at $1.4 \mu \mathrm{m}$ lateral resolution. ${ }^{156}$ The technique was utilized to visualize subcellular lipid, metabolite, and peptide profiles that differentiate the cilia and oral groove on Paramecium caudatum.

Mass Spectrometry Profiling and Imaging of Individual Cells Based on Secondary Ion Mass Spectrometry. SIMS was the first mass spectrometric technique used for chemical imaging dating back to $1960 \mathrm{~s}^{157}$ and has been used for a variety of biological samples, including cells. Routinely obtained small spot sizes in vacuum (down to $\sim 50 \mathrm{~nm}$, using, e.g., bright point sources, electrostatic lenses) and high surface sensitivity make SIMS a favorable mass spectrometric technique for $2 \mathrm{D}$ and $3 \mathrm{D}$ molecular imaging of individual cells. Thus far, however, ultrahigh resolution experiments have always yielded atomic ions and low-mass molecular fragments, and secondary ion yields decreased with increasing $m / z$.

SIMS involves bombarding the sample surface with a beam of primary ions in order to cause sputtering of intact molecules, fragments, and atoms, predominantly as neutral species but also as cations and anions. The primary route toward enhanced 2D and 3D molecular SIMS was the development of improved primary ion beam technology. The traditional atomic ion beams such as $\mathrm{Ar}^{+}, \mathrm{Ga}^{+}$, and $\mathrm{In}^{+}$penetrated deep in the sample surface and resulted in severe molecular fragmentation and extensive chemical damage, leading to results uncharacteristic of the original chemistry of the sample. Moreover, ion yields for molecular species were very low at high spatial resolutions. The development of cluster ion beams, such as $\mathrm{Au}_{3}{ }^{+}$and $\mathrm{Bi}_{3}{ }^{+}$, provided enhanced sputter and ion yields (importantly for higher mass species, $m / z \leq 1000$ ) which resulted in impressive 2D SIMS imaging. The low-damage impact and surface sensitivity $\left(12-30 \mathrm{~nm}\right.$ depth profiling) of $\mathrm{a} \mathrm{C}_{60}{ }^{+}$primary ion beam allowed detection of intact molecules, specific fragments, and their 3D imaging in individual cells. Furthermore, the newly developed gas cluster ion beams (GCIBs) that comprise clusters of often several thousand argon atoms ${ }^{158}$ and which are demonstrated to enhance the intact molecular ion species (such as lipids, small peptides with less damage accumulation in depth profiling compared to $\mathrm{C}_{60}{ }^{+}$) in high mass ranges at high spatial-resolutions but limited, so far, to around 1-3 $\mu \mathrm{m} .159$

All in all, there is a general trade-off between the spatial resolution and molecular information and sensitivity, and therefore methods have been developed to improve the molecular information at high-spatial resolutions within individual cells. Moreover, previously developed workflows were also applied for biological single cell investigations.

Bacterial cells such as $E$. coli cells $(2-3 \mu \mathrm{m})$ are significantly smaller than eukaryotic cells $(5-100 \mu \mathrm{m})$, which makes it challenging to acquire the necessary spatial resolution and sensitivity for molecular imaging experiments. To tackle this, Tian et al. utilized a $\mathrm{C}_{60}{ }^{+}$primary cluster ion gun to determine the localization (at $\sim 300 \mathrm{~nm}$ spatial resolution and $\sim 200 \mathrm{~nm}$ depth resolution) of unlabeled intact antiobiotics, ampicillin (AMP) and tetracycline (TET), in individual E. coli cells. ${ }^{160}$ The methodology was validated by observing the reduction of tetracycline accumulation in an E. coli strain expressing the tetracycline-specific efflux pump (TetA) compared to the isogenic control.

To increase the analytical throughput, sensitivity, and molecular coverage of SIMS profiling analysis of individual cells, Do et al. recently used an optical-microscopy-guided, ionic liquid matrix-enhanced SIMS (ME-SIMS) method. ${ }^{161}$ Populations of cells from the Aplysia californica central nervous system, the rat dorsal root ganglion (DRG) and the rat cerebellum (from Aplysia californica neurons larger than 75 to $7 \mu \mathrm{m}$ rat cerebellar neurons) were dispersed onto the substrate (ITO glass), and the ionic matrixes were sprayed over. Then, using the cell locations determined by optical microscopy, SIMS spectra were acquired from several cells using a $\mathrm{C}_{60}{ }^{+}$ SIMS Q-TOF mass spectrometer. This was followed by multivariate statistical analysis to profile and distinguish single cells based on the detected multiple saturated and unsaturated phosphatidylcholines (PCs) and their fragments. ${ }^{161}$ Alternatively, a facile, high-throughput, single-cell patterning ( $\mathrm{ScP}$ ) method for single cell SIMS profiling was reported by Huang et al. $^{162}$ It comprises the use of a micropatterned poly(dimethylsiloxane) (PDMS) stencil film and centrifugationassisted cell trapping for the preparation of on-surface singlecell microarrays, followed by TOF-SIMS measurement (performed in a TOF-SIMS V spectrometer, Ion-TOF $\mathrm{GmbH}$, Germany). A liquid metal ion gun (LMIG) was applied to produce the pulsed $25 \mathrm{kV} \mathrm{Bi}^{3+}$ beam for analysis, and an electron impact gun was equipped to produce the 10 $\mathrm{kV} \mathrm{C}_{60}{ }^{+}$beam for etching. ${ }^{162}$ The methodology was utilized to profile molecular changes of cisplatin-induced phenotypic alterations in individual HeLa cells. It was found that the ion species from cholesterol and fatty acids reduced dramatically after cisplatin treatment, which is a hallmark of cell apoptosis, while ion counts from fragmented DNA bases increased significantly, which implied enhanced DNA ionization due to chromosome disassembly and DNA fragmentation.

Hua et al. investigated the silver nanoparticle (Ag NPs) induced lipid changes on individual macrophage cells using TOF-SIMS (with a $30 \mathrm{keV} \mathrm{Bi}^{3+}$ primary ion gun) in delayed extraction mode for high-spatial and high-mass resolution. ${ }^{163}$ Principal component analysis (PCA) results indicated clear distinctions between the cell groups treated with a high or low dose of Ag NPs, with cholesterol, diacylglycerol (DAG), and monoacylglycerol (MAG) being the main separation factors. Meanwhile, the chemical mapping of single cell components showed that cholesterol and DAG tend to migrate to the surrounding of the cells after high-dose Ag NPs treatment. Another application of TOF-SIMS (with a $25 \mathrm{keV} \mathrm{Bi}^{3+}$ primary ion beam) was performed by Court et al. to describe molecular changes of how various polarizations (expression of different functional programs in response to microenvironmental signals) are modified by low-oxygen exposure of macrophage 
A a)

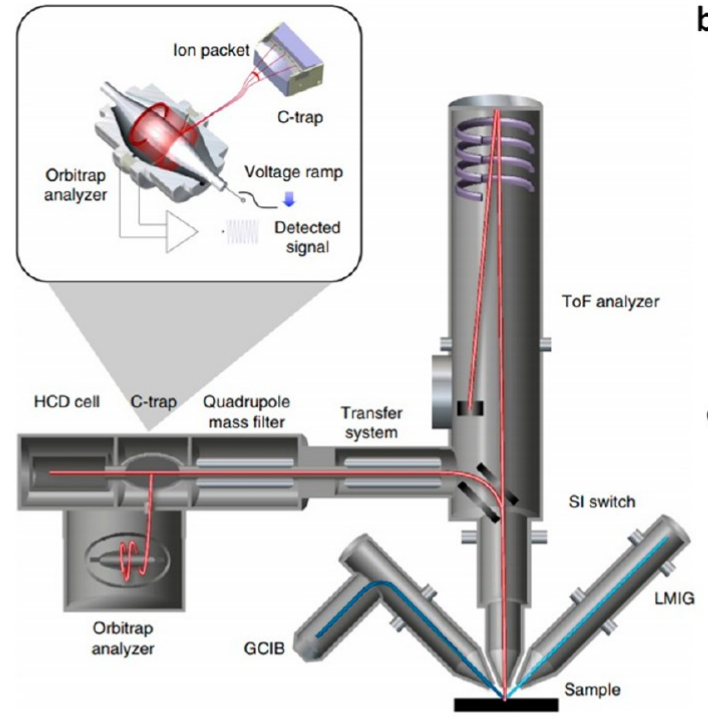

b)

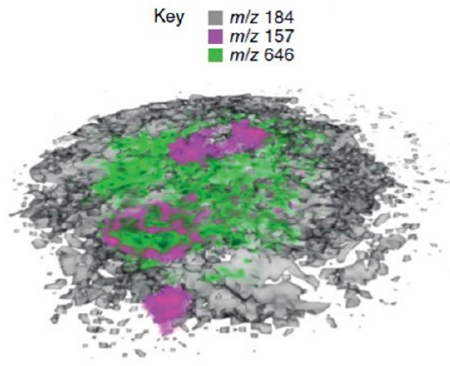

c)

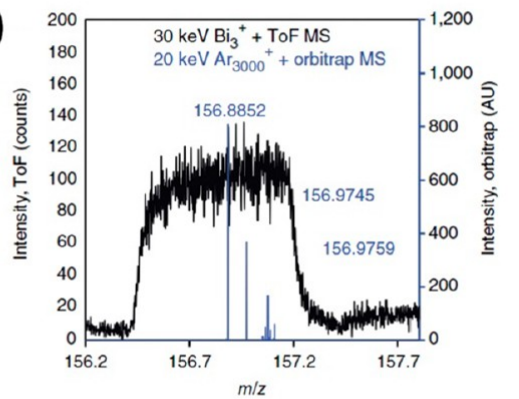

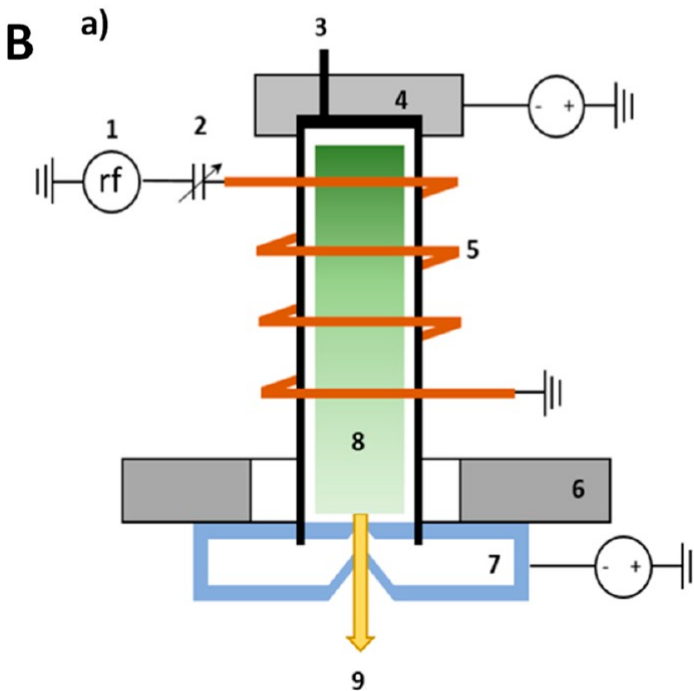

b)
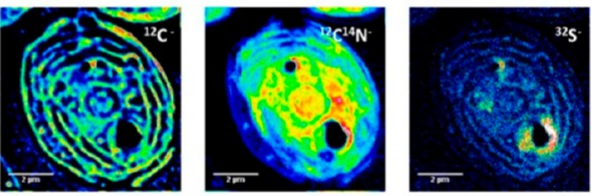

c)
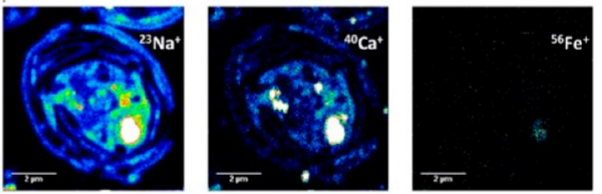

d)
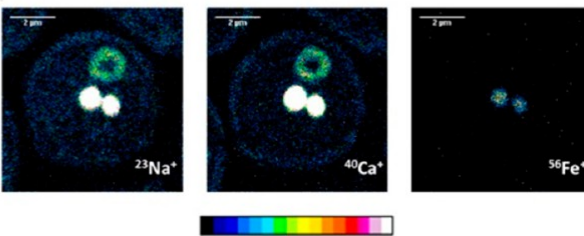

[min-max]

Figure 8. (A) The 3D OrbiSIMS spectrometer. (a) Schematic of the 3D OrbiSIMS and b) 3D MS imaging of single rat alveolar macrophage cell incubated in media with the drug, using dual beam and dual spectrometer. 3D rendering of the cell with phosphocholine marker, $(m / z 184$, gray, opacity 0.40$)$, nuclear marker $\left(\mathrm{m} / z\right.$ 157, magenta), and amiodarone $[\mathrm{M}+\mathrm{H}]^{+}(\mathrm{m} / z$ 646), green. (c) High-mass-resolution spectrum from sputtered material using Orbitrap MS (blue) and low-mass-resolution spectra obtained during imaging with the TOF MS (black) for phosphocholine marker. Reprinted by permission from Macmillan Publishers Ltd.: NATURE, Passarelli, M. K.; Pirkl, A.; Moellers, R.; Grinfeld, D.; Kollmer, F.; Havelund, R.; Newman, C. F.; Marshall, P. S.; Arlinghaus, H.; Alexander, M. R. Nature Methods 2017, 14 (12), 1175 (ref 166). Copyright 2017. (B) (a) Simplified sketch of the different parts of the rf plasma oxygen primary ion source with (1) rf source, (2) impedancematching capacitors, (3) gas inlet, (4) dielectric plasma tube, (5) coil, (6) variable-strength electromagnet, (7) extraction and skimmer block, (8) plasma, and (9) ion beam and $8 \times 8 \mu \mathrm{m}^{2}$ field of view NanoSIMS images, $256 \times 256$ pixels, of Chlamydomonas reinhardtii algae cells using three different primary ion sources: (b) $\mathrm{Cs}^{+}$source, $1 \mathrm{pA}, 10 \mathrm{~ms} / \mathrm{pix}$, total image acquisition time approximately $11 \mathrm{~min}$; (c) $\mathrm{O}^{-} \mathrm{rf}$ plasma source, $1.4 \mathrm{pA}$, $10 \mathrm{~ms} /$ pix, total image acquisition time approximately $11 \mathrm{~min}$; (d) $\mathrm{O}^{-}$duoplasmatron source, $1.5 \mathrm{pA}, 8 \mathrm{~ms} /$ pix, total image acquisition time approximately $9 \mathrm{~min}$. Scale bar $=2 \mu \mathrm{m}$. Reproduced from Malherbe, J.; Penen, F.; Isaure, M.-P.; Frank, J.; Hause, G.; Dobritzsch, D.; Gontier, E.; Horréard, F. O.; Hillion, F. O.; Schaumlöffel, D., Anal. Chem. 2016, 88 (14), 7130-7136 (ref 171). Copyright 2016 American Chemical Society.

cells. ${ }^{164}$ Macrophages are innate immune cells presenting a strong phenotypic plasticity and are deeply involved in tissue homeostasis. After staining with phalloidin, the morphology of macrophages with various polarizations was studied using confocal microscopy. Multivariate analysis of the TOF-SIMS spectra provided ion species associated with the exposure of macrophages to low oxygen concentration.

Vanbellingen et al. used a retrofitted TOF-SIMS instrument (ION-TOF, Münster, Germany), comprised of a liquid metal ion gun analytical beam for high spatial resolution $(25 \mathrm{keV}$ $\left.\mathrm{Bi}^{3+}\right)$, an argon cluster ion beam $(20 \mathrm{keV}$ with a distribution centered at $\mathrm{Ar}_{1500}{ }^{+}$) for "soft" sputtering and depth profiling and an electron flood gun to reduce surface charging during mass spectrometry analysis. ${ }^{165}$ This dual beam analysis allowed label free, 3D-TOF-SIMS imaging analysis of freeze-dried A172 human glioblastoma cells treated with B-cell lymphoma 2 (Bcl-2) inhibitor ABT-737. The TOF-SIMS instrument was operated in spectral ("high current bunched", HCBU) and 
imaging ("burst alignment", BA) modes. In spectral HCBU mode, mass spectra were collected in dual polarity at $1.2 \mu \mathrm{m}$ spatial resolution, with relatively high-mass resolving power, whereas the imaging BA mode provides a higher spatial resolution ( $\sim 250 \mathrm{~nm}$ measured) and nominal mass resolution. The high spatial $(<250 \mathrm{~nm})$ and high mass resolution $(m / \Delta m$ $\sim 10000)$ of TOF-SIMS permitted the localization and identification of intact, unlabeled molecular drug ions as well as of characteristic fragment ions in BA and HBCU mode, respectively. The spatial distribution maps of endogenous molecular markers showed that the ABT-737 is mainly localized in subsurface regions and absent in the nucleus. ${ }^{165}$

While axial-TOF analyzers have the speed required for large $2 \mathrm{D}$ and $3 \mathrm{D}$ data sets, they lack the high-mass resolution necessary for the accurate identification of chemicals. Passarelli et al. introduced a hybrid mass analyzer design, allowing the user to switch between high-speed TOF imaging and the high mass-resolving power and MS/MS capability of a Q Exactive HF Orbitrap (Figure 8A,a). ${ }^{166}$ This 3DOrbiSIMS instrument then combined high-spatial resolution (at $200 \mathrm{~nm}$ for inorganic species and at $2 \mu \mathrm{m}$ for biomolecules) of SIMS with the high mass-resolving power of an Orbitrap (>240000 at $\mathrm{m} / \mathrm{z}$ 200). ${ }^{166}$ For subcellular-resolution, 3D imaging of single cells, the instrument is operated using a dual beam and dual spectrometer mode: the Bi liquid metal ion gun (LMIG) with TOF acquisition for high-spatial-resolution images, and the argon GCIB sputtering cycle between images for highresolution mass spectra using the Orbitrap analyzer. This method was used to profile the metabolomics of rat alveolar macrophage cells incubated with the drug amiodarone. This revealed the upregulation of phospholipids which are correlated with the accumulation of amiodarone (Figure $8 \mathrm{~A}, \mathrm{~b})$. High mass resolution provided accurate identification of each species such as phosphocholine marker (Figure 8A,c).

NanoSIMS is capable of sensitive elemental (mainly atomic or diatomic) and isotopic imaging at a spatial resolution of $\sim 50 \mathrm{~nm}$ and with high surface specificity (a few atomic layers). Therefore, it is applicable to subcellular imaging of elements and endogenous biomolecules including neurotransmitters, lipids, DNA, proteins, as well as exogenous molecules such as drugs. NanoSIMS involves a primary ion beam, which is accelerated from the ion sources (either $\mathrm{Cs}^{+}$or $\mathrm{O}^{-}$) by a vacuum accelerator and then bombards the surface of samples of a conductive material. The produced secondary ions are then transferred to multiple-detector magnetic sector mass analyzer, separated by different mass-to-charge $(\mathrm{m} / \mathrm{z})$ ratios. For analysis of single cells, elemental and/or molecular information (via isotopic imaging) obtained with NanoSIMS at subcellular resolutions is often correlated with highresolution microscopy to enhance the biological information associated with cellular histological features.

Sekine et al. performed complementary multimodal imaging using dark-field microscopy (DF-LM), electron microscopy, and NanoSIMS, allowing light-, electron-, and mass-based microscopy, respectively, to visualize and chemically identify surface-functionalized silver nanoparticles (NPs) and their interactions with the algae Raphidocelis subcapitata. ${ }^{167}$ The interactions of Ag-NPs with $R$. subcapitata were identified by DF-LM under aqueous conditions, localized with high resolution using SEM, and their chemical identity was confirmed by using NanoSIMS (NanoSIMS 50 ion microprobe CAMECA, Gennevilliers, France) imaging using a $\mathrm{Cs}^{+}$primary ion source operated at $16 \mathrm{keV} .^{167}$ This combined technique revealed that the interactions of Ag-NPs with the green algae are dependent on their size $(10 \mathrm{~nm}$ vs $60 \mathrm{~nm})$ and surface functionality (tannic acid vs branched polyethylenimine, bPEI) of the NPs.

In an effort to spatially resolve and quantify the neurotransmitter content across nanometer neuroendocrine vesicles in nerve-like cells, Lovric et al. combined NanoSIMS not only with high-resolution microscopy but also with electrochemical cytometry. ${ }^{168}$ A combination of transmission electron microscopy (TEM) and NanoSIMS (NanoSIMS 50 ion microprobe CAMECA, using the $\mathrm{Cs}^{+}$primary ion source operated at $16 \mathrm{keV}$ ) was used to image profiles of dopamine across nanometer-sized individual transmitter vesicles. Electrochemical cytometry provided a means to quantify and relate vesicle neurotransmitter content and release, which was used to determine that dopamine transfer between the nanometer vesicular compartments, is kinetically limited.

Schreiber et al. utilized NanoSIMS for time-resolved measurements of metabolic activities in individual $\mathrm{N}_{2}$-fixing bacterium Klebsiella oxytoca (a facultative anaerobic bacterium that fixes $\mathrm{N}_{2}$ in the absence of oxygen) which were subjected to different levels of substrate limitation and substrate shifts. ${ }^{169}$ The goal was to investigate whether phenotypic heterogeneity in metabolism is affected by substrate limitation, and to analyze whether such heterogeneity would allow microorganisms to grow in fluctuating nutrient environments. Single cells were detected using Hoechst general DNA stain. NanoSIMS (NanoSIMS 50L with $\mathrm{Cs}^{+}$primary ion beam) was utilized to answer whether cells that fix $\mathrm{N}_{2}$ in a $\mathrm{NH}_{4}{ }^{+}$-limited environment could resume growth faster after an environmental switch to full $\mathrm{NH}_{4}^{+}$depletion. This was done by analyzing and imaging the nitrogen isotopic composition (via a pulse-chase/ pulse, nondynamic approach to extract quantitative information) of individual cell biomasses. ${ }^{169}$

While NanoSIMS imaging provides ultrahigh-resolution ion images, the correlation of ion images with high-resolution microscopic images can still be enhanced using image fusion. Vollnhals et al. investigated two approaches, intensity-huesaturation (HIS) fusion and Laplacian pyramid fusion (LPF), for image fusion in the context of combining the inherently lower-resolution chemical images obtained using secondary ion mass spectrometry (SIMS) with the high-resolution ultrastructural images obtained using electron microscopy (EM). ${ }^{170}$ These approaches were evaluated for an investigation of the toxicity of $\mathrm{TiO}_{2}$ nanoparticles toxicity on Escherichia coli cells. TEM and NanoSIMS were used for correlative chemical and microscopic imaging. The microscopy for this study is challenging due to the coexistence of both organic and inorganic materials, which require relatively strong and weak defocusing, respectively, for sufficient image contrast. LPF was more robust compared to HIS and showed only a minimal color shift between the input and sharpened image of fused TEM microscopy and NanoSIMS ion images. ${ }^{12} \mathrm{C}^{14} \mathrm{~N}^{-}$and ${ }^{48} \mathrm{Ti}^{16} \mathrm{O}^{-}$obtained from bacterial cells confirmed the preservation of color fidelity in LPF fusion, whereas IHC gave more image artifacts.

While $\mathrm{Cs}^{+}$primary ion sources routinely provide negative secondary ions $\left(\mathrm{C}^{-}, \mathrm{CN}^{-}, \mathrm{S}^{-}, \mathrm{P}^{-}\right)$at ultrahigh-spatial resolution in NanoSIMS images, the larger primary ion beam size of commonly used duoplasmatron $\mathrm{O}^{-}$primary ion sources does not allow the same quality ion secondary ion images in positive ion mode compared to $\mathrm{Cs}^{+}$. This is due to the lower brightness of the ion source and higher energy dispersion of 
the ion beam through the chromatic aberration by the final objective lens. To tackle this, Malherbe et al. recently introduced a new oxygen ion source using a rf plasma fitted and characterized on a NanoSIMS50L instrument. ${ }^{171}$ The new radio frequency plasma oxygen primary ion source involves an impedance-matching circuit for efficient transfer of power to the plasma. The source design results in almost no plasma fluctuation by adjusting the phase shift across the antenna, which minimizes energy spread of the ions. The collision of electrons with atoms around the plasma produces high-density ions with relatively low thermal ion energy. The electromagnet placed between the end of the coil and the extraction aperture and lenses is designed to reduce electron diffusion and loss to the wall of the plasma tube, thus increasing plasma density in the extraction region (Figure $8 \mathrm{~B}, \mathrm{a}$ ). As a result, the new rf plasma oxygen source gave rise to an improved primary beam current density compared to the commonly used duoplasmatron source, which in turn resulted in higher ultimate lateral resolution down to $37 \mathrm{~nm}$, and which provided a 5-45 times higher apparent sensitivity for electropositive elements. This new rf plasma oxygen primary ion source was applied to determine the spatial localizations of essential macroelements and trace metals at basal levels in individual cells of Chlamydomonas reinhardtii and Arabidopsis thaliana. ${ }^{171}$ The application of all three primary ion sources, $\mathrm{Cs}^{+}$, duoplasmatron $\mathrm{O}^{-}$, and $\mathrm{rf}$ plasma $\mathrm{O}^{-}$, to $C$. reinhardtii cells revealed that rf plasma $\mathrm{O}^{-}$gave better spatial resolution for $\mathrm{Fe}, \mathrm{Ca}, \mathrm{Na}$ detection compared to duoplasmatron $\mathrm{O}^{-}$. The spatial resolution obtained with $\mathrm{rf}$ plasma $\mathrm{O}^{-}$was comparable to the detection of $\mathrm{C}, \mathrm{CN}, \mathrm{S}$ with the $\mathrm{Cs}^{+}$source (Figure $8 \mathrm{~B}, \mathrm{~b}, \mathrm{c}, \mathrm{d})$.

Mass Spectrometric Analysis of Individual Cells Based on Inductively Coupled Plasma. While mass spectrometric ionization techniques such as ESI, MALDI, and GCIB-SIMS are mainly used for intact molecular MS analysis, elemental MS utilizes a high-temperature plasma discharge as a source for mainly single, positively charged ions. Inductively coupled plasma (ICP)MS suggests attractive features for single-cell analysis, such as high sensitivity (ng $\mathrm{L}^{-1}$ range), wide linear dynamic detection range, and specificity for the accurate detection and quantification of metals, metalloids, and heteroelements (including nonmetals, semimetals, and halogens). ICPs mostly utilize noble gases such as argon as plasma gas, in which a high temperature process provides the efficient vaporization, dissociation or atomization, excitation, and final ionization of the detectable atomic constituents, which are released and analyzed with MS. Moreover, detection of complex molecules, such as proteins, nucleic acids, or even small organic molecules can be performed via metal-tagging followed by ICPMS.

Laser ablation (LA) is often coupled with ICPMS for two modes of single-cell analysis: either for single cell profiling or imaging of cell surfaces. Löhr et al. compared these two modes for the quantification of metals in single fibroblast cells. ${ }^{172}$ Several cells were stained with two metal dyes (mDOTA-Ho, Ir-DNA-intercalator) and analyzed in imaging and single-spot profiling analysis modes. Results indicated that single spot analysis, where the whole cell body is ablated with a single laser shot, is faster due to its higher throughput (with slightly better signal-to-noise ratio) and straightforward data evaluation. Using matrix-matched calibration based on standards spotted onto a nitrocellulose membrane, detection limits of 12 femtogram (fg) for Ir and $30 \mathrm{fg}$ for Ho were achieved per single cell and these elements were quantified. On the other hand, Herrmann et al. optimized the staining procedures for single-cell analysis with the LA-ICPMS for high lateral resolution imaging of metals. ${ }^{173}$ An iridium intercalator was utilized to stain the cell nuclei, whereas the whole cell was stained by the use of maleimido-mono-amideDOTA (mDOTA) complexing lanthanide(III) ions. The method allowed determination of absolute metal stain amounts in the range of 2.34 to 9.81 femtomole per cell, which allowed elemental microscopy of a single cell and its compartments.

To investigate the complex cellular systems and detect lowabundant cellular molecules at single cell resolution, mass cytometry involving a fusion of flow cytometry with ICPMS was developed. The technique involves antibodies which are conjugated with isotopically pure elements, and these antibodies are used to label cellular molecules (mostly proteins). Currently, mass cytometry allows simultaneous measurement of over 40 cellular parameters at single cell resolution with the throughput required to survey millions of cells from an individual sample. ${ }^{174}$

Ajami et al. used single-cell mass cytometry (cyTOF) to investigate the differences in brain myeloid cells in mouse neuroinflammation and neurodegeneration mouse models. ${ }^{175}$ These included an autoimmune encephalomyelitis (EAE) model of multiple sclerosis, the R6/2 model of Huntington's disease (HD), and the mutant superoxide dismutase 1 (mSOD1) model of amyotrophic lateral sclerosis (ALS). CyTOF analysis revealed novel molecular information in three myeloid cell populations exclusive to the central nervous system and present in each disease model. For instance, signaling and cytokine production were different within similar myeloid cell populations in EAE compared to HD and ALS models. These analyses also highlighted $\alpha 5$ integrin on myeloid cells as a potential therapeutic target for neuroinflammation.

CyTOF can also be used in imaging analysis mode by coupling with laser ablation, termed imaging mass cytometry (IMC). In the imaging process, the target cell is treated with a cocktail of antibodies, each labeled with a specific rare-earth isotope. Regions of interest in the slides are scanned with a focused laser pulse which vaporizes the sample, and the released ions are analyzed with ICPMS. The ion counts can then be assembled into a protein expression image with subcellular localization. Gerdtsson et al. used integration of IMC with a high-definition, single-cell analysis workflow (provides immunofluorescent and morphological information before IMC about the cells) with the goal of integrating the morphology, proteomics, and genomics of rare single cells in a single, streamlined process. ${ }^{176}$ The technique was utilized to analyze several cells from liquid biopsies of a metastatic cancer case, which revealed that IMC can characterize dozens of proteins from circulating tumor cells. The technique can be helpful in the understanding of biological properties of these cells when coupled with simultaneous phenotyping of thousands of leukocytes.

\section{ELECTROCHEMICAL ANALYSIS OF SINGLE CELLS}

One of the powerful and predominant techniques for real-time single cell analysis is electrochemistry. This is due to its high temporal resolution and the capability of electrodes to be miniaturized without great loss of sensitivity. ${ }^{4,177-180}$ In this section, we focus on the unique features and novel applications of electrochemical methods at the single-cell level, including 
A

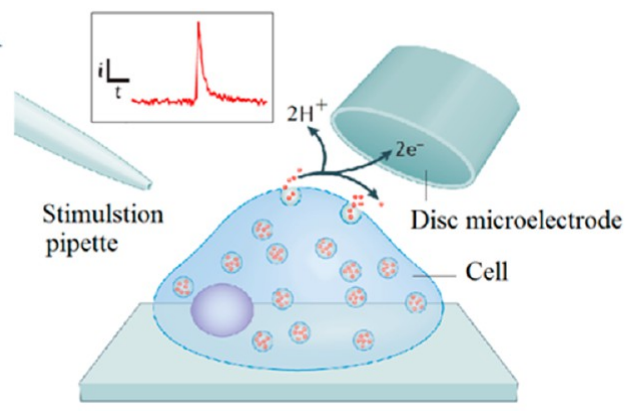

B

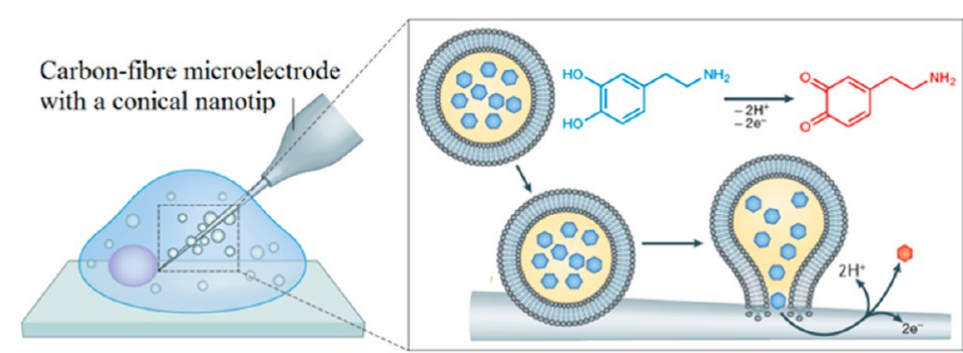

Figure 9. (A) Schematic illustration of exocytosis monitoring using SCA with a disk carbon fiber microelectrode. The inset depicts a typical amperometric current transient that represents an exocytosis event. (B) Schematic illustration of vesicular transmitter content quantification in live cells using IVIEC with a nanometer tip conical carbon-fiber microelectrode placed in the cytoplasm of a single PC12 cell. The inset shows dopamine (neurotransmitter) released from a vesicle can undergo two-electron oxidation to dopamine o-quinone at the in situ microelectrode. Reprinted and adapted by permission from Macmillan Publishers Ltd.: NATURE, Phan, N. T.; Li, X.; Ewing, A. G., Nature Reviews Chemistry 2017, 1, 0048 (ref 178). Copyright 2017.

single-cell amperometry, intracellular electrochemical analysis, enzyme-based biosensors, electrochemical microscopy, electrochemical impedance technique, and electrochemiluminescence imaging applied in living systems.

Single-Cell Amperometry and Intracellular Electrochemical Analysis. Single-cell amperometry (SCA, Figure $9 A)$ is the most used technique to quantitatively study individual exocytosis events at the single-cell level, which is aimed at the quantification of secreted electroactive neurotransmitters. In this technique, a microelectrode (e.g., a carbon fiber microelectrode) is placed on top of a cell as working electrode with a reference electrode positioned nearby in the surrounding buffered solution. Using a $\mathrm{K}^{+}$-ion-rich solution, release of neurotransmitters from vesicles docked at the cell membrane is triggered. A constant applied potential between the working and reference electrodes leads to oxidation of electro-active molecules at the working electrode. Such events are observed in the form of current transients, which appear as spikes in a plot of current versus time. Integrating these spikes gives the total charge transferred $(Q)$, which is related to the number of neurotransmitter molecules released $(N)$ according to Faraday's law: $N=Q / n F$, where $n$ is the number of electrons exchanged in the electrochemical reaction and $F$ is Faraday's constant. Although integration of the area under the current transient determines the number of released neurotransmitter molecules, the shape of the signal can be related to the release dynamics. $^{181}$

Intracellular electrochemical monitoring has also been instrumental in the understanding of various fundamental biological processes. This technique requires a special electrode to penetrate the cell membrane without damaging the cell and its intracellular organelles and so maintaining the cell viability during measurement. ${ }^{182,183}$ The Ewing group invented a technique called intracellular vesicle impact electrochemical cytometry (IVIEC, Figure 9B), which uses a flame-etched nanotip conical carbon fiber electrode to penetrate the cell membrane and quantify the neurotransmitter content in single vesicles in the cytoplasm of individual living cells. ${ }^{184,185}$ In this method, the inserted electrode contacts the cell cytoplasm through which the vesicles diffuse. The vesicles adsorb and stochastically rupture on the electrode surface, which is held at a predefined potential. Stimulation is not needed in this method. Here again, oxidation of the neurotransmitters content is observed as current transients and the integration of these transients gives the total number of molecules inside each individual vesicle that ruptured at the electrode surface.

A successful combination of SCA and IVIEC has been used by the Ewing group to study the impact of exposure of cells to drugs associated with cognitive function. Through SCA measurements, $\mathrm{Li}$ et al. revealed that cisplatin modulates the exocytosis events of single pheochromocytoma (PC12) cells. ${ }^{186}$ They showed that low concentrations of cisplatin (2 $\mu \mathrm{M})$ enhanced the frequency of exocytosis events and reduced the event duration, whereas high concentrations $(100 \mu \mathrm{M})$ of this drug decreased the frequency of events and increased their duration. The number of neurotransmitter molecules released $(N)$ did not change at the low dose of cisplatin, whereas the high dose of cisplatin significantly increased $N$. Interestingly, their IVIEC results showed that vesicular neurotransmitter content did not significantly change upon cisplatin incubation. This result suggests cisplatin likely modulates exocytosis by altering the cell membrane and fusion-pore dynamics, rather than the vesicle properties. In another study, Ren et al. showed that exposure of cells to micromolar-concentrations of zinc leads to changes in exocytosis dynamics as well as a decrease in vesicle content of individual PC12 cells, yet the amount of neurotransmitter released remains the same. ${ }^{187}$ It is very interesting that in total, they observed a larger fraction of released dopamine in each event after zinc treatment.

Recently, time-resolved quantitative measurements with SCA and IVIEC was conducted to investigate whether lidocaine can regulate neurotransmitter release or storage in PC12 cells. ${ }^{188}$ It was found that lidocaine has biphasic effects on exocytosis in a way that increases the number of neurotransmitter released at low concentration, while at high concentration leads to decrease in the neurotransmitter released amount, which can apparently be attributed to the lidocaine neurotoxicity effect. The effects of barbiturate ${ }^{189}$ and curcumin $^{190}$ on altering exocytosis in PC12 cells were also studied. Such electrochemical data could help further understanding of the function of these drugs in memory at the single cell level.

Cans and co-workers used SCA and IVIEC to study the osmotic stress on exocytosis activity, quantal release, and catecholamine content of single cells. They subjected chromaffin cells to either an isotonic $(310 \mathrm{mOsm} / \mathrm{kg})$ or a hypertonic environment $(730 \mathrm{mOsm} / \mathrm{kg})$. They showed that hypertonic stress hampers exocytosis secretion and that extracellular osmotic stress causes catecholamine-filled vesicles 
to shrink, mainly by reducing the volume of the halo solution surrounding the protein matrix in dense-core vesicles. Similarly to work done with TEM and amperometry in the past, their IVIEC measurements suggest that vesicles reduce the catecholamine content to maintain a constant concentration within the vesicle compartment in response to hypertonic stress. $^{191}$

Wang et al. fabricated $\mathrm{Au}$ ring microelectrodes by deposition of nanostructured gold thin films on the rigid outer surface of pulled glass capillaries using a novel ultrasonic-aided approach. They employed this electrode to amperometric measurements of exocytosis at single rat chromaffin cells. ${ }^{192}$ The ultrasonication used in this work helps to accelerate microelectrode fabrication and control nanostructured surface morphology. The nanostructured surfaces of the gold microelectrodes provided improved sensing of dopamine oxidation.

Oxidative stress is an important carcinogenic factor, and its analysis using amperometry is of great interest. During this stress condition, high levels of reactive oxygen/nitrogen species (ROS/RNS) are produced that overwhelm cellular radicalscavenging and repairing systems. ${ }^{193,194}$ Huang, Amatore, and their co-workers have recently presented real-time intracellular measurements of ROS and RNS in individual phagolysosomes of living macrophages by use of a core-shell nanowire electrode (NWE) to carry out IVIEC. ${ }^{195}$ A silicon carbide $(\mathrm{SiC})$ nanowire was first coated by a layer of carbon through chemical vapor deposition. The carbon-coated $\mathrm{SiC}$ nanowire ( $\mathrm{SiC} @ \mathrm{C} \mathrm{NWE}$ ) was then transferred to a nanopipet, in contact with liquid metal, and sealed with wax. The resulting SiC@C NWE was then modified by partial platinization to allow probing of intracellular events. Representative traces from the amperometric measurement with this electrode were attributed to the detection of ROS/RNS inside phagolysosomes bursting onto the platinized surfaces upon inserting the nanowire electrode into the macrophages. This phenomenon certainly seems in agreement with a proposed mechanism described for vesicle impact electrochemical cytometry (VIEC) or IVIEC, ${ }^{184,196,197}$ in which each vesicle would rupture and expel its contents upon contact with an electrode holding fixed potential. Since the shell material in this reported design (SiC@C NWE) can be tailored for any specific detection purpose, it can be applied to further quantitative measurements of biological molecules occurring inside cells and their organelles.

Accurate measurement of nitric oxide (NO) levels at living cells is very difficult due to its trace-level release from cells, short half-life, and rapid diffusion. Xu et al. recently reported real-time, in situ amperometric monitoring of NO release from human umbilical vein endothelial cells in response to Larginine stimulation. ${ }^{198}$ L-Arginine, the substrate of $\mathrm{NO}$ synthase in biological systems, was used to trigger NO release by the cells. To prepare the modified electrode, at first nitrogen-doped graphene (N-G) was functionalized with ironphthalocyanine $(\mathrm{FePc})$ via $\pi-\pi$ interaction, and the resulting nanocomposites were deposited on ITO electrodes with subsequent assembly of poly-L-lysine (PLL) and Nafion (N$\mathrm{G} / \mathrm{FePc} / \mathrm{Nafion} / \mathrm{PLL} / \mathrm{ITO})$. The excellent electrocatalytic activity and biocompatibility of the N-G/FePc/Nafion/PLL/ ITO electrode resulted in efficient capture of $\mathrm{NO}$ molecules released form the stimulated cells and thus led to successful detection of NO.

Ascorbate release from rat adrenal chromaffin cells was directly observed using pretreated carbon fiber microelectrodes and SCA. ${ }^{199}$ The electrode was pretreated in a weakly basic solution, allowing selective monitoring of ascorbate without interference from other electroactive species present in the cell. Also, this study showed that endogenous ascorbate appears to locate in a vesicular compartment and secrete from the chromaffin cells through an exocytotic mechanism, which is quite similar to the exocytosis of catecholamine via chromaffin vesicles. Furthermore, they appear to have confirmed the vesicular release of ascorbate by investigation of dependency of the high $\mathrm{K}^{+}$-induced endogenous ascorbate release on calcium pathway.

Wigström et al. developed a lithographically microfabricated microelectrode array (MEA) probe, consisting of 16 platinum band electrodes, that has the capability to be placed in close proximity to single adherent cells in culture. Using this MEA probe, they carried out a total of 16 individual simultaneous amperometric recordings of exocytotic release at multiple locations at the surface of a chromaffin cell. This MEA also allows one- and two-dimensional electrochemical imaging of exocytotic release with high spatial resolution. ${ }^{200}$

Enzymatic Biosensors. Enzyme-based biosensors are an important class of electrochemical probes suitable for single cell analysis with the advantages of specificity and applicability in measurement of either electroactive or non-electroactive targets. One example is analysis of cholesterol in the plasma membrane of single living HeLa cells with a newly reported electrochemical biosensor, developed by $\mathrm{Xu}$ et al. ${ }^{201}$ They filled a hollow microcapillary (tip diameter $1 \mu \mathrm{m}$ ) with cholesterol oxidase and Triton X-100 that could park at the capillary tip due to slow hydrodynamic flow. The capillary tip was coated with a ring of $\mathrm{Pt}$ to allow oxidation of hydrogen peroxide generated during the reaction of cholesterol and cholesterol oxidase. When the tip touched the plasma membrane, the Triton X-100 permeabilized the cell membrane (just the contact region) to release cholesterol, so that the membrane cholesterol concentration can be successfully determined with high sensitivity and spatial resolution. The achievement in the analysis of membrane cholesterol using this electrode offers a new strategy for the application of biosensors to single cell analysis, similar to that of Burgess and coworkers $^{202-204}$ published previously.

The Khademhosseini group developed an electrochemical biosensor based on cytochrome-c immobilized on nanoporous gold films for real-time monitoring of superoxide anions generated by skeletal muscle cells. ${ }^{205}$ The fatal effects of superoxide level changes in the cellular environment demand highly sensitive superoxide biosensors. In this work, they calibrated the prepared biosensor using the superoxide produced during the enzymatic reaction of xanthine and xanthine oxidase. Afterward, superoxide generation rates from C2C12 myoblast cells were monitored upon stimulation with an endogenous superoxide producing drug, phorbol 12myristate 13-acetate. They observed that superoxide generation rates follow the concentration of the drug in a quasilinear manner, which agrees with earlier reported measurements on a contractile skeletal muscle bundle. Electrochemical results in this study were validated with a fluorescent superoxide probe, MitoSOX, which demonstrated a similar trend in the measurement of superoxide generation with drug concentration.

In another study, amperometric monitoring of glutamate quantal release from a single neuron was performed using a $\mathrm{Pt}$ nanoparticle electrodeposited on carbon fiber microelectrode 

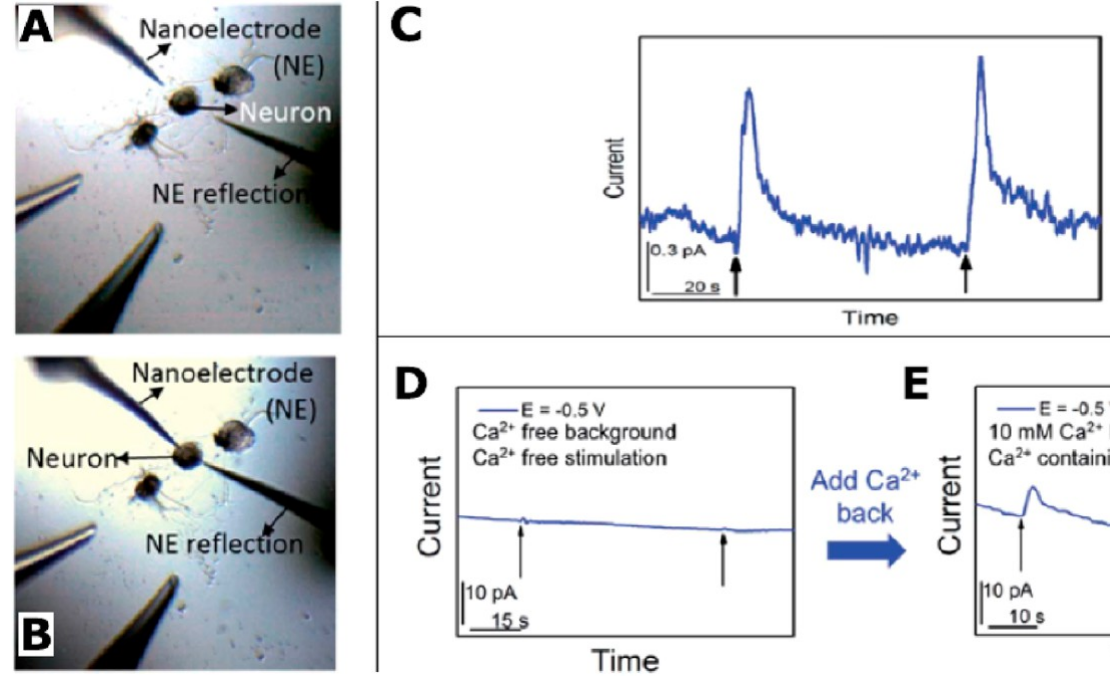

Time
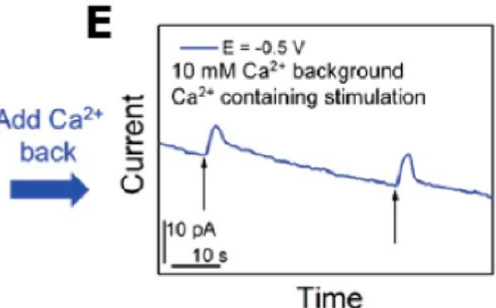

Figure 10. (A, B) High-resolution spatiotemporal observation of acetylcholine (ACh) somatic exocytosis. The nanoITIES electrode for ACh detection was positioned with a nanometer-resolution scanning electrochemical microscope (SECM). Optical microscope images prior to SECM positioning (A) and after SECM positioning (B). (C) Amperometric recordings of ACh release from a single Aplysia neuron in response to high concentration $\mathrm{K}^{+}$stimulation, indicated by the arrows. The nanoelectrode radius is $860 \mathrm{~nm}$. (D, E) Calcium-dependence of acetylcholine exocytosis from an Aplysia californica neuron in response to high concentration $\mathrm{K}^{+}$stimulation. (D) Amperometric current response in response to chemical stimulation $\left(\mathrm{Ca}^{2+}\right.$ free, elevated $\mathrm{K}^{+}$solution, indicated by black arrows) measured at 50 min after replacing standard artificial seawater (ASW) with $\mathrm{Ca}^{2+}$-free ASW. (E) Amperometric current response from the cell upon stimulation $\left(\mathrm{Ca}^{2+}\right.$-containing, elevated $\mathrm{K}^{+}$solution, indicated by black arrows), $10 \mathrm{~min}$ after the addition of $\mathrm{Ca}^{2+}$ solution to a final concentration of $10 \mathrm{mM}$. The nanoelectrode radius is $780 \mathrm{~nm}$. Reproduced and adapted from Welle, T. M.; Alanis, K.; Colombo, M. L.; Sweedler, J. V.; Shen, M. Chemical Science 2018, 9, 4937-4941 (ref 211), with permission of The Royal Society of Chemistry.

with subsequent immobilization with glutamate oxidase. ${ }^{206}$ The prominent catalytic activity of the enzyme and small dimension of the proposed biosensor offered real-time monitoring of glutamate exocytosis with high sensitivity and spatial-temporal resolution. This kind of biosensor can be further employed to explore the cellular mechanism of neuronal communication and synaptic plasticity.

Electrochemical Microscopy. Scanning electrochemical microscopy (SECM) employs ultramicroelectrodes (UMEs) that move in the proximity of a sample surface with extreme precision, while recording a faradaic current response. ${ }^{207}$ This response depends on both the topography and the electrochemical activity of the surface (substrate) itself. This method has been widely applied in biological research (commonly referred to as Bio-SECM ${ }^{208}$ ) on single living cells, e.g. PC12 cells. The key advantages of Bio-SECM are its high temporal and spatial resolution, and it has thus served as a noninvasive platform for measuring biochemical release from individual cells. ${ }^{209-211}$

$\mathrm{Li}$ et al. used platinized carbon nanoelectrodes as SECM probes to measure ROS/RNS inside noncancerous (MCF10A) and metastatic human breast (MDA-MB-231 and MDAMB-468) cells. ${ }^{212}$ By performing time-resolved, quantitative amperometric measurements at different potentials, the relative concentrations of four key ROS/RNS (including hydrogen peroxide, peroxynitrite, nitrogen monoxide, and nitrite ion) in the cell cytoplasm and their dynamics were determined. A strong correlation between intracellular ROS/RNS production and metastatic activity was found.

Using the nanointerface between two immiscible electrolyte solutions (ITIES) and SECM, the Sweedler and Shen groups reported a quantitative study of acetylcholine $(\mathrm{ACh})$ release from individual neuronal soma of Aplysia for the first time. ${ }^{211}$ The nanoelectrode (radii of 750-860 nm) was placed $140 \mathrm{~nm}$ away (vertically) from the release sites on the soma (Figure $10 \mathrm{~A}, \mathrm{~B})$, and the extracellular concentration of the ACh was measured from the amperometric release peaks (Figure 10C). Information about cellular permeability, vesicle density, number of molecules released, and the release dynamics was provided. They suggested the pathway of somatic ACh release from Aplysia was via calcium-dependent exocytosis (Figure $10 \mathrm{D}, \mathrm{E})$, although apparently not single exocytosis events to date.

Solda et al. fabricated a glucose biosensor for SECM by immobilizing glucose oxidase on electropolymerized Pt UMEs $(10 \mu \mathrm{m})$. These served as microprobes for SECM to monitor metabolites at the single-cell level (MCF10A cells). ${ }^{213} \mathrm{~A}$ voltage-switch approach was employed to discriminate the topographical contribution of the cells, enabling quantitative measurements of cellular uptake. Two separate signals were sequentially collected: the first one containing both a functional and a topographical contribution, which is associated with the analyte of interest (glucose), and the second one only containing a topographical contribution obtained after the voltage switching, which results from the response of a secondary redox mediator (hexaaminoruthenium chloride). Finally, the absolute value of glucose concentration relative to the cellular uptake at single cell level was estimated. A 2D SECM image of glucose uptake of a culture of MCF10A cells showed that each single cell was characterized by a specific glucose uptake profile and that the profiles of the single cells were not overlapping.

Comparable to the way UMEs have been used in SECM, nanopipet probes have been applied in scanning ion conductance microscopy (SICM). This approach allows the probing of local ion conductance and surface topography at the single-cell level as well as dynamic observation of subcellular structures. $^{214}$ As an example, surface charge mapping and 
topographical imaging of neurites formed by PC12 cells using a novel SICM-approach was demonstrated by Unwin et al. ${ }^{215}$ Simultaneous SICM and SECM images of the target molecules in living cells were also reported. This was achieved by using a multifunctional, dual-channel scanning probe nanopipet, which enabled differentiation in molecular uptake rates of single cells throughout several regions of cells with nanoscale resolution. $^{216,217}$

In another study, a nanopipet was functionalized with glucose oxidase by Nascimento et al. and used to measure free glucose levels in individual human fibroblasts and metastatic breast cancer lines (MDA-MB-231 and MCF7). ${ }^{218}$ They inserted the nanopipet inside the target cells using an SICM setup, after which intracellular glucose measurements were conducted by applying a fixed current. They found that intercellular glucose concentration in MCF7 cells (2.69 mM) and MDA-MB-231 cells $(1.21 \mathrm{mM})$ is higher compared to the fibroblasts tested $(0.63 \mathrm{mM})$ and confirmed the hypothesized increase in glucose uptake associated with cancer cell metabolism. Furthermore, they suggested that the differential expression of glucose transporter proteins might cause the significant difference in intracellular glucose concentrations observed between MCF-7 and MDAMB-231.

Electrochemical Impedance Spectroscopy. Impedance measurements of living cells are widely known as a label-free and nondestructive analytical method for cell status assessment. These advantages make impedance measurements especially suitable for (long-time) live-cell monitoring. ${ }^{219}$ In electrochemical impedance spectroscopy (EIS), single cells are characterized based on their electrical response over a particular frequency range. EIS can be employed for the characterization of electrical, mechanical, and physical properties of cell membranes. Model lipid membranes of cells (e.g., planar and supported lipid bilayers, tethered lipid membranes, liposomes) can be investigated to obtain detailed information about properties of real biological membranes and associated electrochemical processes. ${ }^{220}$

Supported lipid membranes have been extensively used as versatile models for biophysical studies of single cell membranes. ${ }^{220-222}$ EIS studies were conducted by Diamanti et al. on lipid bilayers supported by polyelectrolyte multilayer (PEM) cushions. ${ }^{223}$ Their impedance measurements showed relatively high membrane capacitance and resistance values which were attributed to the changes in the dielectric environment of the lipid layer and the formation of a dense lipid bilayer with a limited number of defects or pores, respectively. They showed that lipid composition and the conformational state of vesicles are very important in order to reach a continuous bilayer on PEM with desirable electrical properties. The high resistance obtained in this work envisages the combination of lipid layers with channels or transmembrane proteins to increase selective transport in sensor devices or as model for biological processes, taking advantage of the use of PEM as hydrophilic spacers.

Zhou et al. used a PDMS-glass-based microfluidic device in order to perform real-time impedance measurements of mouse embryonic stem cells (mESCs) during cell membrane lysis. ${ }^{224}$ They compared the impedance magnitude and phase spectra of mESCs before and after the lysis process. A significant enhancement in conductivity (diminished impedance magnitude) of the cell membrane was observed during lysis, owing to the formation of pores. Also, they found that the specific capacitance of the cell membrane during this process was increased, and the conductivity of the cytoplasm was decreased.

Schnakenberg and co-workers conducted EIS on single mouse oocytes with and without the surrounding glycoprotein matrix, called zona pellucida, using a microfluidic device. ${ }^{225}$ They modified a microelectrode with poly(pyrrole-polystyrene) sulfonate, increasing their useful frequency range. The results revealed higher impedance values for zona pellucida-free oocytes compared with the zona pellucida-intact oocytes (reflecting the known high electrical conductivity of the zona pellucida). They suggested that the difference between these impedance values could be related to the porous structure of the zona pellucida, supporting the assumption of a conductive layer.

Shah et al. reported the assessment of nanoparticle toxicity at single cells and small cell colonies using an EIS technique with a chip-based approach and different-sized microwells. ${ }^{226}$ Both electrochemical analysis and dielectrophoretic single-cell capture were carried out at the electrodes. After exposing individual PC12 cells to $\mathrm{CuO}$ and $\mathrm{TiO}_{2}$ nanoparticles, they compared the changes in impedance signal. During nanoparticle exposure, the cell size decreased and the cell detached from the electrode. At this point, the impedance at the electrode surface decreased, which was attributed to an increase in current flow between the sensing and reference electrodes. They found that the $\mathrm{CuO}$ nanoparticles started to affect the morphology of the single PC12 cells and their attachment to the electrode surface earlier than $\mathrm{TiO}_{2}$ nanoparticles. They also carried out a comparative study on a different cell population, which demonstrated that the small population of cells with appropriate microwell-electrode size ( $80 \mu \mathrm{m}$ diameter) has a higher sensitivity to nanotoxicity when compared to a single cell placed in a smaller microwellelectrode.

Electrochemiluminescence Imaging. Electrochemiluminescence (ECL) is an electrochemically triggered optical radiation process generated by relaxation of the excited species after electron transfer. ${ }^{227}$ For the typical luminol-hydrogen peroxide system, the electro-oxidation of luminol generates the luminol intermediate, which reacts with hydrogen peroxide to produce the excited species for the luminescence.

An important breakthrough in the development of ECL applications has been its implementation as an imaging technique to visualize electrochemically single objects. In fact, ECL imaging of single cells is a powerful hyphenated technique, offering the advantages of electrochemical sensitivity and the superior spatial resolution provided by fluorescence microscopy. ${ }^{228}$ The lack of an external light source in ECL promises zero background in comparison with other light-emission methods which suffer from nonselective photoexcitation-induced background. Much research has focused on ECL imaging of visual details at the single cell level. ${ }^{229,230}$

Liu et al. reported direct ECL imaging as a tool to evaluate the effect of the drug diphenyleneiodonium (DPI, an NADPH oxidase inhibitor) at the single-cell level. ${ }^{231}$ Figure 11 shows the ECL imaging setup in this study. Using a modified electrode introduced in their work, chitosan and nano $\mathrm{TiO}_{2}$ modified fluoride-doped tin oxide (FTO) conductive glass, single-cell ECL imaging without the steric hindrance effect of the cell was achieved for the first time in a visualization study. Upon stimulation of HeLa cells by $\mathrm{N}$-formylmethionyl-leucylphenylalanine (fMLP), immediate secretion of hydrogen 


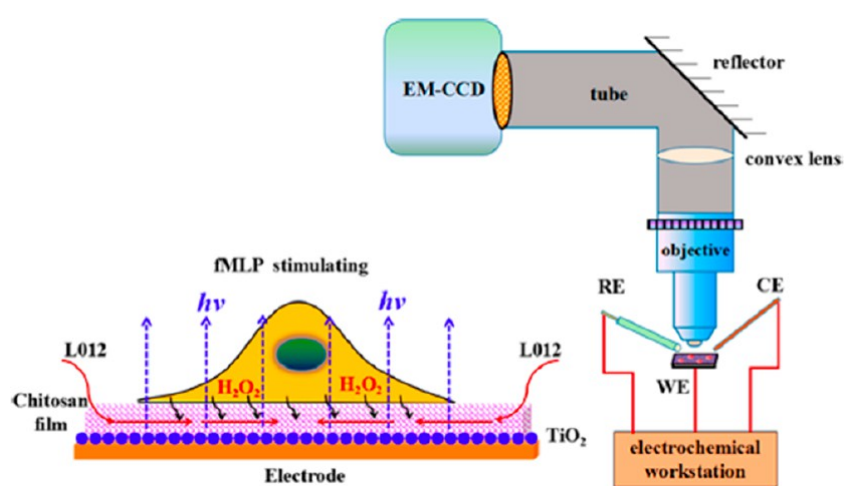

Figure 11. Setup and strategy for the ECL imaging of cells. A CHI electrochemical workstation was the signal actuating device to generate and record electrochemical responses. An electron multiplying CCD (EMCCD) was the signal collecting device to output images. The optical path system was built with a water immersion objective, a convex lens, a reflector, and tubes. The ECL imaging test must be operated in a shielding room. A conventional three-electrode system was used for all electrochemical experiments, which consisted of an FTO glass or a modified electrode as the working electrode, a $\mathrm{Ag} / \mathrm{AgCl}$. Reproduced and adapted from Liu, G.; Ma, C.; Jin, B.-K.; Chen, Z.; Zhu, J.-J. Anal. Chem. 2018, 90, 4801-4806 (ref 231). Copyright 2018 American Chemical Society.

peroxide from the cells occurred and ECL images were collected from the DPI-treated and control cells (Figure $12 \mathrm{~A}, \mathrm{~B})$. DPI was applied to inhibit the production of fMLPstimulated hydrogen peroxide. The results showed that the luminescence (from the ECL reaction between luminol (L012) and hydrogen peroxide) of DPI-treated HeLa cells decreased compared with control cells. They also measured the concentration of hydrogen peroxide released from $\mathrm{HeLa}$ cells, which showed that DPI-treated cells secreted hydrogen peroxide less than control cells (Figure 12C). This is in agreement with the ECL-imaging data. Similar results obtained from MCF-7 cells were reported in this work.

The first spatially resolved ECL imaging of membrane protein distribution of a single tumor cell was realized by the Sojic group. ${ }^{232}$ They labeled the whole cell membrane to analyze the ECL intensity distribution. This demonstrated that ECL emission only contributes to the region of the membrane in the immediate proximity of the electrode surface, as opposed to fluorescence. Labeling of the cell membrane with a model luminophore, $\mathrm{Ru}(\mathrm{bpy})_{3}{ }^{2+}$, via a biotin-streptavidin link and immunochemistry strategies were used for ECL imaging of the membrane epidermal growth factor receptor on cancer cells at the surface of carbon nanotubes-based inkjet-printed disposable electrodes. The ECL imaging assay is promising for ultrasensitive imaging of single cells and membrane proteins.

The Jiang group reported the analysis of intracellular glucose using ECL imaging at the single-cell level. ${ }^{233}$ They placed individual cells in 64 microwells on an indium tin oxide (ITO) slide on which gold nanoparticles were electrodeposited. The microwells were coupled with the ECL imaging platform which enabled fast single cell analysis (60 s). They lysed the cell membrane by introducing Triton X-100, which allows release of intracellular glucose. Along with the Triton X-100, glucose oxidase and luminol were added to the buffer. The secreted glucose from the cell reacted with glucose oxidase, generating hydrogen peroxide which induced luminol luminescence at positive potential. They observed a high heterogeneity in intracellular glucose of normal cells compared to starved cells, based on the produced luminescence intensity. This ECL imaging approach can potentially be applied for fast analysis of more intracellular molecules in single cells to elucidate cellular heterogeneity.

\section{AUTHOR INFORMATION}

\section{Corresponding Author}

*E-mail: andrew.ewing@chem.gu.se.

\section{ORCID}

Pieter E. Oomen: 0000-0001-8395-7331

Ibrahim Kaya: 0000-0003-3345-5602

Andrew G. Ewing: 0000-0002-2084-0133

\section{Author Contributions}

${ }^{\perp}$ M.A.A., I.K, and N.T.N. P. contributed equally to this work. P.E.O., N.T.N.P., I.K., and M.A.A. worked on the microfluidics, super-resolution microscopy, mass spectrometry, and electrochemistry sections, respectively.

\section{Notes}

The authors declare no competing financial interest.

\section{Biographies}

Pieter E. Oomen is a postdoctoral researcher at the Department of Chemistry and Molecular Biology at the University of Gothenburg, Sweden. He received his B.Sc. (2009) and M.Sc. (2012) degrees in pharmacy from the University of Groningen, The Netherlands. He obtained his Ph.D. degree in analytical chemistry and microfluidics at the same university in 2016. After a brief postdoc there and
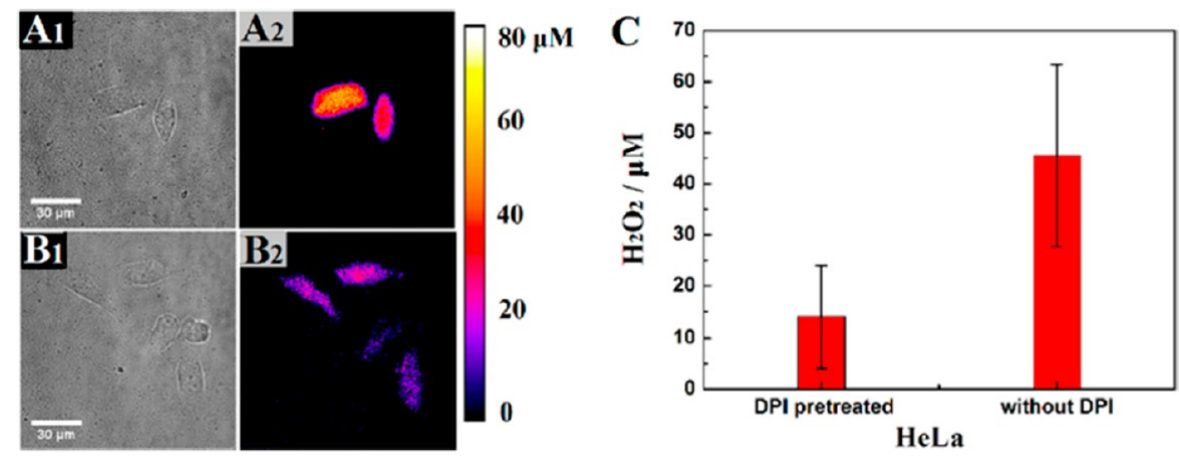

Figure 12. ECL images of HeLa cells on $\mathrm{FTO} / \mathrm{TiO}_{2} / \mathrm{CS}$. (A1, B1) Bright-field image in PBS (pH 7.4, $10 \mathrm{mM}$ ). (A2) ECL pseudocolor image without DPI pretreatment in $400 \mu \mathrm{M}$ L012. (B2) ECL pseudocolor image with DPI pretreatment in $400 \mu \mathrm{M} \mathrm{L012}$. (C) The $\mathrm{H}_{2} \mathrm{O}_{2}$ released from HeLa cells with and without DPI pretreatment and the data obtained from 25 HeLa cells. Reproduced from Liu, G.; Ma, C.; Jin, B.-K.; Chen, Z.; Zhu, J.-J. Anal. Chem. 2018, 90, 4801-4806 (ref 231). Copyright 2018 American Chemical Society. 
subsequently working as a researcher in industry for 9 months, he joined the group of Andrew Ewing in 2017. His research interests include the study of fundamental neurochemical and pharmacological phenomena using (bio)sensors and microfluidics.

Mohaddeseh A. Aref is a Marie Skłodowska-Curie postdoctoral fellow in the Department of Chemistry and Molecular Biology at the University of Gothenburg. She obtained her joint Ph.D. degree in analytical chemistry from the University of Antwerp (Belgium) and University of Mazandaran (Iran) in 2015. She joined the Andrew Ewing group in 2017 and continued her research there by her grant from the European Commission (Grant H2020-MSCA-IF) since 2018. Her research focuses on electrochemistry applied to single cell and subcellular analysis.

Ibrahim Kaya is currently a Ph.D. student at the Gothenburg Imaging Mass Spectrometry (Go:IMS) Laboratory, University of Gothenburg/ Chalmers University of Technology, Sweden. He received his B.Sc. (2013) degree in chemistry from Izmir Institute of Technology, Turkey, and Institute of Chemical Technology, Prague, Czech Republic. He obtained his M.Sc. degree in chemistry from Izmir Institute of Technology in 2015, which included a stay at the University of Gothenburg for 6 months. He worked as a research associate at Sahlgrenska Academy, Gothenburg, Sweden, before starting his $\mathrm{Ph}, \mathrm{D}$. His research interests include the development and application of SIMS and MALDI imaging mass spectrometry techniques for probing molecular disease pathologies, in particular amyloid pathology in Alzheimer's disease.

Nhu T. N. Phan received her Ph.D. at the University of Gothenburg, Sweden, with John S. Fletcher. She is now doing her postdoctoral research in the lab of Silvio O. Rizzoli, Goettingen University Medical Center, Germany, supported by her international postdoc grant from The Swedish Research Council (VR). Her research focuses on mass spectrometry imaging (SIMS and nanoSIMS) and super-resolution microscopy (STED) applied to neurochemistry, especially for studying the molecular structures, turnovers, and functions of neurons and brains.

Andrew G. Ewing is Professor of Chemistry at the University of Gothenburg in Sweden. He received his B.S. from Saint Lawrence University in Canton, NY, and his Ph.D. at Indiana University in Bloomington, IN, with R. Mark Wightman. He was a postdoc in the laboratory of Royce Murray at the University of North Carolina. He is an elected member of the Royal Swedish Academy of Sciences in chemistry. His research interests have been in single cell and subcellular analysis in neurochemistry, with a recent emphasis on new electrochemical strategies to both measure release during exocytosis and the contents of individual nanometer vesicles in cells.

\section{ACKNOWLEDGMENTS}

We acknowledge the many co-workers that have come before and whose works we cite in this review. We would like to especially acknowledge Per Malmberg and John Fletcher for critically reading the mass spectrometry section. We acknowledge support from the European Research Council (ERC Advanced Grant), the Knut and Wallenberg Foundation in Sweden, the Swedish Research Council (VR), and the USA National Institutes of Health (NIH). M.A.A. acknowledges funding from the European Union's Horizon 2020 research and innovation program under the Marie Skłodowska-Curie Grant Agreement No. 793324.

\section{REFERENCES}

(1) Altschuler, S. J.; Wu, L. F. Cell 2010, 141 (4), 559-63.
(2) Murphy, T. W.; Zhang, Q.; Naler, L. B.; Ma, S.; Lu, C. Analyst 2018, 143 (1), 60-80.

(3) Khan, M.; Mao, S.; Li, W.; Lin, J. M. Chem. - Eur. J. 2018, 24, 15398.

(4) Armbrecht, L.; Dittrich, P. S. Anal. Chem. 2017, 89 (1), 2-21.

(5) Huang, L.; Bian, S.; Cheng, Y.; Shi, G.; Liu, P.; Ye, X.; Wang, W. Biomicrofluidics 2017, 11 (1), 011501.

(6) Attayek, P. J.; Hunsucker, S. A.; Sims, C. E.; Allbritton, N. L.; Armistead, P. M. Integr. Biol. 2016, 8 (12), 1208-1220.

(7) Attayek, P. J.; Waugh, J. P.; Hunsucker, S. A.; Grayeski, P. J.; Sims, C. E.; Armistead, P. M.; Allbritton, N. L. Biosens. Bioelectron. 2017, 91, 175-182.

(8) Gonzalez-Suarez, A. M.; Pena-Del Castillo, J. G.; HernandezCruz, A.; Garcia-Cordero, J. L. Anal. Chem. 2018, 90 (14), 83318336.

(9) Feng, J. G.; Fohlerova, Z.; Liu, X. C.; Chang, H. L.; Neuzil, P. Sens. Actuators, B 2018, 269, 288-292.

(10) Mi, L.; Huang, L.; Li, J.; Xu, G.; Wu, Q.; Wang, W. Lab Chip 2016, 16 (23), 4507-4511.

(11) Yesilkoy, F.; Ueno, R.; Desbiolles, B. X.; Grisi, M.; Sakai, Y.; Kim, B. J.; Brugger, J. Biomicrofluidics 2016, 10 (1), 014120.

(12) Weng, L.; Ellett, F.; Edd, J.; Wong, K. H. K.; Uygun, K.; Irimia, D.; Stott, S. L.; Toner, M. Lab Chip 2017, 17 (23), 4077-4088.

(13) Son, K. J.; Rahimian, A.; Shin, D. S.; Siltanen, C.; Patel, T.; Revzin, A. Analyst 2016, 141 (2), 679-88.

(14) Zhou, Y.; Basu, S.; Wohlfahrt, K. J.; Lee, S. F.; Klenerman, D.; Laue, E. D.; Seshia, A. A. Sens. Actuators, B 2016, 232, 680-691.

(15) Ohiri, K. A.; Kelly, S. T.; Motschman, J. D.; Lin, K. H.; Wood, K. C.; Yellen, B. B. Lab Chip 2018, 18 (14), 2124-2133.

(16) Zhao, Y. Y.; Li, Q.; Hu, X. M. Anal. Methods 2018, 10 (28), 3489-3497.

(17) Che, J.; Yu, V.; Dhar, M.; Renier, C.; Matsumoto, M.; Heirich, K.; Garon, E. B.; Goldman, J.; Rao, J.; Sledge, G. W.; Pegram, M. D.; Sheth, S.; Jeffrey, S. S.; Kulkarni, R. P.; Sollier, E.; Di Carlo, D. Oncotarget 2016, 7 (11), 12748-60.

(18) Renier, C.; Pao, E.; Che, J.; Liu, H. E.; Lemaire, C. A.; Matsumoto, M.; Triboulet, M.; Srivinas, S.; Jeffrey, S. S.; Rettig, M.; Kulkarni, R. P.; Di Carlo, D.; Sollier-Christen, E. NPJ. Precis. Oncol. 2017, 1 (1), 15.

(19) Khojah, R.; Stoutamore, R.; Di Carlo, D. Lab Chip 2017, 17 (15), 2542-2549.

(20) Dhar, M.; Lam, J. N.; Walser, T.; Dubinett, S. M.; Rettig, M. B.; Di Carlo, D. Proc. Natl. Acad. Sci. U. S. A. 2018, 115 (40), 99869991.

(21) Yeo, T.; Tan, S. J.; Lim, C. L.; Lau, D. P.; Chua, Y. W.; Krisna, S. S.; Iyer, G.; Tan, G. S.; Lim, T. K.; Tan, D. S.; Lim, W. T.; Lim, C. T. Sci. Rep. 2016, 6, 22076.

(22) Qiu, X.; Huang, J. H.; Westerhof, T. M.; Lombardo, J. A.; Henrikson, K. M.; Pennell, M.; Pourfard, P. P.; Nelson, E. L.; Nath, P.; Haun, J. B. Sci. Rep. 2018, 8 (1), 2774.

(23) Li, C.; Yu, J.; Schehr, J.; Berry, S. M.; Leal, T. A.; Lang, J. M.; Beebe, D. J. ACS Appl. Mater. Interfaces 2018, 10 (20), 17065-17070.

(24) Teh, S. Y.; Lin, R.; Hung, L. H.; Lee, A. P. Lab Chip 2008, 8 (2), 198-220.

(25) Li, Z. Y.; Huang, M.; Wang, X. K.; Zhu, Y.; Li, J. S.; Wong, C. C. L.; Fang, Q. Anal. Chem. 2018, 90 (8), 5430-5438.

(26) Ng, E. X.; Miller, M. A.; Jing, T.; Chen, C. H. Biosens. Bioelectron. 2016, 81, 408-414.

(27) Moon, H. S.; Je, K.; Min, J. W.; Park, D.; Han, K. Y.; Shin, S. H.; Park, W. Y.; Yoo, C. E.; Kim, S. H. Lab Chip 2018, 18 (5), 775784

(28) Zilionis, R.; Nainys, J.; Veres, A.; Savova, V.; Zemmour, D.; Klein, A. M.; Mazutis, L. Nat. Protoc. 2017, 12 (1), 44-73.

(29) De Bie, J.; Demeyer, S.; Alberti-Servera, L.; Geerdens, E.; Segers, H.; Broux, M.; De Keersmaecker, K.; Michaux, L.; Vandenberghe, P.; Voet, T.; Boeckx, N.; Uyttebroeck, A.; Cools, J. Leukemia 2018, 32, 1358.

(30) Nguyen, Q. H.; Pervolarakis, N.; Blake, K.; Ma, D.; Davis, R. T.; James, N.; Phung, A. T.; Willey, E.; Kumar, R.; Jabart, E.; Driver, 
I.; Rock, J.; Goga, A.; Khan, S. A.; Lawson, D. A.; Werb, Z.; Kessenbrock, K. Nat. Commun. 2018, 9 (1), 2028.

(31) Antfolk, M.; Kim, S. H.; Koizumi, S.; Fujii, T.; Laurell, T. Sci. Rep. 2017, 7, 46507.

(32) Guo, F.; Mao, Z.; Chen, Y.; Xie, Z.; Lata, J. P.; Li, P.; Ren, L.; Liu, J.; Yang, J.; Dao, M.; Suresh, S.; Huang, T. J. Proc. Natl. Acad. Sci. U. S. A. 2016, 113 (6), 1522-7.

(33) Huang, N. T.; Hwong, Y. J.; Lai, R. L. Microfluid. Nanofluid. 2018, $22(2), 16$.

(34) Islam, M.; Brink, H.; Blanche, S.; DiPrete, C.; Bongiorno, T.; Stone, N.; Liu, A.; Philip, A.; Wang, G.; Lam, W.; Alexeev, A.; Waller, E. K.; Sulchek, T. Sci. Rep. 2017, 7 (1), 1997.

(35) Ren, X.; Ghassemi, P.; Babahosseini, H.; Strobl, J. S.; Agah, M. ACS Sens 2017, 2 (2), 290-299.

(36) Okumus, B.; Baker, C. J.; Arias-Castro, J. C.; Lai, G. C.; Leoncini, E.; Bakshi, S.; Luro, S.; Landgraf, D.; Paulsson, J. Nat. Protoc. 2018, 13 (1), 170-194.

(37) Chen, X.; Love, J. C.; Navin, N. E.; Pachter, L.; Stubbington, M. J.; Svensson, V.; Sweedler, J. V.; Teichmann, S. A. Nat. Biotechnol. 2016, 34 (11), 1111-1118.

(38) Chen, X.; Teichmann, S. A.; Meyer, K. B. Annu. Rev. of Biomed. Data Sci. 2018, 1, 29-51.

(39) Clark, S. J.; Lee, H. J.; Smallwood, S. A.; Kelsey, G.; Reik, W. Genome Biol. 2016, 17, 72.

(40) Gawad, C.; Koh, W.; Quake, S. R. Nat. Rev. Genet. 2016, 17 (3), 175-88.

(41) Karemaker, I. D.; Vermeulen, M. Trends Biotechnol. 2018, 36 (9), 952-965.

(42) Tasic, B. Curr. Opin. Neurobiol. 2018, 50, 242-249.

(43) Prakadan, S. M.; Shalek, A. K.; Weitz, D. A. Nat. Rev. Genet. 2017, 18 (6), 345-361.

(44) Zheng, G. X.; Terry, J. M.; Belgrader, P.; Ryvkin, P.; Bent, Z. W.; Wilson, R.; Ziraldo, S. B.; Wheeler, T. D.; McDermott, G. P.; Zhu, J.; Gregory, M. T.; Shuga, J.; Montesclaros, L.; Underwood, J. G.; Masquelier, D. A.; Nishimura, S. Y.; Schnall-Levin, M.; Wyatt, P. W.; Hindson, C. M.; Bharadwaj, R.; Wong, A.; Ness, K. D.; Beppu, L. W.; Deeg, H. J.; McFarland, C.; Loeb, K. R.; Valente, W. J.; Ericson, N. G.; Stevens, E. A.; Radich, J. P.; Mikkelsen, T. S.; Hindson, B. J.; Bielas, J. H. Nat. Commun. 2017, 8, 14049.

(45) Stephenson, W.; Donlin, L. T.; Butler, A.; Rozo, C.; Bracken, B.; Rashidfarrokhi, A.; Goodman, S. M.; Ivashkiv, L. B.; Bykerk, V. P.; Orange, D. E.; Darnell, R. B.; Swerdlow, H. P.; Satija, R. Nat. Commun. 2018, 9 (1), 791.

(46) Guo, S.; Lin, W. N.; Hu, Y.; Sun, G.; Phan, D. T.; Chen, C. H. Lab Chip 2018, 18 (13), 1914-1920.

(47) Chu, W. K.; Edge, P.; Lee, H. S.; Bansal, V.; Bafna, V.; Huang, X.; Zhang, K. Proc. Natl. Acad. Sci. U. S. A. 2017, 114 (47), 1251212517.

(48) Lan, F.; Demaree, B.; Ahmed, N.; Abate, A. R. Nat. Biotechnol. 2017, 35 (7), 640-646.

(49) VanInsberghe, M.; Zahn, H.; White, A. K.; Petriv, O. I.; Hansen, C. L. PLoS One 2018, 13 (1), No. e0191601.

(50) Kaiser, M.; Jug, F.; Julou, T.; Deshpande, S.; Pfohl, T.; Silander, O. K.; Myers, G.; van Nimwegen, E. Nat. Commun. 2018, 9 (1), 212.

(51) Rullan, M.; Benzinger, D.; Schmidt, G. W.; Milias-Argeitis, A.; Khammash, M. Mol. Cell 2018, 70 (4), 745-756.

(52) Liao, M. C.; Muratore, C. R.; Gierahn, T. M.; Sullivan, S. E.; Srikanth, P.; De Jager, P. L.; Love, J. C.; Young-Pearse, T. L. J. Neurosci. 2016, 36 (5), 1730-46.

(53) Xia, J.; Zhou, J.; Zhang, R.; Jiang, D.; Jiang, D. Anal. Bioanal. Chem. 2018, 410 (20), 4787-4792.

(54) Zhou, Y.; Basu, S.; Laue, E.; Seshia, A. A. Biosens. Bioelectron. 2016, 81, 249-258.

(55) Cermak, N.; Olcum, S.; Delgado, F. F.; Wasserman, S. C.; Payer, K. R.; Murakami, M. A.; Knudsen, S. M.; Kimmerling, R. J.; Stevens, M. M.; Kikuchi, Y.; Sandikci, A.; Ogawa, M.; Agache, V.; Baleras, F.; Weinstock, D. M.; Manalis, S. R. Nat. Biotechnol. 2016, 34 (10), 1052-1059.
(56) Stevens, M. M.; Maire, C. L.; Chou, N.; Murakami, M. A.; Knoff, D. S.; Kikuchi, Y.; Kimmerling, R. J.; Liu, H.; Haidar, S.; Calistri, N. L.; Cermak, N.; Olcum, S.; Cordero, N. A.; Idbaih, A.; Wen, P. Y.; Weinstock, D. M.; Ligon, K. L.; Manalis, S. R. Nat. Biotechnol. 2016, 34 (11), 1161-1167.

(57) Schmidt, R.; Wurm, C. A.; Jakobs, S.; Engelhardt, J.; Egner, A.; Hell, S. W. Nat. Methods 2008, 5 (6), 539-44.

(58) Hell, S. W.; Stelzer, E. H. K. J. Opt. Soc. Am. A 1992, 9 (12), 2159-2166.

(59) Curdt, F.; Herr, S. J.; Lutz, T.; Schmidt, R.; Engelhardt, J.; Sahl, S. J.; Hell, S. W. Opt. Express 2015, 23 (24), 30891-903.

(60) D’Este, E.; Kamin, D.; Balzarotti, F.; Hell, S. W. Proc. Natl. Acad. Sci. U. S. A. 2017, 114 (2), E191-E199.

(61) Hruska, M.; Henderson, N.; Le Marchand, S. J.; Jafri, H.; Dalva, M. B. Nat. Neurosci. 2018, 21 (5), 671-682.

(62) Rust, M. J.; Bates, M.; Zhuang, X. Nat. Methods 2006, 3 (10), 793-5.

(63) Rahbek-Clemmensen, T.; Lycas, M. D.; Erlendsson, S.; Eriksen, J.; Apuschkin, M.; Vilhardt, F.; Jorgensen, T. N.; Hansen, F. H.; Gether, U. Nat. Commun. 2017, 8 (1), 740.

(64) Shi, X.; Garcia, G., 3rd; Van De Weghe, J. C.; McGorty, R.; Pazour, G. J.; Doherty, D.; Huang, B.; Reiter, J. F. Nat. Cell Biol. 2017, 19 (10), $1178-1188$.

(65) Sunwoo, H.; Colognori, D.; Froberg, J. E.; Jeon, Y.; Lee, J. T. Proc. Natl. Acad. Sci. U. S. A. 2017, 114 (40), 10654-10659.

(66) Gustafsson, M. G. L. J. Microsc. 2000, 198, 82-87.

(67) Ponsetto, J. L.; Bezryadina, A.; Wei, F.; Onishi, K.; Shen, H.; Huang, E.; Ferrari, L.; Ma, Q.; Zou, Y.; Liu, Z. ACS Nano 2017, 11 (6), 5344-5350.

(68) Lagache, T.; Grassart, A.; Dallongeville, S.; Faklaris, O.; Sauvonnet, N.; Dufour, A.; Danglot, L.; Olivo-Marin, J. C. Nat. Commun. 2018, 9 (1), 698.

(69) Vicidomini, G.; Bianchini, P.; Diaspro, A. Nat. Methods 2018, 15 (3), 173-182.

(70) Li, C.; Liu, S.; Wang, W.; Liu, W.; Kuang, C.; Liu, X. J. Microsc. 2018, 271 (1), 4-16.

(71) Castello, M.; Tortarolo, G.; Hernandez, I. C.; Bianchini, P.; Buttafava, M.; Boso, G.; Tosi, A.; Diaspro, A.; Vicidomini, G. Microsc. Res. Tech. 2016, 79 (9), 785-91.

(72) Gottfert, F.; Pleiner, T.; Heine, J.; Westphal, V.; Gorlich, D.; Sahl, S. J.; Hell, S. W. Proc. Natl. Acad. Sci. U. S. A. 2017, 114 (9), 2125-2130.

(73) Balzarotti, F.; Eilers, Y.; Gwosch, K. C.; Gynnå, A. H.; Westphal, V.; Stefani, F. D.; Elf, J.; Hell, S. W. Science 2017, 355 (6325), 606-612.

(74) Huang, X.; Fan, J.; Li, L.; Liu, H.; Wu, R.; Wu, Y.; Wei, L.; Mao, H.; Lal, A.; Xi, P.; Tang, L.; Zhang, Y.; Liu, Y.; Tan, S.; Chen, L. Nat. Biotechnol. 2018, 36 (5), 451-459.

(75) Heine, J.; Reuss, M.; Harke, B.; D’Este, E.; Sahl, S. J.; Hell, S. W. Proc. Natl. Acad. Sci. U. S. A. 2017, 114 (37), 9797-9802.

(76) Eilers, Y.; Ta, H.; Gwosch, K. C.; Balzarotti, F.; Hell, S. W. Proc. Natl. Acad. Sci. U. S. A. 2018, 115 (24), 6117-6122.

(77) Mehedi, M.; Smelkinson, M.; Kabat, J.; Ganesan, S.; Collins, P. L.; Buchholz, U. J. Bio-Protocol 2017, 7 (17), e2543.

(78) Wang, Y.; Woehrstein, J. B.; Donoghue, N.; Dai, M.; Avendano, M. S.; Schackmann, R. C. J.; Zoeller, J. J.; Wang, S. S. H.; Tillberg, P. W.; Park, D.; Lapan, S. W.; Boyden, E. S.; Brugge, J. S.; Kaeser, P. S.; Church, G. M.; Agasti, S. S.; Jungmann, R.; Yin, P. Nano Lett. 2017, 17 (10), 6131-6139.

(79) Sidenstein, S. C.; D’Este, E.; Bohm, M. J.; Danzl, J. G.; Belov, V. N.; Hell, S. W. Sci. Rep. 2016, 6, 26725.

(80) Winter, F. R.; Loidolt, M.; Westphal, V.; Butkevich, A. N.; Gregor, C.; Sahl, S. J.; Hell, S. W. Sci. Rep. 2017, 7, 46492.

(81) Fox-Roberts, P.; Marsh, R.; Pfisterer, K.; Jayo, A.; Parsons, M.; Cox, S. Nat. Commun. 2017, 8, 13558.

(82) Wegner, W.; Ilgen, P.; Gregor, C.; van Dort, J.; Mott, A. C.; Steffens, H.; Willig, K. I. Sci. Rep. 2017, 7 (1), 11781.

(83) Jin, D.; Xi, P.; Wang, B.; Zhang, L.; Enderlein, J.; van Oijen, A. M. Nat. Methods 2018, 15 (6), 415-423. 
(84) Shang, L.; Gao, P.; Wang, H.; Popescu, R.; Gerthsen, D.; Nienhaus, G. U. Chem. Sci. 2017, 8 (3), 2396-2400.

(85) He, H.; Liu, X.; Li, S.; Wang, X.; Wang, Q.; Li, J.; Wang, J.; Ren, H.; Ge, B.; Wang, S.; Zhang, X.; Huang, F. Anal. Chem. 2017, 89 (21), 11831-11838.

(86) Zhi, B.; Cui, Y.; Wang, S.; Frank, B. P.; Williams, D. N.; Brown, R. P.; Melby, E. S.; Hamers, R. J.; Rosenzweig, Z.; Fairbrother, D. H.; Orr, G.; Haynes, C. L. ACS Nano 2018, 12, 5741.

(87) Thompson, A. D.; Omar, M. H.; Rivera-Molina, F.; Xi, Z.; Koleske, A. J.; Toomre, D. K.; Schepartz, A. Angew. Chem., Int. Ed. 2017, 56 (35), 10408-10412.

(88) Takakura, H.; Zhang, Y.; Erdmann, R. S.; Thompson, A. D.; Lin, Y.; McNellis, B.; Rivera-Molina, F.; Uno, S. N.; Kamiya, M.; Urano, Y.; Rothman, J. E.; Bewersdorf, J.; Schepartz, A.; Toomre, D. Nat. Biotechnol. 2017, 35 (8), 773-780.

(89) Halabi, E. A.; Thiel, Z.; Trapp, N.; Pinotsi, D.; Rivera-Fuentes, P. J. Am. Chem. Soc. 2017, 139 (37), 13200-13207.

(90) Han, Y.; Li, M.; Qiu, F.; Zhang, M.; Zhang, Y. H. Nat. Commun. 2017, 8 (1), 1307.

(91) Lukinavicius, G.; Mitronova, G. Y.; Schnorrenberg, S.; Butkevich, A. N.; Barthel, H.; Belov, V. N.; Hell, S. W. Chem. Sci. 2018, 9 (13), 3324-3334.

(92) Huisken, J.; Swoger, J.; Bene, F. D.; Wittbrodt, J.; Stelzer, E. H. K. Science 2004, 305 (5686), 1007.

(93) Gustavsson, A. K.; Petrov, P. N.; Moerner, W. E. Opt. Express 2018, 26 (10), 13122-13147.

(94) Chakkarapani, S. K.; Sun, Y.; Lee, S.; Fang, N.; Kang, S. H. ACS Nano 2018, 12 (5), 4156-4163.

(95) Gustavsson, A. K.; Petrov, P. N.; Lee, M. Y.; Shechtman, Y.; Moerner, W. E. Nat. Commun. 2018, 9 (1), 123.

(96) Olarte, O. E.; Andilla, J.; Gualda, E. J.; Loza-Alvarez, P. Adv. Opt. Photonics 2018, 10 (1), 111-179.

(97) Truckenbrodt, S.; Maidorn, M.; Crzan, D.; Wildhagen, H.; Kabatas, S.; Rizzoli, S. O. EMBO Rep. 2018, 19, e45836.

(98) Schnitzbauer, J.; Strauss, M. T.; Schlichthaerle, T.; Schueder, F.; Jungmann, R. Nat. Protoc. 2017, 12 (6), 1198-1228.

(99) Dertinger, T.; Colyer, R.; Iyer, G.; Weiss, S.; Enderlein, J. Proc. Natl. Acad. Sci. U. S. A. 2009, 106 (52), 22287-92.

(100) Deschout, H.; Lukes, T.; Sharipov, A.; Feletti, L.; Lasser, T.; Radenovic, A. Proc. SPIE 2017, 10071, 100710E DOI: 10.1117/ 12.2252865 .

(101) Hainsworth, A. H.; Lee, S.; Foot, P.; Patel, A.; Poon, W. W.; Knight, A. E. Neuropathol. Appl. Neurobiol. 2018, 44 (4), 417-426.

(102) Chen, F.; Tillberg, P. W.; Boyden, E. S. Science 2015, 347 (6221), 543-548.

(103) Chang, J. B.; Chen, F.; Yoon, Y. G.; Jung, E. E.; Babcock, H.; Kang, J. S.; Asano, S.; Suk, H. J.; Pak, N.; Tillberg, P. W.; Wassie, A. T.; Cai, D.; Boyden, E. S. Nat. Methods 2017, 14 (6), 593-599.

(104) Gao, M.; Maraspini, R.; Beutel, O.; Zehtabian, A.; Eickholt, B.; Honigmann, A.; Ewers, H. ACS Nano 2018, 12 (5), 4178-4185.

(105) Halpern, A. R.; Alas, G. C. M.; Chozinski, T. J.; Paredez, A. R.; Vaughan, J. C. ACS Nano 2017, 11 (12), 12677-12686.

(106) Jungmann, R.; Avendano, M. S.; Woehrstein, J. B.; Dai, M.; Shih, W. M.; Yin, P. Nat. Methods 2014, 11 (3), 313-8.

(107) Schueder, F.; Strauss, M. T.; Hoerl, D.; Schnitzbauer, J.; Schlichthaerle, T.; Strauss, S.; Yin, P.; Harz, H.; Leonhardt, H.; Jungmann, R. Angew. Chem., Int. Ed. 2017, 56 (14), 4052-4055.

(108) Schueder, F.; Lara-Gutierrez, J.; Beliveau, B. J.; Saka, S. K.; Sasaki, H. M.; Woehrstein, J. B.; Strauss, M. T.; Grabmayr, H.; Yin, P.; Jungmann, R. Nat. Commun. 2017, 8 (1), 2090.

(109) Wang, L.; Ta, H.; Ullal, C.; Wang, F.; Wang, C.; Dong, G. RSC Adv. 2017, 7 (20), 11821-11826.

(110) Wang, C.; Taki, M.; Sato, Y.; Fukazawa, A.; Higashiyama, T.; Yamaguchi, S. J. Am. Chem. Soc. 2017, 139 (30), 10374-10381.

(111) Butkevich, A. N.; Lukinavicius, G.; D’Este, E.; Hell, S. W. J. Am. Chem. Soc. 2017, 139 (36), 12378-12381.

(112) Shewring, J. R.; Cankut, A. J.; McKenzie, L. K.; Crowston, B. J.; Botchway, S. W.; Weinstein, J. A.; Edwards, E.; Ward, M. D. Inorg. Chem. 2017, 56 (24), 15259-15270.
(113) Lehmann, M.; Lichtner, G.; Klenz, H.; Schmoranzer, J. J. Biophotonics 2016, 9 (1-2), 161-70.

(114) Ni, M.; Zhuo, S.; So, P. T.; Yu, H. J. Biophotonics 2017, 10 (1), $11-23$.

(115) Roubinet, B.; Bischoff, M.; Nizamov, S.; Yan, S.; Geisler, C.; Stoldt, S.; Mitronova, G. Y.; Belov, V. N.; Bossi, M. L.; Hell, S. W. J. Org. Chem. 2018, 83 (12), 6466-6476.

(116) Ye, S.; Yan, W.; Zhao, M.; Peng, X.; Song, J.; Qu, J. Adv. Mater. 2018, 30 (23), 1800167.

(117) Chen, X.; Liu, Z.; Li, R.; Shan, C.; Zeng, Z.; Xue, B.; Yuan, W.; Mo, C.; Xi, P.; Wu, C.; Sun, Y. ACS Nano 2017, 11 (8), 80848091.

(118) Lin, Y.; Nienhaus, K.; Nienhaus, G. U. ChemNanoMat 2018, 4 (3), 253-264.

(119) Urban, N. T.; Foreman, M. R.; Hell, S. W.; Sivan, Y. ACS Photonics 2018, 5 (7), 2574-2583.

(120) Gregor, C.; Sidenstein, S. C.; Andresen, M.; Sahl, S. J.; Danzl, J. G.; Hell, S. W. Sci. Rep. 2018, 8 (1), 2724.

(121) Matela, G.; Gao, P.; Guigas, G.; Eckert, A. F.; Nienhaus, K.; Nienhaus, G. U. Chem. Commun. 2017, 53 (5), 979-982.

(122) Comi, T. J.; Do, T. D.; Rubakhin, S. S.; Sweedler, J. V. J. Am. Chem. Soc. 2017, 139 (11), 3920-3929.

(123) Zhang, L.; Vertes, A. Angew. Chem., Int. Ed. 2018, 57 (17), 4466-4477.

(124) Yang, Y.; Huang, Y.; Wu, J.; Liu, N.; Deng, J.; Luan, T. TrAC, Trends Anal. Chem. 2017, 90, 14-26.

(125) Qi, M.; Philip, M. C.; Yang, N.; Sweedler, J. V. ACS Chem. Neurosci. 2018, 9 (1), 40-50.

(126) Fenn, J. B.; Mann, M.; Meng, C. K.; Wong, S. F.; Whitehouse, C. M. Mass Spectrom. Rev. 1990, 9 (1), 37-70.

(127) Yin, R.; Prabhakaran, V.; Laskin, J. Anal. Chem. 2018, 90 (13), $7937-7945$.

(128) Zhu, H.; Zou, G.; Wang, N.; Zhuang, M.; Xiong, W.; Huang, G. Proc. Natl. Acad. Sci. U. S. A. 2017, 114, 2586-2591.

(129) Nakashima, T.; Wada, H.; Morita, S.; Erra-Balsells, R.; Hiraoka, K.; Nonami, H. Anal. Chem. 2016, 88 (6), 3049-3057.

(130) Hu, J.; Jiang, X.-X.; Wang, J.; Guan, Q.-Y.; Zhang, P.-K.; Xu, J.-J.; Chen, H.-Y. Anal. Chem. 2016, 88 (14), 7245-7251.

(131) Si, X.; Xiong, X.; Zhang, S.; Fang, X.; Zhang, X. Anal. Chem. 2017, 89 (4), 2275-2281.

(132) Xu, M.; Pan, R.; Zhu, Y.; Jiang, D.; Chen, H.-Y. Analyst 2018, DOI: $10.1039 /$ C8AN00483H.

(133) Zhang, L.; Khattar, N.; Kemenes, I.; Kemenes, G.; Zrinyi, Z.; Pirger, Z.; Vertes, A. Sci. Rep. 2018, 8 (1), 12227.

(134) Zhang, L.; Vertes, A. Anal. Chem. 2015, 87 (20), 1039710405.

(135) Lombard-Banek, C.; Moody, S. A.; Nemes, P. Angew. Chem., Int. Ed. 2016, 55 (7), 2454-2458.

(136) Zhang, L.; Sevinsky, C. J.; Davis, B. M.; Vertes, A. Anal. Chem. 2018, 90 (7), 4626-4634.

(137) Hillenkamp, F.; Unsöld, E.; Kaufmann, R.; Nitsche, R. Appl. Phys. 1975, 8 (4), 341-348.

(138) Walker, B. N.; Stolee, J. A.; Pickel, D. L.; Retterer, S. T.; Vertes, A. J. Phys. Chem. C 2010, 114 (11), 4835-4840.

(139) Stopka, S. A.; Rong, C.; Korte, A. R.; Yadavilli, S.; Nazarian, J.; Razunguzwa, T. T.; Morris, N. J.; Vertes, A. Angew. Chem., Int. Ed. 2016, 55 (14), 4482-4486.

(140) Lee, J. K.; Jansson, E. T.; Nam, H. G.; Zare, R. N. Anal. Chem. 2016, 88 (10), 5453-5461.

(141) Kuznetsov, I.; Filevich, J.; Dong, F.; Woolston, M.; Chao, W.; Anderson, E. H.; Bernstein, E. R.; Crick, D. C.; Rocca, J. J.; Menoni, C. S. Nat. Commun. 2015, 6, 6944.

(142) Wang, J.; Liu, F.; Mo, Y.; Wang, Z.; Zhang, S.; Zhang, X. Rev. Sci. Instrum. 2017, 88 (11), 114102.

(143) Wang, J.; Wang, Z.; Liu, F.; Mo, Y.; Cai, L.; Sun, C.; Zhang, S.; Zhang, R.; Abliz, Z.; Zhang, X. Int. J. Mass Spectrom. 2018, 432, 9.

(144) Wang, J.; Wang, Z.; Liu, F.; Cai, L.; Pan, J.; Li, Z.; Zhang, S.C.; Chen, H.-Y.; Zhang, X.; Mo, Y. Anal. Chem. 2018, 90 (11), 10009-10015. 
(145) Tanaka, K.; Waki, H.; Ido, Y.; Akita, S.; Yoshida, Y.; Yoshida, T.; Matsuo, T. Rapid Commun. Mass Spectrom. 1988, 2 (8), 151-153. (146) Karas, M.; Hillenkamp, F. Anal. Chem. 1988, 60 (20), 22992301.

(147) Urban, P. L.; Jefimovs, K.; Amantonico, A.; Fagerer, S. R.; Schmid, T.; Mädler, S.; Puigmarti-Luis, J.; Goedecke, N.; Zenobi, R. Lab Chip 2010, 10 (23), 3206-3209.

(148) Krismer, J.; Tamminen, M.; Fontana, S.; Zenobi, R.; Narwani, A. ISME J. 2017, 11 (4), 988.

(149) Guillaume-Gentil, O.; Rey, T.; Kiefer, P.; Ibáñez, A. J.; Steinhoff, R.; Brönnimann, R.; Dorwling-Carter, L.; Zambelli, T.; Zenobi, R.; Vorholt, J. A. Anal. Chem. 2017, 89 (9), 5017-5023.

(150) Phelps, M. S.; Sturtevant, D.; Chapman, K. D.; Verbeck, G. F. J. Am. Soc. Mass Spectrom. 2016, 27 (2), 187-193.

(151) Do, T. D.; Ellis, J. F.; Neumann, E. K.; Comi, T. J.; Tillmaand, E. G.; Lenhart, A. E.; Rubakhin, S. S.; Sweedler, J. V. ChemPhysChem 2018, 19 (10), 1180-1191.

(152) Jansson, E. T.; Comi, T. J.; Rubakhin, S. S.; Sweedler, J. V. ACS Chem. Biol. 2016, 11 (9), 2588-2595.

(153) Diesner, M.; Neupert, S. Anal. Chem. 2018, 90 (13), 80358043.

(154) Dreisewerd, K.; Yew, J. Y. Nat. Methods 2017, 14 (12), 1139.

(155) Kompauer, M.; Heiles, S.; Spengler, B. Nat. Methods 2017, 14 (12), 1156.

(156) Kompauer, M.; Heiles, S.; Spengler, B. Nat. Methods 2017, 14 (1), 90.

(157) Castaing, R.; Slodzian, G. Comptes Rendus Acad. Sci. 1962, 255 (16), 1893.

(158) Yamada, I.; Matsuo, J.; Toyoda, N. Nucl. Instrum. Methods Phys. Res., Sect. B 2003, 206, 820-829.

(159) Angerer, T. B.; Blenkinsopp, P.; Fletcher, J. S. Int. J. Mass Spectrom. 2015, 377, 591-598.

(160) Tian, H.; Six, D. A.; Krucker, T.; Leeds, J. A.; Winograd, N. Anal. Chem. 2017, 89 (9), 5050-5057.

(161) Do, T. D.; Comi, T. J.; Dunham, S. J.; Rubakhin, S. S.; Sweedler, J. V. Anal. Chem. 2017, 89 (5), 3078-3086.

(162) Huang, L.; Chen, Y.; Weng, L.-T.; Leung, M.; Xing, X.; Fan, Z.; Wu, H. Anal. Chem. 2016, 88 (24), 12196-12203.

(163) Hua, X.; Li, H.-W.; Long, Y.-T. Anal. Chem. 2018, 90 (2), $1072-1076$.

(164) Court, M.; Barnes, J. P.; Millet, A. Rapid Commun. Mass Spectrom. 2017, 31 (19), 1623-1632.

(165) Vanbellingen, Q. P.; Castellanos, A.; Rodriguez-Silva, M.; Paudel, I.; Chambers, J. W.; Fernandez-Lima, F. A. J. Am. Soc. Mass Spectrom. 2016, 27 (12), 2033-2040.

(166) Passarelli, M. K.; Pirkl, A.; Moellers, R.; Grinfeld, D.; Kollmer, F.; Havelund, R.; Newman, C. F.; Marshall, P. S.; Arlinghaus, H.; Alexander, M. R. Nat. Methods 2017, 14 (12), 1175.

(167) Sekine, R.; Moore, K. L.; Matzke, M.; Vallotton, P.; Jiang, H.; Hughes, G. M.; Kirby, J. K.; Donner, E.; Grovenor, C. R.; Svendsen, C. ACS Nano 2017, 11 (11), 10894-10902.

(168) Lovrić, J.; Dunevall, J.; Larsson, A.; Ren, L.; Andersson, S.; Meibom, A.; Malmberg, P.; Kurczy, M. E.; Ewing, A. G. ACS Nano 2017, 11 (4), 3446-3455.

(169) Schreiber, F.; Littmann, S.; Lavik, G.; Escrig, S.; Meibom, A.; Kuypers, M. M.; Ackermann, M. Nat. Microbiol. 2016, 1 (6), 16055. (170) Vollnhals, F.; Audinot, J.-N.; Wirtz, T.; Mercier-Bonin, M.; Fourquaux, I.; Schroeppel, B.; Kraushaar, U.; Lev-Ram, V.; Ellisman, M. H.; Eswara, S. Anal. Chem. 2017, 89 (20), 10702-10710.

(171) Malherbe, J.; Penen, F.; Isaure, M.-P.; Frank, J.; Hause, G.; Dobritzsch, D.; Gontier, E.; Horréard, F. o.; Hillion, F. o.; Schaumlöffel, D. Anal. Chem. 2016, 88 (14), 7130-7136.

(172) Löhr, K.; Traub, H.; Wanka, A. J.; Panne, U.; Jakubowski, N. J. Anal. At. Spectrom. 2018, 33 (9), 1579-1587.

(173) Herrmann, A. J.; Techritz, S.; Jakubowski, N.; Haase, A.; Luch, A.; Panne, U.; Müller, L. Analyst 2017, 142 (10), 1703-1710.

(174) Spitzer, M. H.; Nolan, G. P. Cell 2016, 165 (4), 780-791.
(175) Ajami, B.; Samusik, N.; Wieghofer, P.; Ho, P. P.; Crotti, A.; Bjornson, Z.; Prinz, M.; Fantl, W. J.; Nolan, G. P.; Steinman, L. Nat. Neurosci. 2018, 21 (4), 541.

(176) Gerdtsson, E.; Pore, M.; Thiele, J.-A.; Gerdtsson, A. S.; Malihi, P. D.; Nevarez, R.; Kolatkar, A.; Velasco, C. R.; Wix, S.; Singh, M. Converg. Sci. Phys. Oncol. 2018, 4 (1), 015002.

(177) Zhang, J.; Zhou, J.; Pan, R.; Jiang, D.; Burgess, J. D.; Chen, H. Y. ACS Sens 2018, 3 (2), 242-250.

(178) Phan, N. T.; Li, X.; Ewing, A. G. Nat. Rev. Chem. 2017, 1 (6), 0048.

(179) Wightman, R. M.; Dominguez, N.; Borges, R. Pfluegers Arch. 2018, 470 (1), 135-141.

(180) Ganesana, M.; Lee, S. T.; Wang, Y.; Venton, B. J. Anal. Chem. 2017, 89 (1), 314-341.

(181) Wightman, R. M.; Jankowski, J. A.; Kennedy, R. T.; Kawagoe, K. T.; Schroeder, T. J.; Leszczyszyn, D. J.; Near, J. A.; Diliberto, E. J., Jr.; Viveros, O. H. Proc. Natl. Acad. Sci. U. S. A. 1991, 88 (23), 10754-10758.

(182) Clausmeyer, J.; Schuhmann, W. TrAC, Trends Anal. Chem. 2016, 79, 46-59.

(183) Oja, S. M.; Fan, Y.; Armstrong, C. M.; Defnet, P.; Zhang, B. Anal. Chem. 2016, 88 (1), 414-430.

(184) Li, X.; Dunevall, J.; Ewing, A. G. Acc. Chem. Res. 2016, 49 (10), 2347-2354.

(185) Li, X.; Majdi, S.; Dunevall, J.; Fathali, H.; Ewing, A. G. Angew. Chem., Int. Ed. 2015, 54 (41), 11978-11982.

(186) Li, X.; Dunevall, J.; Ewing, A. G. Angew. Chem., Int. Ed. 2016, 55 (31), 9041-9044.

(187) Ren, L.; Pour, M. D.; Majdi, S.; Li, X.; Malmberg, P.; Ewing, A. G. Angew. Chem., Int. Ed. 2017, 56 (18), 4970-4975.

(188) Ye, D.; Gu, C.; Ewing, A. G. ACS Chem. Neurosci. 2018, DOI: 10.1021/acschemneuro.8b00130.

(189) Ye, D.; Ewing, A. ChemPhysChem 2018, 19 (10), 1173-1179.

(190) Li, X.; Mohammadi, A. S.; Ewing, A. G. J. Electroanal. Chem. 2016, 781, 30-35.

(191) Fathali, H.; Dunevall, J.; Majdi, S.; Cans, A.-S. ACS Chem. Neurosci. 2017, 8 (2), 368-375.

(192) Wang, K.; Zhao, X.; Li, B.; Wang, K.; Zhang, X.; Mao, L.; Ewing, A.; Lin, Y. Anal. Chem. 2017, 89 (17), 8683-8688.

(193) Dębowska, K.; Smulik-Izydorczyk, R.; Pięta, J.; Adamus, J.; Michalski, R.; Sikora, A. Free Radical Biol. Med. 2018, 120, S78.

(194) Moldogazieva, N.; Mokhosoev, I.; Feldman, N.; Lutsenko, S. Free Radical Res. 2018, 52, 507-543.

(195) Zhang, X. W.; Qiu, Q. F.; Jiang, H.; Zhang, F. L.; Liu, Y. L.; Amatore, C.; Huang, W. H. Angew. Chem. 2017, 129 (42), 1317713180.

(196) Lovrić, J.; Najafinobar, N.; Dunevall, J.; Majdi, S.; Svir, I.; Oleinick, A.; Amatore, C.; Ewing, A. G. Faraday Discuss. 2016, 193, $65-79$.

(197) Dunevall, J.; Fathali, H.; Najafinobar, N.; Lovric, J.; Wigstrom, J.; Cans, A. S.; Ewing, A. G. J. Am. Chem. Soc. 2015, 137 (13), 43444346.

(198) Xu, H.; Liao, C.; Liu, Y.; Ye, B.-C.; Liu, B. Anal. Chem. 2018, 90 (7), 4438-4444.

(199) Wang, K.; Xiao, T.; Yue, Q.; Wu, F.; Yu, P.; Mao, L. Anal. Chem. 2017, 89 (17), 9502-9507.

(200) Wigström, J.; Dunevall, J.; Najafinobar, N.; Lovrić, J.; Wang, J.; Ewing, A. G.; Cans, A.-S. Anal. Chem. 2016, 88 (4), 2080-2087.

(201) Xu, H.; Zhou, S.; Jiang, D.; Chen, H.-Y. Anal. Chem. 2018, 90 (2), 1054-1058.

(202) Devadoss, A.; Burgess, J. D. J. Am. Chem. Soc. 2004, 126 (33), 10214-10215.

(203) Jiang, D.; Devadoss, A.; Palencsár, M. S.; Fang, D.; White, N. M.; Kelley, T. J.; Smith, J. D.; Burgess, J. D. J. Am. Chem. Soc. 2007, 129 (37), 11352-11353.

(204) Devadoss, A.; Burgess, J. D. Langmuir 2002, 18 (25), 96179621. 
(205) Sadeghian, R. B.; Ostrovidov, S.; Han, J.; Salehi, S.; Bahraminejad, B.; Bae, H.; Chen, M.; Khademhosseini, A. ACS Sens 2016, 1 (7), 921-928.

(206) Qiu, Q. F.; Zhang, F. L.; Tang, Y.; Zhang, X. W.; Jiang, H.; Liu, Y. L.; Huang, W. H. Electroanalysis 2018, 30 (6), 1054-1059.

(207) Amemiya, S.; Bard, A. J.; Fan, F.-R. F.; Mirkin, M. V.; Unwin, P. R. Annu. Rev. Anal. Chem. 2008, 1 (1), 95-131.

(208) Bauermann, L. P.; Schuhmann, W.; Schulte, A. Phys. Chem. Chem. Phys. 2004, 6 (15), 4003-4008.

(209) Li, M. S.; Filice, F. P.; Ding, Z. J. Electroanal. Chem. 2016, 779, 176-186.

(210) Polcari, D.; Dauphin-Ducharme, P.; Mauzeroll, J. Chem. Rev. 2016, 116 (22), 13234-13278.

(211) Welle, T. M.; Alanis, K.; Colombo, M. L.; Sweedler, J. V.; Shen, M. Chem. Sci. 2018, 9 (22), 4937-4941.

(212) Li, Y.; Hu, K.; Yu, Y.; Rotenberg, S. A.; Amatore, C.; Mirkin, M. V. J. Am. Chem. Soc. 2017, 139 (37), 13055-13062.

(213) Soldà, A.; Valenti, G.; Marcaccio, M.; Giorgio, M.; Pelicci, P. G.; Paolucci, F.; Rapino, S. ACS Sens 2017, 2 (9), 1310-1318.

(214) Chen, C. C.; Zhou, Y.; Baker, L. A. Annu. Rev. Anal. Chem. 2012, 5, 207-228.

(215) Page, A.; Perry, D.; Young, P.; Mitchell, D.; Frenguelli, B. G.; Unwin, P. R. Anal. Chem. 2016, 88 (22), 10854-10859.

(216) Page, A.; Kang, M.; Armitstead, A.; Perry, D.; Unwin, P. R. Anal. Chem. 2017, 89 (5), 3021-3028.

(217) Page, A.; Perry, D.; Unwin, P. R. Proc. R. Soc. London, Ser. A 2017, 473 (2200), 20160889.

(218) Nascimento, R. A.; Özel, R. E.; Mak, W. H.; Mulato, M.; Singaram, B.; Pourmand, N. Nano Lett. 2016, 16 (2), 1194-1200.

(219) Xu, Y.; Xie, X.; Duan, Y.; Wang, L.; Cheng, Z.; Cheng, J. Biosens. Bioelectron. 2016, 77, 824-836.

(220) Skalová, Š.; Vyskočil, V.; Barek, J.; Navrátil, T. Electroanalysis 2018, 30 (2), 207-219.

(221) Glazier, R.; Salaita, K. Biochim. Biophys. Acta, Biomembr. 2017, 1859 (9), 1465-1482.

(222) Zhang, Z.; Sohgawa, M.; Yamashita, K.; Noda, M. Electroanalysis 2016, 28 (3), 620-625.

(223) Diamanti, E.; Gregurec, D.; Rodríguez-Presa, M. J.; Gervasi, C. A.; Azzaroni, O.; Moya, S. E. Langmuir 2016, 32 (25), 6263-6271.

(224) Zhou, Y.; Basu, S.; Laue, E. D.; Seshia, A. A. Biomed. Microdevices 2016, 18 (4), 56.

(225) El Hasni, A.; Schmitz, C.; Bui-Göbbels, K.; Bräunig, P.; Jahnen-Dechent, W.; Schnakenberg, U. Sens. Actuators, B 2017, 248, 419-429.

(226) Shah, P.; Zhu, X.; Zhang, X.; He, J.; Li, C.-z. ACS Appl. Mater. Interfaces 2016, 8 (9), 5804-5812.

(227) Richter, M. M. Chem. Rev. 2004, 104 (6), 3003-36.

(228) Li, L.; Chen, Y.; Zhu, J.-J. Anal. Chem. 2017, 89 (1), 358-371.

(229) Guo, W.; Liu, Y.; Cao, Z.; Su, B. J. Anal. Test. 2017, 1 (2), 14.

(230) He, R.; Tang, H.; Jiang, D.; Chen, H.-y. Anal. Chem. 2016, 88 (4), 2006-2009.

(231) Liu, G.; Ma, C.; Jin, B.-K.; Chen, Z.; Zhu, J.-J. Anal. Chem. 2018, 90 (7), 4801-4806.

(232) Valenti, G.; Scarabino, S.; Goudeau, B.; Lesch, A.; Jovic, M.; Villani, E.; Sentic, M.; Rapino, S.; Arbault, S.; Paolucci, F.; Sojic, N. J. Am. Chem. Soc. 2017, 139 (46), 16830-16837.

(233) Xu, J.; Huang, P.; Qin, Y.; Jiang, D.; Chen, H.-y. Anal. Chem. 2016, 88 (9), 4609-4612. 